\title{
Effect of redox on Fe-Mg-Mn exchange between olivine and melt and an oxybarometer for basalts
}

\author{
Jon Blundy ${ }^{1,8}$ (C) Elena Melekhova ${ }^{1} \cdot$ Luca Ziberna $^{2} \cdot$ Madeleine C. S. Humphreys $^{3} \cdot$ Valerio Cerantola $^{4}$. \\ Richard A. Brooker ${ }^{1} \cdot$ Catherine A. McCammon $^{5} \cdot$ Michel Pichavant $^{6} \cdot$ Peter Ulmer $^{7}$
}

Received: 28 April 2020 / Accepted: 11 September 2020 / Published online: 15 October 2020

(c) The Author(s) 2020

\begin{abstract}
The Fe-Mg exchange coefficient between olivine (ol) and melt (m), defined as $\mathrm{Kd}_{\mathrm{Fe}^{T}-\mathrm{Mg}}=\left(\mathrm{Fe}_{\mathrm{ol}} / \mathrm{Fe}_{\mathrm{m}}\right) \cdot\left(\mathrm{Mg}_{\mathrm{m}} / \mathrm{Mg}_{\mathrm{ol}}\right)$, with all $\mathrm{Fe}^{\mathrm{T}}$ expressed as $\mathrm{Fe}^{2+}$, is one of the most widely used parameters in petrology. We explore the effect of redox conditions on $\mathrm{Kd}_{\mathrm{Fe}^{T}-\mathrm{Mg}}$ using experimental, olivine-saturated basaltic glasses with variable $\mathrm{H}_{2} \mathrm{O}\left(\leq 7 \mathrm{wt} \%\right.$ ) over a wide range of $f \mathrm{O}_{2}$ (ironwüstite buffer to air), pressure $(\leq 1.7 \mathrm{GPa})$, temperature $\left(1025-1425{ }^{\circ} \mathrm{C}\right)$ and melt composition. The ratio of $\mathrm{Fe}^{3+}$ to total $\mathrm{Fe}\left(\mathrm{Fe}^{3+} / \sum \mathrm{Fe}\right)$, as determined by Fe K-edge $\mu$ XANES and/or Synchrotron Mössbauer Source (SMS) spectroscopy, lies in the range $0-0.84$. Measured $\mathrm{Fe}^{3+} / \sum \mathrm{Fe}$ is consistent $( \pm 0.05)$ with published algorithms and appears insensitive to dissolved $\mathrm{H}_{2} \mathrm{O}$. Combining our new data with published experimental data having measured glass $\mathrm{Fe}^{3+} / \sum \mathrm{Fe}$, we show that for $\mathrm{Fo}_{65-98}$ olivine in equilibrium with basaltic and basaltic andesite melts, $\mathrm{Kd}_{\mathrm{Fe}^{T}-\mathrm{Mg}}$ decreases linearly with $\mathrm{Fe}^{3+} / \sum \mathrm{Fe}$ with a slope and intercept of $0.3135 \pm 0.0011$. After accounting for non-ideal mixing of forsterite and fayalite in olivine, using a symmetrical regular solution model, the slope and intercept become $0.3642 \pm 0.0011$. This is the value at $\mathrm{Fo}_{50}$ olivine; at higher and lower Fo the value will be reduced by an amount related to olivine non-ideality. Our approach provides a straightforward means to determine $\mathrm{Fe}^{3+} / \sum \mathrm{Fe}$ in olivine-bearing experimental melts, from which $f_{2}$ can be calculated. In contrast to $\mathrm{Kd}_{\mathrm{Fe}^{T}-\mathrm{Mg}}$, the $\mathrm{Mn}-\mathrm{Mg}$ exchange coefficient, $\mathrm{Kd}_{\mathrm{Mn}-\mathrm{Mg}}$, is relatively constant over a wide range of $\mathrm{P}-\mathrm{T}-f \mathrm{O}_{2}$ conditions. We present an expression for $\mathrm{Kd}_{\mathrm{Mn}-\mathrm{Mg}}$ that incorporates the effects of temperature and olivine composition using the lattice strain model. By applying our experimentally-calibrated expressions for $\mathrm{Kd}_{\mathrm{Fe}^{T}-\mathrm{Mg}}$ and $\mathrm{Kd}_{\mathrm{Mn}-\mathrm{Mg}}$ to olivine-hosted melt inclusions analysed by electron microprobe it is possible to correct simultaneously for post-entrapment crystallisation (or dissolution) and calculate melt $\mathrm{Fe}^{3+} / \sum \mathrm{Fe}$ to a precision of $\leq 0.04$.
\end{abstract}

Keywords Olivine $\cdot$ Experiments $\cdot$ Melt inclusions $\cdot \mu$ XANES $\cdot$ Mössbauer $\cdot$ Oxygen fugacity

Communicated by Dante Canil.

Electronic supplementary material The online version of this article (https://doi.org/10.1007/s00410-020-01736-7) contains supplementary material, which is available to authorized users.

Jon Blundy

jonathan.blundy@earth.ox.ac.uk

1 School of Earth Sciences, University of Bristol, Wills Memorial Building, Bristol BS8 1RJ, UK

2 Department of Mathematics and Geosciences, University of Trieste, Via Weiss 8, 34128 Trieste, Italy

3 Department of Earth Sciences, Durham University, Science Labs, Durham DH1 3LE, UK

4 European X-Ray Free-Electron Laser Facility (XFEL), Holzkoppel 4, 22869 Schenefeld, Germany

\section{Introduction}

The exchange of iron and magnesium between olivine and coexisting melt bears directly on the generation and chemical evolution of basaltic magmas. Consequently, the

5 Bayerisches Geoinstitut, Universität Bayreuth, 95440 Bayreuth, Germany

6 Institut des Sciences de la Terre d'Orléans, UMR 7327 CNRS-Université d'Orléans-BRGM, 1a Rue de la Férollerie, 45071 Orléans, France

7 Institut für Geochemie und Petrologie, ETH Zürich, Clausiusstrasse 25, 8092 Zurich, Switzerland

8 Department of Earth Sciences, University of Oxford, South Parks Road, Oxford OX1 3AN, UK 
$\mathrm{Fe}-\mathrm{Mg}$ exchange coefficient, $\mathrm{Kd}_{\mathrm{Fe}-\mathrm{Mg}}$, is one of the mostly widely used parameters in petrology.

$\mathrm{Kd}_{\mathrm{Fe}-\mathrm{Mg}}$ is related to the equilibrium constant for the exchange reaction:

$$
\begin{aligned}
\left.\mathrm{Fe}_{2} \mathrm{SiO}_{4}(\text { melt })+\mathrm{Mg}_{2} \mathrm{SiO}_{4} \text { (olivine }\right)= & \mathrm{Fe}_{2} \mathrm{SiO}_{4} \text { (olivine) } \\
& +\mathrm{Mg}_{2} \mathrm{SiO}_{4} \text { (melt) }
\end{aligned}
$$

and is defined as

$$
\mathrm{Kd}_{\mathrm{Fe}^{2+}-\mathrm{Mg}}=\frac{\left(\mathrm{Fe}^{2+} / \mathrm{Mg}\right)_{\mathrm{ol}}}{\left(\mathrm{Fe}^{2+} / \mathrm{Mg}\right)_{\text {melt }}},
$$

where $\mathrm{Fe}^{2+}$ and $\mathrm{Mg}$ are expressed as atomic concentrations. At equilibrium $\mathrm{Kd}_{\mathrm{Fe}^{2+}-\mathrm{Mg}}$ is expected to vary with the free energy of exchange reaction (1) for the pure end-members, as well as any non-ideal interactions of $\mathrm{Fe}^{2+}$ and $\mathrm{Mg}$ dissolved in melts and in olivine. As the enthalpies, entropies and volumes of fusion of the olivine end-members forsterite and fayalite are somewhat different from each other (e.g., Lange and Carmichael 1990) one would expect, a priori, some temperature and pressure dependence of $\mathrm{Kd}_{\mathrm{Fe}^{2+}-\mathrm{Mg}}$. In addition, the non-ideality of silicate melts and, to a lesser extent, of olivine solid solutions would be expected to confer significant compositional dependence on $\mathrm{Kd}_{\mathrm{Fe}^{2+}-\mathrm{Mg}}$. However, despite these expectations, the seminal work of Roeder and Emslie (1970) showed that $\mathrm{Kd}_{\mathrm{Fe}^{2+}-\mathrm{Mg}}$ is remarkably constant over a wide range of pressure, temperature and composition $(\mathrm{P}-\mathrm{T}-\mathrm{X})$, such that a value of $0.30 \pm 0.03$ can be used with some confidence to describe melting and crystallisation in a wide variety of olivine-bearing systems. We refer to this as the 'canonical' value of $\mathrm{Kd}_{\mathrm{Fe}^{2+}-\mathrm{Mg} \text {. }}$.

There have been many subsequent studies of olivinemelt equilibrium (e.g., Ulmer 1989; Beattie et al. 1991; Beattie 1993; Herzberg and O'Hara 2002; Toplis 2005; Mysen 2006; Matzen et al. 2011; Putirka 2016) and associated attempts to refine the canonical value or establish its sensitivity to $\mathrm{P}-\mathrm{T}-\mathrm{X}$, but it has remained one of the most durable underpinning tenets of basalt petrology, used in a wide variety of ways, from tests of the primitive (i.e., mantle-derived) character of basaltic magmas, to corrections for post-entrapment crystallisation of melt inclusions, to fractionation of basaltic magmas in the crust and mantle.

A particular challenge with using Eq. (1) is the need to know the $\mathrm{Fe}^{3+}$ content of the silicate melt, which is not readily measurable by conventional electron microprobe techniques (see review by Hughes et al. 2018). Olivine contains negligible $\mathrm{Fe}^{3+}$ (less then a few thousand ppm and not more than a few percent of the total $\mathrm{Fe}, \mathrm{Fe}^{\mathrm{T}}$; Ejima et al. 2018) so that where $\mathrm{Fe}^{3+}$ in the melt is low, i.e., in relatively reduced systems, $\mathrm{Kd}_{\mathrm{Fe}^{2+}-\mathrm{Mg}}$ can be used with confidence assuming that $\mathrm{Fe}^{2+}=\mathrm{Fe}^{\mathrm{T}}$. In such cases a variant of Eq. (2), with all $\mathrm{Fe}$ expressed as $\mathrm{Fe}^{\mathrm{T}}$, i.e., $\mathrm{Fe}^{\mathrm{T}}=\Sigma \mathrm{Fe}=\mathrm{Fe}^{2+}+\mathrm{Fe}^{3+}$, may be used instead:

$\mathrm{Kd}_{\mathrm{Fe}^{T}-\mathrm{Mg}}=\frac{\left(\mathrm{Fe}^{T} / \mathrm{Mg}\right)_{\mathrm{ol}}}{\left(\mathrm{Fe}^{T} / \mathrm{Mg}\right)_{\text {melt }}}$.

Most natural magmatic systems contain some $\mathrm{Fe}^{3+}$, thus $\mathrm{Kd}_{\mathrm{Fe}^{T}-\mathrm{Mg}}$, as expressed in (3), will be sensitive to redox state. $\mathrm{Fe}^{3+} / \Sigma \mathrm{Fe}$ ratios vary widely in basaltic magmas, from almost zero in the case of lunar basalts to $>0.5$ in the case of some oxidised, hydrous subduction-related igneous rocks (Stolper and Bucholz 2019). Moreover, even at constant P, T and $f \mathrm{O}_{2}, \mathrm{Fe}^{3+} / \Sigma \mathrm{Fe}$ is known to vary with melt composition (Kress and Carmichael 1991; Putirka 2016; Borisov et al. 2018). For example, elevated $\mathrm{Fe}^{3+} / \Sigma \mathrm{Fe}$ occurs in alkaline basaltic magmas due to the stabilising effect of $\mathrm{Na}^{+}$and $\mathrm{K}^{+}$on $\mathrm{Fe}^{3+}$ (Mysen and Virgo 1989; Kress and Carmichael 1991). Thus, in some tectonic environments, $\mathrm{Kd}_{\mathrm{Fe}^{T}-\mathrm{Mg}}$ can be lower than $\mathrm{Kd}_{\mathrm{Fe}^{2+}-\mathrm{Mg}}$ by as much as a factor of two or more, with far-reaching implications for olivine-melt equilibrium in basaltic systems.

If the availability of $\mathrm{Fe}^{2+}$ in the melt is the dominant control on $\mathrm{Fe}-\mathrm{Mg}$ exchange, then $\mathrm{Kd}_{\mathrm{Fe}^{T}-\mathrm{Mg}}$ should vary systematically with the redox state of the system; the relationship between $\mathrm{Kd}_{\mathrm{Fe}^{T}-\mathrm{Mg}}$ and $\mathrm{Kd}_{\mathrm{Fe}^{2+}-\mathrm{Mg}}$ will reflect the proportion of total iron in the melt that is trivalent $\left(\mathrm{Fe}^{3+}\right)$ at the pressure, temperature and melt composition of interest:

$\mathrm{Kd}_{\mathrm{Fe}^{T}-\mathrm{Mg}}=\mathrm{Kd}_{\mathrm{Fe}^{2+}-\mathrm{Mg}} \times\left(1-\frac{\mathrm{Fe}^{3+}}{\Sigma \mathrm{Fe}}\right)$.

Recognising the problem of $\mathrm{Fe}^{3+}$ in the melt Roeder and Emslie (1970) attempted to account for its effect by determining, via wet chemistry, the $\mathrm{Fe}^{3+} / \Sigma \mathrm{Fe}$ ratio of their bulk experimental charges and making a correction for any contained olivine crystals using a simple mass balance. The behaviour predicted in Eq. (4) is apparent in the original Roeder and Emslie (1970) dataset (Fig. 1), although the uncertainty in the $\mathrm{Fe}^{3+} / \Sigma \mathrm{Fe}$ ratio of the glass (as opposed to the bulk) precludes any meaningful conclusions. For example, it is unclear if the scatter in Fig. 1 arises due to temperature or compositional effects, the use of different capsule materials (and attendant Fe loss from the glass), or the presence of crystals in the aliquot of the experimental charge used for measuring $\mathrm{Fe}^{3+} / \Sigma \mathrm{Fe}$. The scatter is not removed even when more sophisticated mass balance techniques are used, taking into account other iron-bearing mineral phases in the glass, e.g., clinopyroxene, magnetite (Matzen, 2012). However, in principle, if we know the redox state of a magmatic system, usually defined in terms of an oxygen fugacity $\left(f \mathrm{O}_{2}\right)$, and the relationship between $f \mathrm{O}_{2}$ and $\mathrm{Fe}^{3+} / \Sigma \mathrm{Fe}$, then we should be able to use Eq. (4) as an oxybarometer. The potential of this approach was recognised by Putirka (2016) 


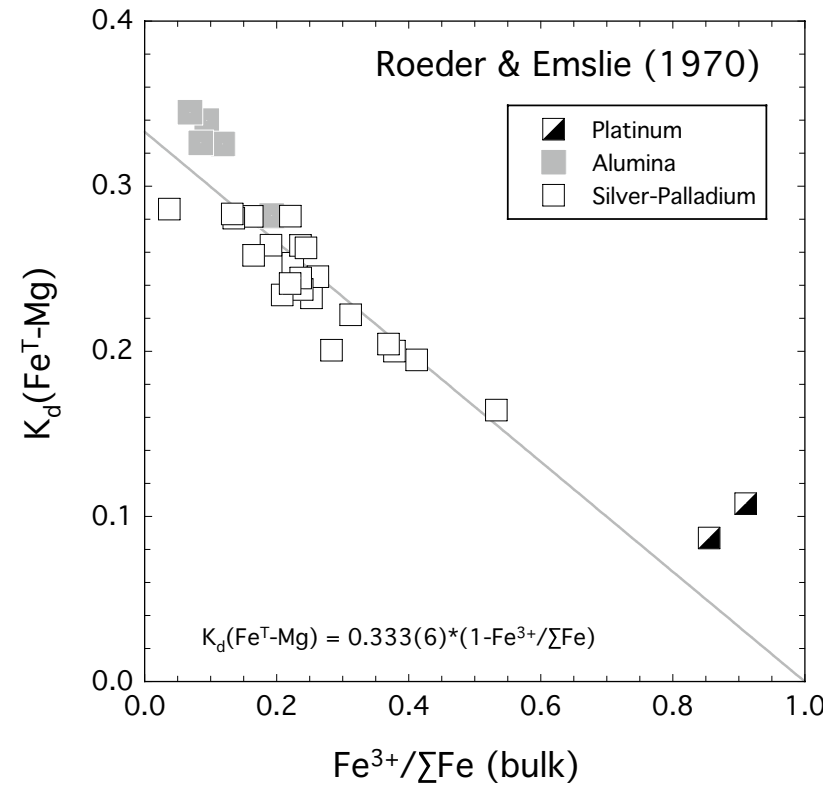

Fig. 1 Variation of olivine-melt $\mathrm{Kd}_{\mathrm{Fe}^{T}-\mathrm{Mg}}$ with $\mathrm{Fe}^{3+} / \Sigma \mathrm{Fe}$ in the bulk experimental run product from the seminal experimental study of Roeder and Emslie (1970). Results for three different capsule materials are shown. The data hint at the operation of a relationship akin to Eq. (4), but the measurement of $\mathrm{Fe}^{3+} / \Sigma \mathrm{Fe}$ is insufficiently precise for a more thorough treatment because of the need to correct the bulk $\mathrm{Fe}^{3+} / \Sigma \mathrm{Fe}$ analysis for included, Fe-bearing crystalline phases. The line and equation correspond to fits to Eq. (4), for comparison to Fig. 6a

who developed an expression for $\mathrm{Kd}_{\mathrm{Fe}^{T}-\mathrm{Mg}}$ that explicitly includes an $\mathrm{fO}_{2}$ term. However, the form of his Eq. (9b) is not optimised for oxybarometry, partly because of the way the fitting was performed, and partly because of the dearth of experimental olivine-melt data with measured $\mathrm{Fe}^{3+} / \Sigma \mathrm{Fe}$.

Application of Eq. (4) as an oxybarometer requires, of course, that the olivine-melt pair of interest is in equilibrium. When $\mathrm{Fe}^{3+} / \Sigma \mathrm{Fe}$ in the melt is unknown, the problem of testing for equilibrium and calculating $\mathrm{OO}_{2}$ becomes circular. To resolve this circularity requires understanding the behaviour of a component that is not redox-sensitive, such as exchange of $\mathrm{Mn}$ and $\mathrm{Mg}$ between olivine and melt, $\mathrm{Kd}_{\mathrm{Mn}-\mathrm{Mg}}$. If the difference between the behaviour of $\mathrm{Fe}$ and $\mathrm{Mn}$ can be quantified, it has the potential to be used to test for olivine-melt equilibrium and so enable oxybarometry. The aim of this study is to (a) compare methods for the reliable, high-spatial resolution measurement of the $\mathrm{Fe}^{3+}$ content of hydrous and anhydrous glasses of broadly basaltic composition synthesised over a range of $f \mathrm{O}_{2}$; and (b) determine the partitioning of $\mathrm{Fe}, \mathrm{Mg}$ and $\mathrm{Mn}$ between olivine and basaltic melt across a wide range of redox conditions. The ultimate objective is to establish whether Eq. (4) provides a useful means to correct $\mathrm{Kd}_{\mathrm{Fe}^{T}-\mathrm{Mg}}$ for $\mathrm{Fe}^{3+}$-rich systems, and whether it is possible to recover $f \mathrm{O}_{2}$ from determinations of $\mathrm{Kd}_{\mathrm{Fe}^{T}-\mathrm{Mg}}$ in natural or experimental basaltic systems by exploiting the redox insensitive exchange of $\mathrm{Mn}$ and $\mathrm{Mg}$ between olivine and melt.

\section{Experimental methods}

This study utilises 72 experimental samples, mainly from our previously published studies with existing, modified or new determinations of the $\mathrm{Fe}^{3+} / \Sigma \mathrm{Fe}$ ratio in the glass to explore the effect of redox on $\mathrm{Kd}_{\mathrm{Fe}^{T}-\mathrm{Mg}}$. Our experimental starting materials comprised eight basalts, two basaltic andesites and one andesite, all based on natural rock compositions from subduction-related magmatic systems: Lesser Antilles arc (St. Vincent, Grenada, Martinique, St. Kitts, Montserrat), Central American arc (Masaya), Aeolian arc (Stromboli), and the post-collisional, calc-alkaline Adamello Batholith, Italy. For St. Vincent and Martinique we used three and two different starting materials, respectively; these are referred to as St. Vincent series 1, 2 and 3, and Martinique series 1 and $2 . \mathrm{MgO}$ contents of the starting materials range from 2.3 to $17.1 \mathrm{wt} \%$; total alkali contents range from 1.6 to $4.7 \mathrm{wt} \%$. $\mathrm{Mg} \#$, expressed in terms of $\mathrm{Fe}^{\mathrm{T}}$ (i.e., molar $\left.\mathrm{Mg} /\left[\mathrm{Mg}+\mathrm{Fe}^{T}\right]\right)$ ranges from 0.34 to 0.76 . Compositions, on an anhydrous basis, of all eleven starting materials are given in Table 1. None of the studied glasses contain sulphur, to prevent possible modifications of $\mathrm{Fe}^{3+} / \Sigma \mathrm{Fe}$ ratios due to the homogeneous reaction $\mathrm{S}^{2-}+8 \mathrm{Fe}^{3+}=\mathrm{S}^{6+}+8 \mathrm{Fe}^{2+}$ during quenching of the glass (Nash et al. 2019).

With the exception of the three 'XANES' experiments (see Supplementary Method in supplementary material 3) all of the experimental runs are taken from the published studies listed in Tables 1 and 2, where the experimental techniques are described in detail, and summarised as follows. One-atmosphere experiments (Adamello series) were run in vertical quench furnaces at the Geophysical Laboratory, Carnegie Institution of Washington, with $\mathrm{CO}-\mathrm{CO}_{2}$ gases to regulate $\mathrm{fO}_{2}$ using methods described in Ulmer (1989) and Kägi et al. (2005). One-atmosphere experiments (Grenada series) were run in vertical quench furnaces at University of Bristol and Australian National University with $\mathrm{CO}-\mathrm{CO}_{2}$ gases to regulate $\mathrm{fO}_{2}$ using methods in Stamper et al. (2014). Internally-heated pressure vessel (IHPV) runs (St. Vincent 2 and 3, St. Kitts, Martinique 1 and 2, and Montserrat series) were performed at Université d'Orléans using techniques reported by Pichavant et al. (2002) and Melekhova et al. (2017) with $\mathrm{fO}_{2}$ controlled by $\mathrm{H}_{2}$ added to the argon pressurising gas, and $\mathrm{fO}_{2}$ monitored using an NiPd sensor. IHPV experiments at Leibnitz University of Hannover (Stromboli and Masaya series) were run using the methods described in Lesne et al. (2011), without $\mathrm{H}_{2}$ control. Piston cylinder (St. Vincent 1 and Grenada series) runs were performed in half-inch pressure cells at University of Bristol using 


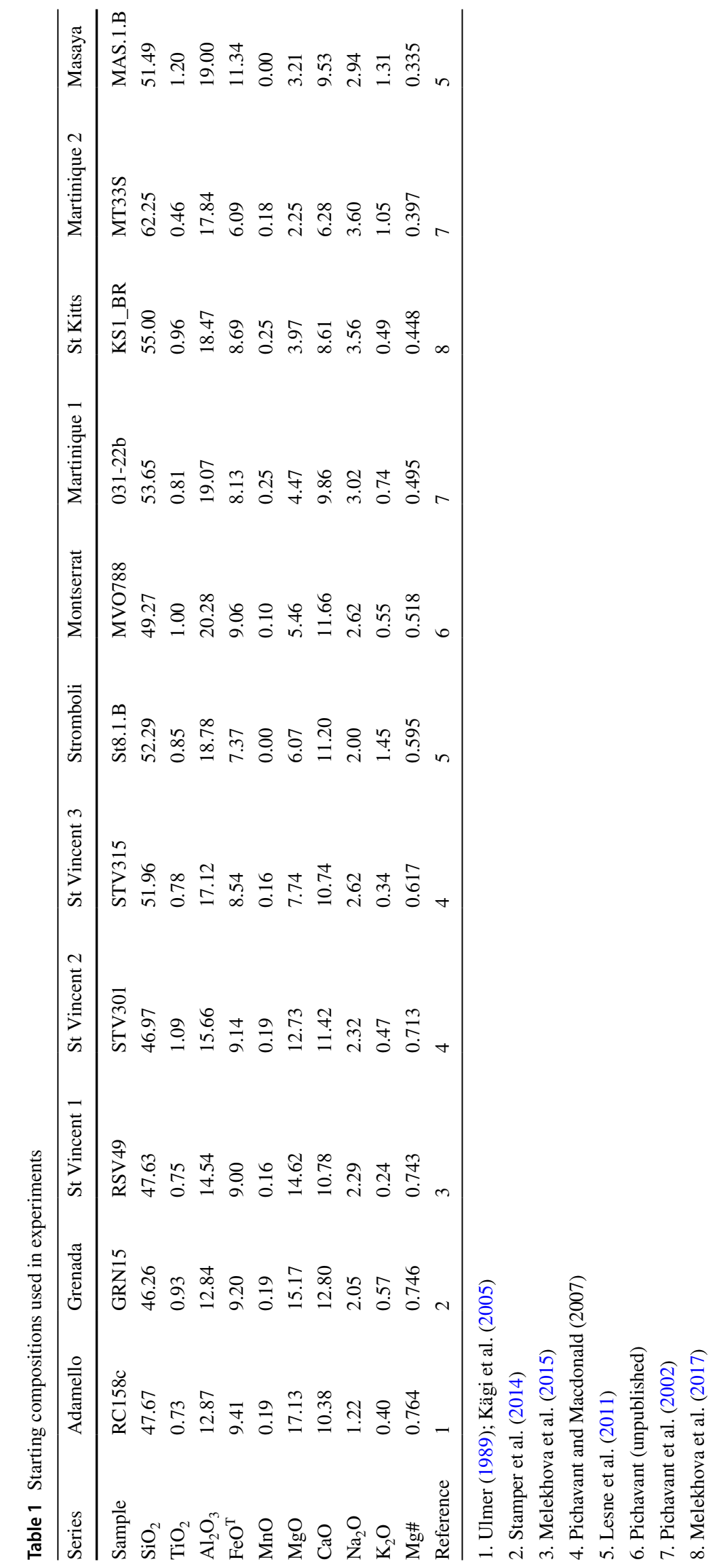




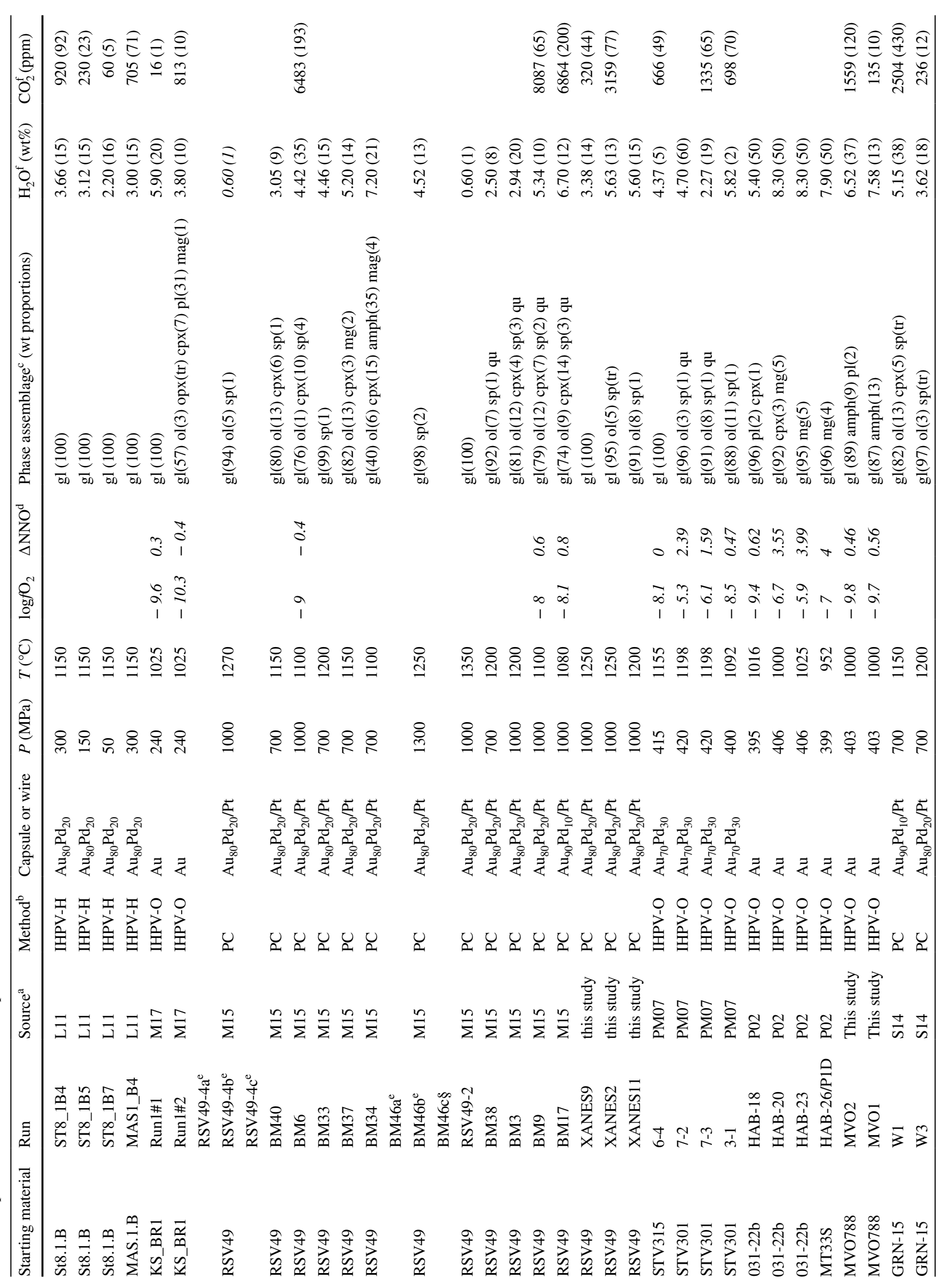




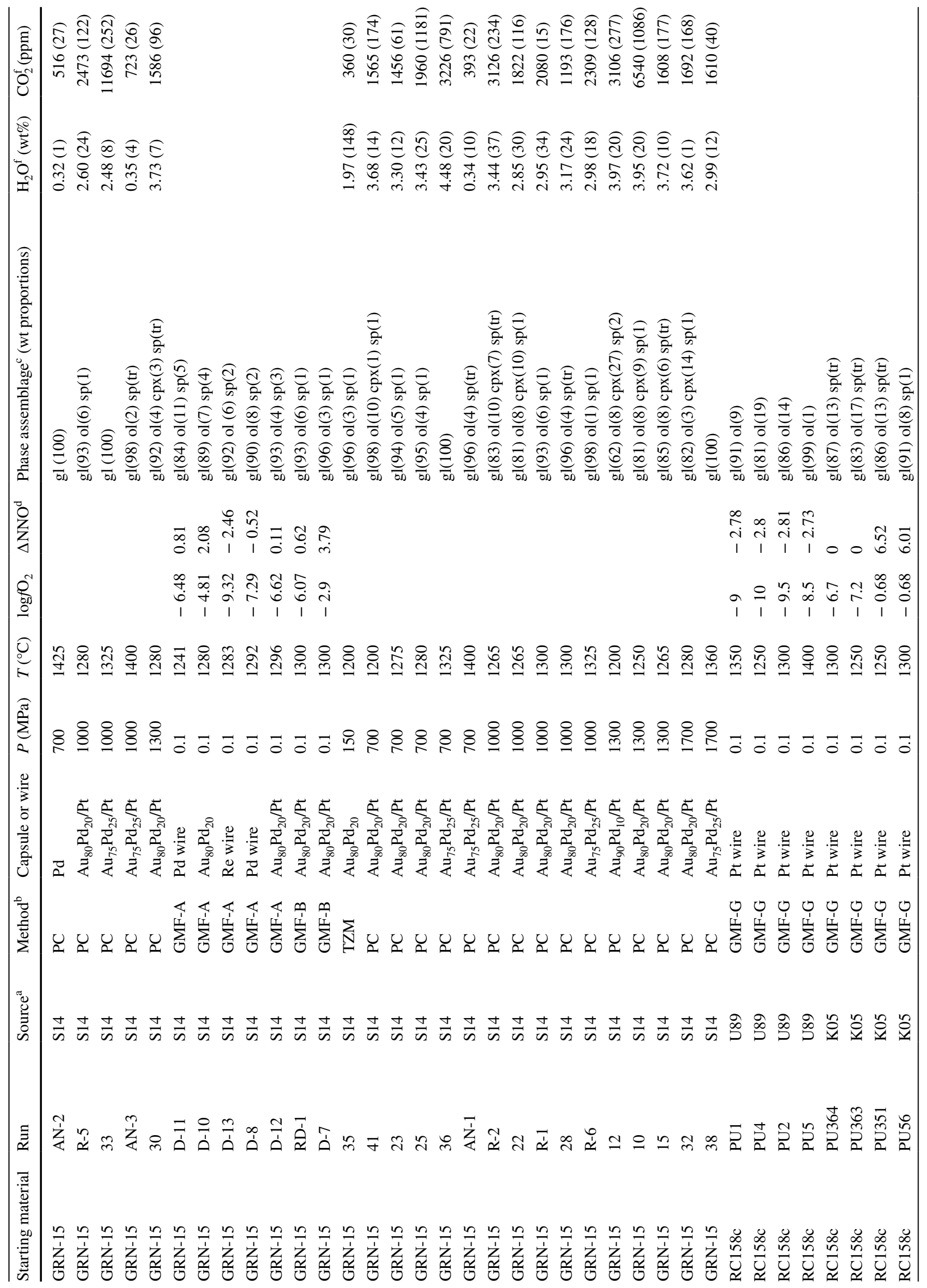


techniques described by Melekhova et al. (2015) and Stamper et al. (2014). Those experiments used a double capsule technique, with sample materials placed in both inner and outer capsules to minimise $\mathrm{H}$ loss or gain by diffusion. In some St. Vincent series 1 runs a sensor capsule of pure $\mathrm{Pd}$, loaded with a mixture of $\mathrm{Ni}, \mathrm{NiO}$ and $\mathrm{H}_{2} \mathrm{O}$, was placed inside the outer capsule to monitor $f_{2}$ by means of analyses of NiPd alloys.

All 72 experiments have the $\mathrm{Fe}^{3+} / \Sigma \mathrm{Fe}$ ratio of their glass determined by one or multiple techniques (see Table 3); two samples have replicate measurements. $f_{2}$ was known most precisely in the 18 one-atmosphere runs. In high-pressure runs, performed at water-undersaturated conditions in IHPV or piston cylinder with NiPd sensors, $f_{2}$ can be calculated only by taking account of the reduced $\mathrm{H}_{2} \mathrm{O}$ activity $\left(a \mathrm{H}_{2} \mathrm{O}\right)$ in the melt at run conditions. This was done using the method of Burnham (1979). The $f \mathrm{O}_{2}$ of the run is then that of the NiPd sensor plus $2 \log \left(a \mathrm{H}_{2} \mathrm{O}\right)$. This approach, which involves a greater uncertainty than the one-atmosphere experiments, provides $f \mathrm{O}_{2}$ estimates for a further 15 runs. The overall range in measured $f \mathrm{O}_{2}$ these 33 experiments is $9.3 \log$ units relative to the NNO buffer (O'Neill and Pownceby 1993) at experimental $\mathrm{P}$ and $\mathrm{T}$ (i.e., from $\mathrm{NNO}-2.8$ to $\mathrm{NNO}+6.5$ ). In the remaining 40 experimental runs the experimental $f \mathrm{O}_{2}$ was not precisely constrained.

In addition, we considered another $\sim 100$ experiments with measured $\mathrm{Fe}^{3+} / \Sigma \mathrm{Fe}$ ratios for the glass (see below) and a database of over 1000 published olivine-bearing experiments conducted at known $f \mathrm{O}_{2}$ above $\mathrm{NNO}-3$, to test various aspects of our parameterizations.

\section{Analytical methods}

\section{Electron probe microanalysis (EPMA)}

Major and minor elements in glasses and minerals in the Adamello (RC158c), St. Vincent 1 (RSV49, XANES) and Montserrat series of experiments were analysed using a Cameca SX100 electron microprobe at University of Bristol. Analytical conditions were: olivine-20 kV primary beam, $10 \mathrm{nA}$ beam current and $1 \mu \mathrm{m}$ beam diameter; glass $-20 \mathrm{kV}$, $4 \mathrm{nA}$ and $10 \mu \mathrm{m}$ beam. Calibration was performed on a range of mineral, oxide and glass standards. Secondary standards used were: St. John's Island olivine, Kakanui hornblende, diopside, Columbia River Basalt glass (USGS) and an inhouse synthetic amphibolite glass (\#3570). All other glasses and minerals are those reported by the original authors (Table 1). At least 5 analyses were made of each olivine and glass. The subset of the 72 experiments containing analysed olivine crystals is 52 . 


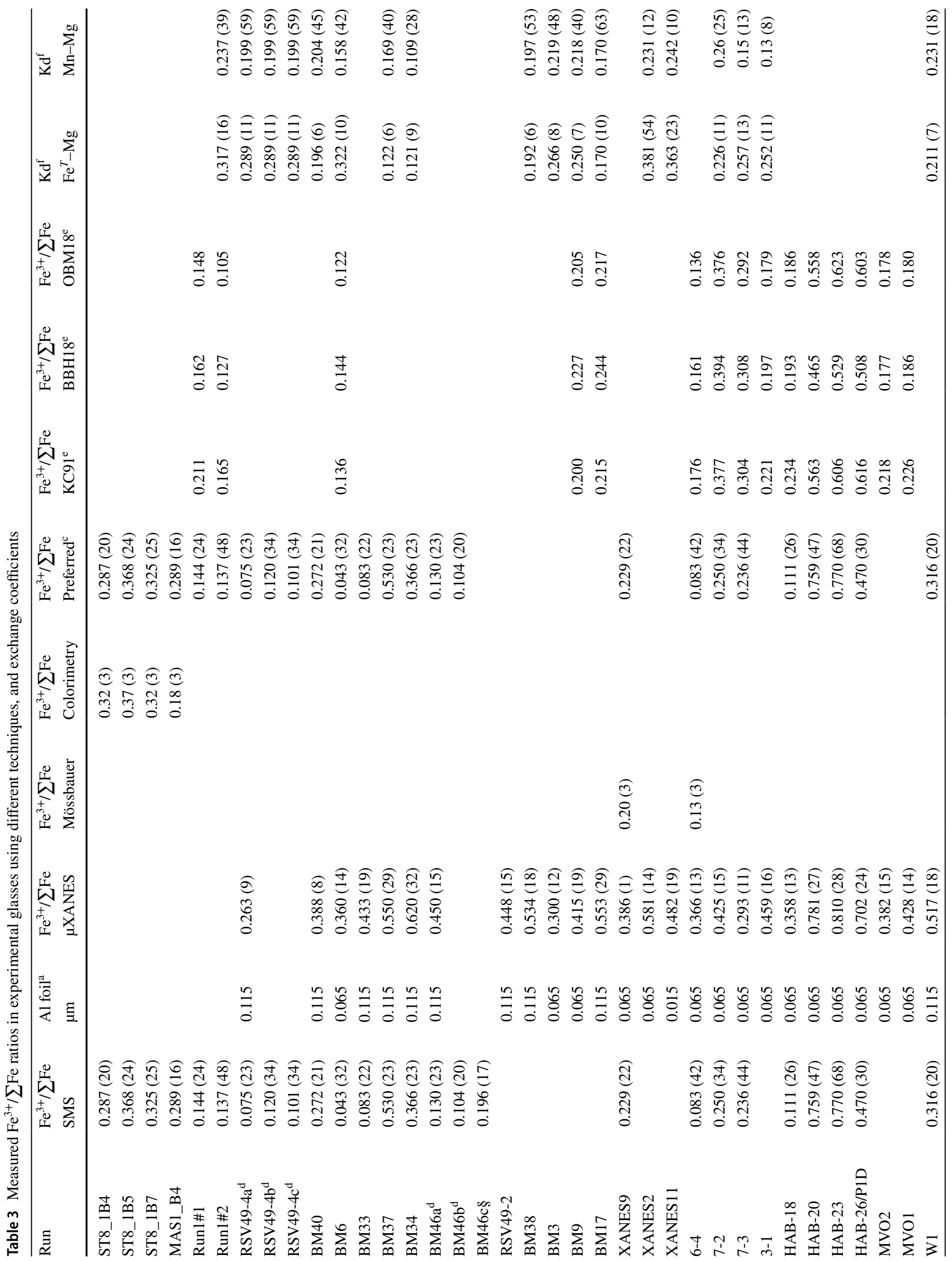




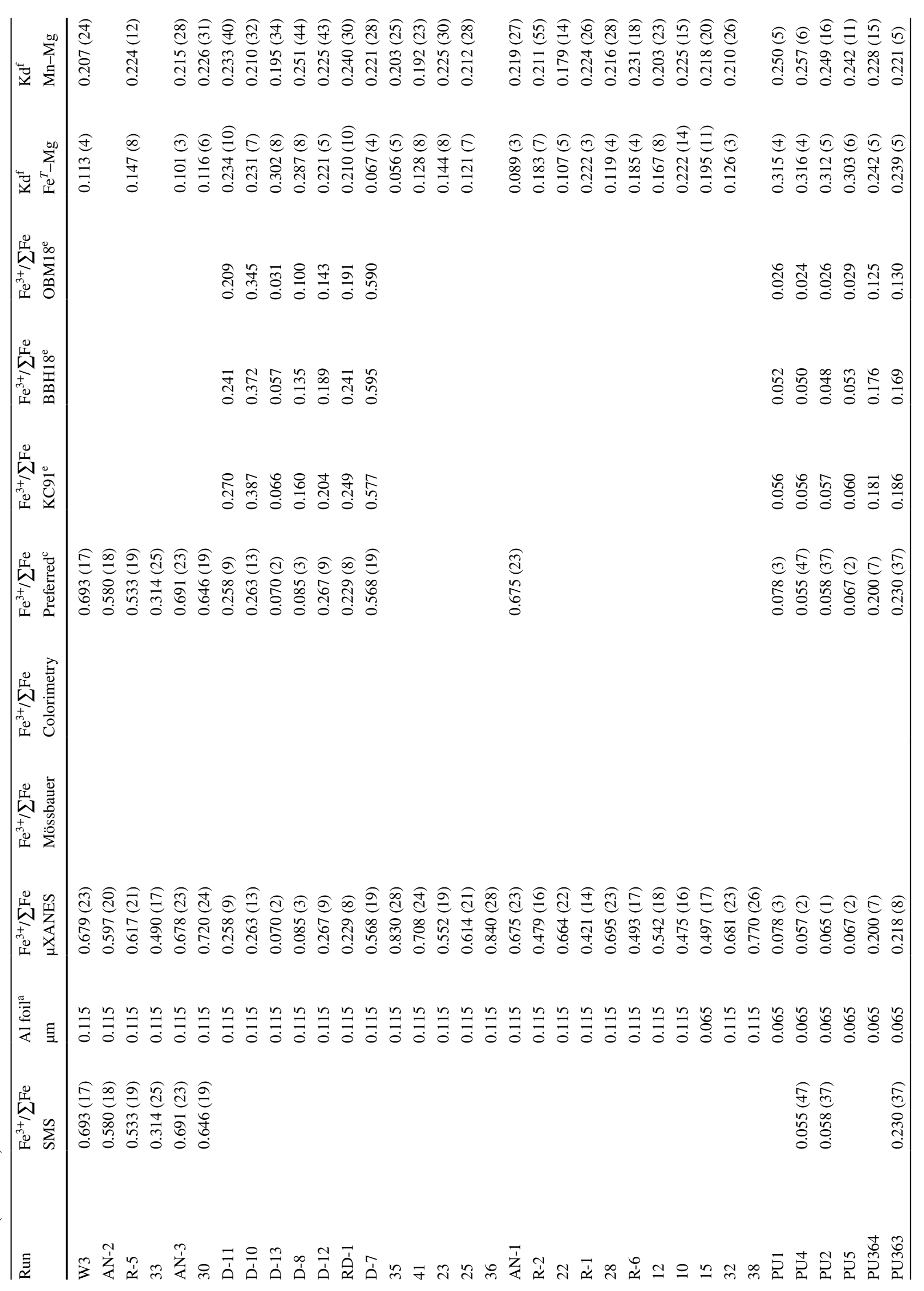




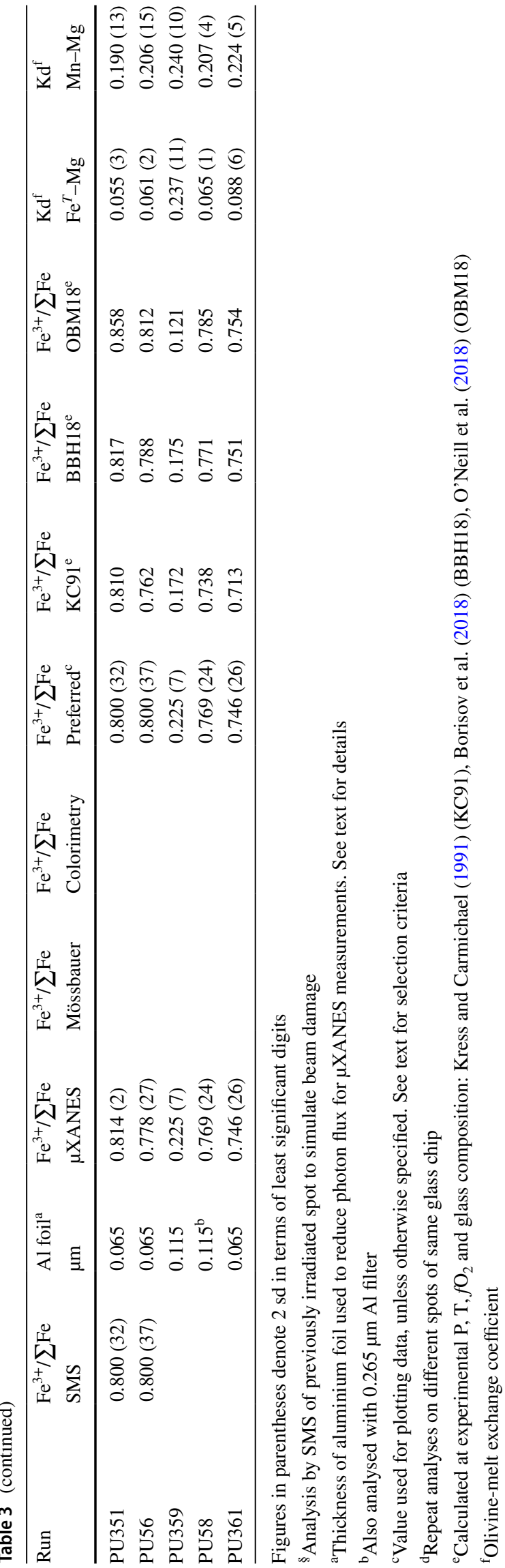

\section{Micro X-ray absorption near-edge spectroscopy ( $\mu$ XANES)}

$\mathrm{Fe}^{3+} / \Sigma \mathrm{Fe}$ ratios were measured in 66 experimental glasses by $\mu$ XANES at the Diamond Light Source synchrotron facility, UK, using techniques described in Stamper et al. (2014), with some modifications, as summarized here. $\mu$ XANES spectra were collected at the $\mathrm{Fe} \mathrm{K}$-edge in fluorescence mode on Beamline I18 using the $\mathrm{Si}(111)$ monochromator. The beam size at the sample was an ellipse with principal axes approximately $2.5 \times 4.5$ microns. The incident beam flux was reduced by placing one or more $50 \mu \mathrm{m}$-thick aluminium foil sheets in front of the sample in addition to the fixed $15 \mu \mathrm{m}$-thick filter used for all analyses (Table 3). The total flux density (defined as total photons delivered per second per square micrometer; Cottrell et al. 2018) is $6.8 \times 10^{10}$ (with $15 \mu \mathrm{m} \mathrm{Al}$ filter) or $2.5 \times \times 10^{10}$ photons $\mathrm{s}^{-1} \mu \mathrm{m}^{-2}$ (with $15+50 \mu \mathrm{m} \mathrm{Al} \mathrm{filters).} \mathrm{One} \mathrm{sample} \mathrm{(PU58)} \mathrm{was} \mathrm{analysed}$ twice with both $65 \mu \mathrm{m}$ and $115 \mu \mathrm{m}$ thickness of Al filters (flux density of $<1.1 \times 10^{10}$ photons $\mathrm{s}^{-1} \mu \mathrm{m}^{-2}$ ); the two measured $\mathrm{Fe}^{3+} / \Sigma \mathrm{Fe}$ ratios are 0.761 and 0.777 ; the mean is reported in Table 3.

Fluorescence counts were normalized to the incident beam flux at every energy step and collected using a 9-element solid-state Ge detector. The energy was calibrated by defining the first peak of the first derivative of $\mathrm{Fe}$ foil to be $7112 \mathrm{eV}$. Each spectrum was collected using four sets of energy acquisition conditions, giving good resolution over the pre-edge region and sufficient post-edge detail to allow high-quality normalization and background fitting. Each point was analyzed for 1000 or $2000 \mathrm{~ms}$, giving total acquisition times of approximately 10-15 min. Calibration was performed on ten basalt glass standards loaned by the Smithsonian Institution (Cottrell et al. 2009), using the revised and updated $\mathrm{Fe}^{3+} / \Sigma \mathrm{Fe}$ values of Zhang et al. (2018). Data processing is described in more detail in Stamper et al. (2014), but their original values have been updated in Table 3. Multiple ( 2 or 3 ) analyses were made of each glass; mean $\mathrm{Fe}^{3+} / \Sigma \mathrm{Fe}$ and 2 standard deviations (s.d.) are reported in Table 3.

\section{Secondary ion mass spectrometry (SIMS)}

Dissolved volatiles $\left(\mathrm{H}_{2} \mathrm{O}, \mathrm{CO}_{2}\right)$ in seven high-pressure experimental glasses from Montserrat and St. Vincent 1, 2 and 3 series were measured by SIMS using a Cameca ims $4 \mathrm{f}$ instrument at the NERC Edinburgh ion-microprobe facility (EIMF), UK. Samples were gold-coated for analysis. The primary beam was $10 \mathrm{keV} \mathrm{O}^{-}$ions with net impact energy of $14.5 \mathrm{keV}$ ( $4.5 \mathrm{kV}$ secondary voltage). Beam current was 5 $\mathrm{nA}$, focussed to $\mathrm{a} \sim 15 \mu \mathrm{m}$ spot at the sample surface. Prior to analysis the sample surface was sputtered with a $25 \times 25 \mu \mathrm{m}$ raster for 3 min to eliminate surface contamination. Positive 
secondary ions of ${ }^{1} \mathrm{H}$ and ${ }^{12} \mathrm{C}$ were collected with the $25 \mu \mathrm{m}$ imaged field and $150 \mu \mathrm{m}$ field aperture in two separate analytical routines with offset voltages of $75\left({ }^{1} \mathrm{H}\right)$ and $50 \mathrm{~V}$ $\left({ }^{12} \mathrm{C}\right)$. To avoid ${ }^{24} \mathrm{Mg}^{2+}$ interference ${ }^{12} \mathrm{C}^{+}$secondary ions were collected at high mass resolution $(M / \Delta M=1200)$. ${ }^{1} \mathrm{H}^{+}$secondary ions were collected at lower mass resolution $(M / \Delta M=500)$. A total of 15 analytical cycles was used, with count times of $5 \mathrm{~s}$ per cycle for ${ }^{1} \mathrm{H}$ and $12 \mathrm{~s}$ for ${ }^{12} \mathrm{C}$. Only the final 5 cycles $\left({ }^{1} \mathrm{H}\right)$ or 7 cycles $\left({ }^{12} \mathrm{C}\right)$ were processed to remove any lingering effects of surface contamination. ${ }^{30} \mathrm{Si}$ was used as an internal standard, based on prior EPMA analyses. Calibration was performed on a suite of $\mathrm{H}_{2} \mathrm{O}$ - and $\mathrm{CO}_{2}$-bearing synthetic and natural glass standards. Backgrounds, monitored on natural quartz grains co-mounted with the experimental glasses, were $2.8 \pm 0.8$ counts per second (cps) ${ }^{12} \mathrm{C}$ and $1600 \pm 700 \mathrm{cps}{ }^{1} \mathrm{H}$. Minimum detection limits, calculated as 3 s.d. on the blanks, were $140 \mathrm{ppm} \mathrm{H}_{2} \mathrm{O}$ and $26 \mathrm{ppm} \mathrm{CO}_{2}$. At least three analyses were made of each glass except for St. Vincent series 2 run 7-3, where only one sufficiently large glass pool could be found.

$\mathrm{H}_{2} \mathrm{O}$ and $\mathrm{CO}_{2}$ contents of a further 32 Grenada, St. Kitts, Stromboli, Masaya and St. Vincent 1 series glasses analysed by SIMS using similar techniques can be found in the original sources. Pichavant et al. (2002) report $\mathrm{H}_{2} \mathrm{O}$, but not $\mathrm{CO}_{2}$, in five St. Vincent 2 and Martinique series glasses. Melekhova et al. (2015) report $\mathrm{H}_{2} \mathrm{O}$ contents for 14 St. Vincent series 1 glasses. Uncertainties on $\mathrm{H}_{2} \mathrm{O}$ and $\mathrm{CO}_{2}$ (Table 2) are based on 1 s.d. of multiple analyses for new SIMS data, or are taken from original data sources.

\section{In-house Mössbauer spectroscopy}

Mössbauer spectroscopy measurements of two experimental glasses were made at Bayerisches Geoinstitut, Bayreuth, using a constant acceleration Mössbauer spectrometer in transmission mode with a nominal $370 \mathrm{MBq}{ }^{57} \mathrm{Co}$ point source in a $12 \mu \mathrm{m} \mathrm{Rh}$ matrix. Active dimensions of the point source were $500 \times 500 \mu \mathrm{m}^{2}$. The velocity scale was calibrated relative to $\alpha-\mathrm{Fe}$ and line widths of $0.36 \mathrm{~mm} \mathrm{~s}^{-1}$ were obtained for outer lines of $\alpha-\mathrm{Fe}$ at room temperature. Experimental glasses were at room temperature during data collection. The glass samples were $200 \mu \mathrm{m}$ thick and Mössbauer spectra were collected over a $500 \mu \mathrm{m}$ diameter region in the middle of each sample. Data collection took 7-12 days.

Mössbauer spectra were fitted using MossA (Prescher et al. 2012) with a linear baseline to account for shadowing. We adopted the xVBFmodel (see Alberto et al. 1996; Lagarec and Rancourt 1997) for the fit, with the full transmission integral to account for thickness effects of the source and absorber (Rancourt 1989), and conventional constraints (doublet components with equal widths and areas). The $\mathrm{Fe}^{2+}$ doublet fit used the xVBFmodel with correlation. One extra
$\mathrm{Fe}^{2+}$ doublet was added to improve the fit of the $\mathrm{Fe}^{2+}$ absorption envelope; we used pseudo-Voigt line shape to minimize the number of extra parameters. The $\mathrm{Fe}^{3+}$ doublet fit used a pseudo-Voigt line shape to approximate the $\mathrm{xVBFmodel}$ with no correlation (see Partzsch et al. 2004; McCammon 2004). The $\mathrm{Fe}^{3+} / \Sigma \mathrm{Fe}$ ratio was determined from relative areas. Spectra were fit with different models to assess dependence of $\mathrm{Fe}^{3+} / \Sigma \mathrm{Fe}$ on fitting model and error bars were estimated accordingly ( \pm 0.03 in the ratio).

\section{Synchrotron Mössbauer Source (SMS) spectroscopy}

Energy-domain SMS measurements on 37 experimental glasses were conducted at the Nuclear Resonance Beamline ID18 (Rüffer and Chumakov 1996) at the European Synchrotron Radiation Facility (ESRF), Grenoble, France, operating in multibunch $(7 / 8+1)$ mode. SMS is based on a nuclear resonant monochromator employing pure nuclear reflections of an iron borate $\left({ }^{57} \mathrm{FeBO}_{3}\right)$ single crystal (Potapkin et al. 2012). This source provides ${ }^{57} \mathrm{Fe}$ resonant radiation at $14.4 \mathrm{keV}$ within a bandwidth of $6 \mathrm{neV}$ which is tuneable in energy over a range of $\pm 0.6 \mu \mathrm{eV}$ (Potapkin et al. 2012). Sample glasses were prepared as 150-350 $\mu$ m-thick, doublypolished wafers. After polishing, the transparent wafers were checked under a microscope to locate areas free of bubbles or crystals.

The X-ray beam was focused at the sample surface to an ellipse with principal axes $17 \times 18 \mu \mathrm{m}$ at the full-width half-maximum (FWHM). Before and after each sample measurement, SMS linewidth was determined using a $\mathrm{K}_{2} \mathrm{Mg}{ }^{57} \mathrm{Fe}(\mathrm{CN})_{6}$ reference single-line absorber. The velocity scale $\left( \pm 5 \mathrm{~mm} \mathrm{~s}^{-1}\right)$ was calibrated relative to a $25 \mu \mathrm{m}$-thick natural $\alpha$-Fe foil. The small cross section, high brilliance and fully resonant and polarized nature of the beam allowed for rapid spectrum collection (approximately $2 \mathrm{~h}$ ). Slightly longer run times (up to $6 \mathrm{~h}$ ) were required for Fe-poor samples. Note that the glasses measured in this study contain only natural abundances of ${ }^{57} \mathrm{Fe}$-atoms, i.e., $~ 2 \%$ of total $\mathrm{Fe}$, thus the total radiation dosage, defined as photon delivered per $\mu \mathrm{m}^{2}$ of the sample is 150 , compared to $10^{12}$ for $\mu$ XANES at Diamond.

Typical samples for SMS analysis are shown in Fig. 2; SMS spectra (and fits) for these samples are shown in Fig. 3. All SMS spectra consist of two broad symmetric doublets, typical of basaltic glasses. The spectra were fitted with a full transmission integral and Lorentzian line shape using the software package MossA (Prescher et al. 2012). The single line spectra were fitted with a normalized Lorentzian-squared source line shape. A linear function was applied to model the background. To obtain the maximum amount of photons we used the confocal Be-lenses installed at the ESRF beamline ID18. Be-lenses always bear traces of iron that result in the presence of two components 

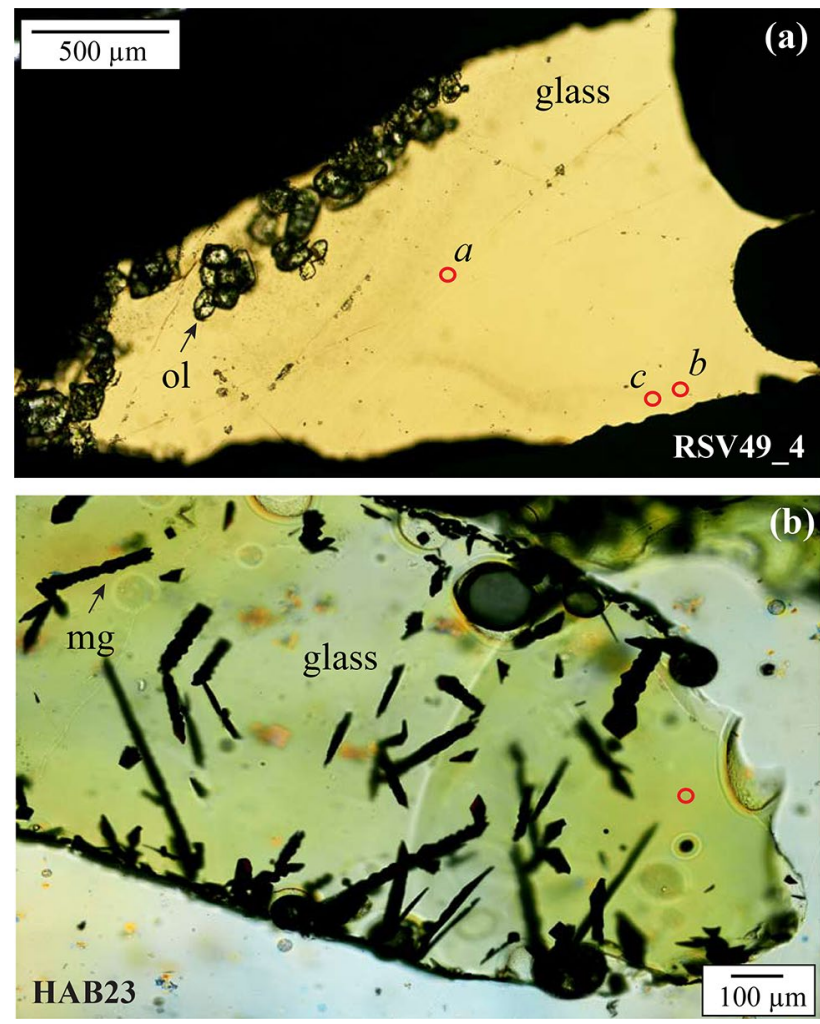

Fig. 2 Transmitted light photomicrographs of typical run products prepared for SMS analysis: a run RSV49_4; and b run HAB23. Doubly polished glass chips show clear glass pools suitable for SMS analysis. Crystalline phases are olivine in $\mathbf{a}$ and magnetite in $\mathbf{b}$. The locations of the SMS analyses reported in Table 3 are shown as red circles

(Supplementary Fig. 1). The signal for iron in Be-lenses is easily corrected for and defined in all of the glass SMS spectra (Fig. 3).

The approach we adopt for the fitting uses only two distinct components represented by two doublets, one for $\mathrm{Fe}^{3+}$ and one for $\mathrm{Fe}^{2+}$. Attempts using a model involving an additional $\mathrm{Fe}^{2+}$ component did not improve the quality of the fitting nor change the final $\mathrm{Fe}^{3+} / \Sigma \mathrm{Fe}$ results. Hyperfine parameters (centre shift, CS, and quadrupole splitting, QS) were first determined from the spectra where the two components were easily identified. For the other samples, the hyperfine parameters were allowed to vary within those ranges. $\mathrm{Fe}^{3+} /$ $\Sigma \mathrm{Fe}$ values were obtained from the relative areas of the two components. The errors ( 2 s.d.) on the $\mathrm{Fe}^{3+} / \Sigma \mathrm{Fe}$ ratios were obtained by normal error propagation.

Hyperfine parameters, $\mathrm{Fe}^{3+} / \Sigma \mathrm{Fe}$ values and related errors for all SMS analyses are reported in Supplementary Table 1. Centre shift varies in the range $1.00-1.12 \mathrm{~mm} \mathrm{~s}^{-1}$ for $\mathrm{Fe}^{2+}$ and $0.27-0.41$ for $\mathrm{Fe}^{3+}$. Quadrupole splitting varies in the range 1.89-2.60 for $\mathrm{Fe}^{2+}$ and $0.74-1.29 \mathrm{~mm} \mathrm{~s}^{-1}$ for $\mathrm{Fe}^{3+}$. With one exception (run HAB23; Supplementary Table 1), absolute errors on $\mathrm{Fe}^{3+} / \Sigma \mathrm{Fe}$ range from 0.02 to 0.05 . Highest errors are typically associated with samples having either
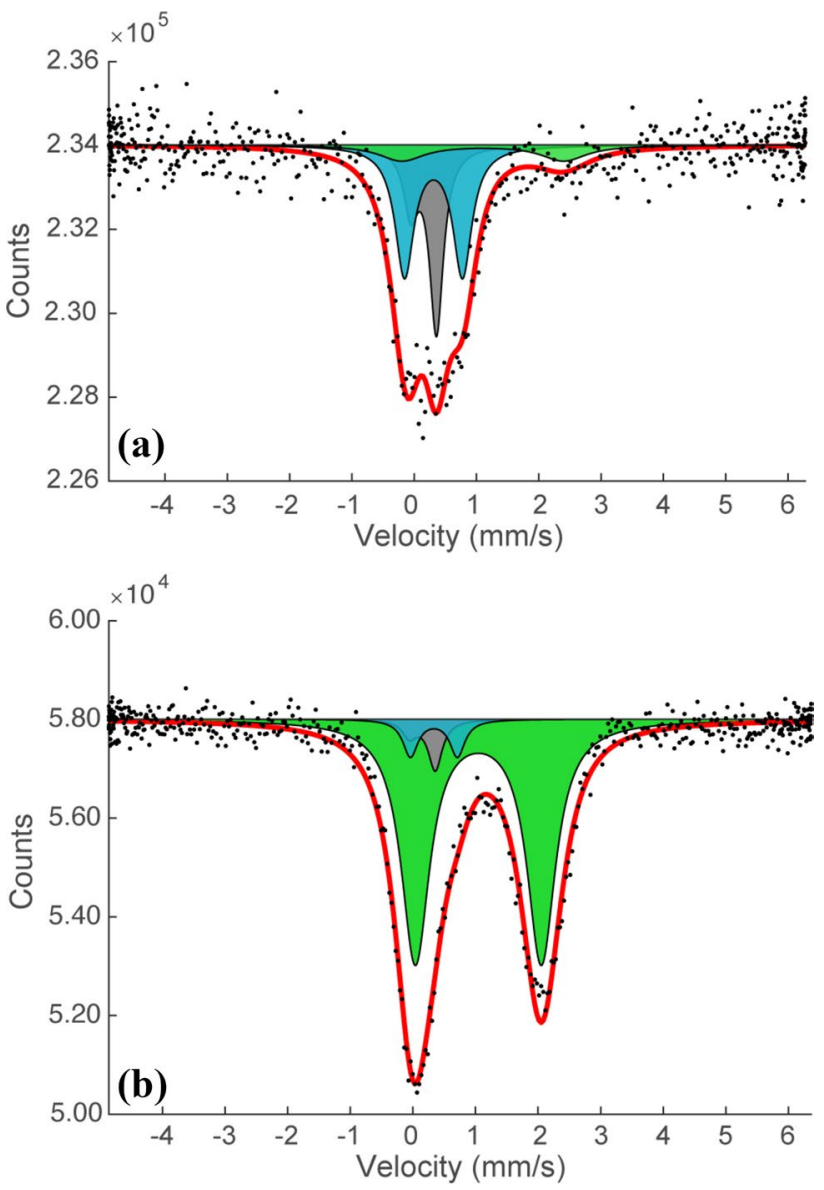

Fig. 3 Mössbauer spectra of experimental samples a HAB23 and b RSV49_4 (spot a) obtained using synchrotron Mössbauer source (SMS) spectroscopy at the beamline ID18, ESRF. Green and blue areas represent the fitted $\mathrm{Fe}^{2+}$ and $\mathrm{Fe}^{3+}$ components, respectively, while the grey area represents the contribution of Fe in Be-lenses (see text and Supplementary Material 1). Red curve represents the sum of all components (i.e., the modelled fit)

low or high $\mathrm{Fe}^{3+} / \Sigma \mathrm{Fe}$, for which the $\mathrm{Fe}^{3+}$ or $\mathrm{Fe}^{2+}$ component is less easily resolved.

\section{Colorimetry}

Four glasses of the Stromboli and Masaya series of Lesne et al. (2011) were analysed previously for $\mathrm{Fe}^{3+} / \Sigma \mathrm{Fe}$ using colorimetric wet-chemistry, following the method of Schuessler et al. (2008).

\section{Results}

Experimental run conditions and products are presented in Table $2, \mathrm{Fe}^{3+} / \Sigma \mathrm{Fe}$ ratios and exchange coefficient in Table 3, and analyses of glasses and olivines in Tables 4 and 5 , respectively. On an anhydrous basis glasses are basalts 
毒 人ू

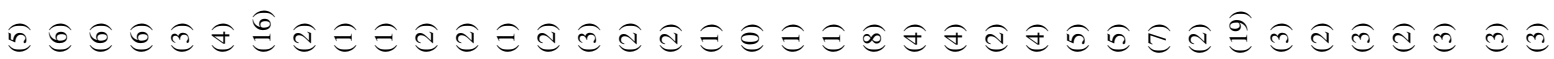

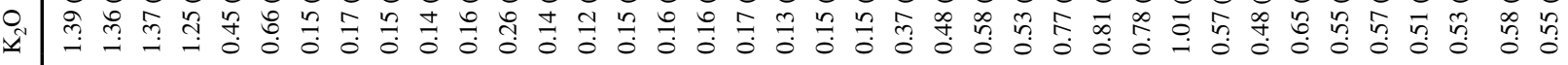

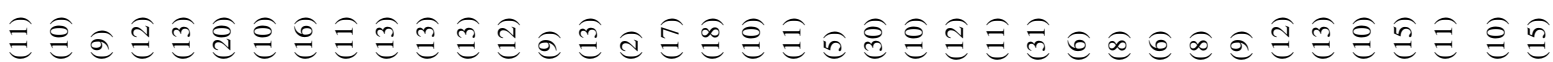

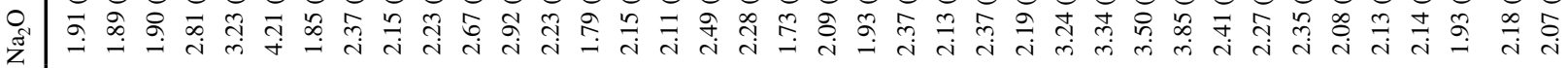

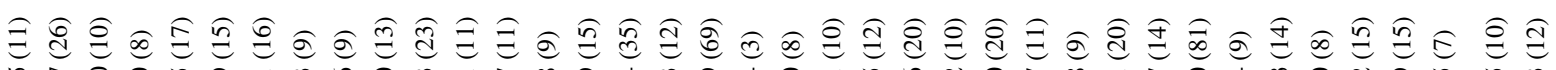

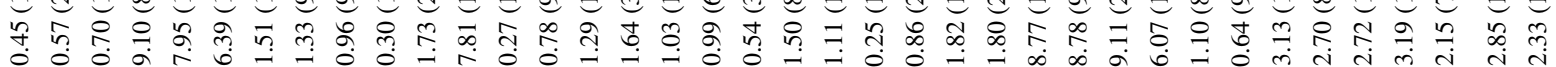

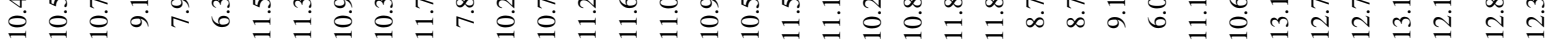

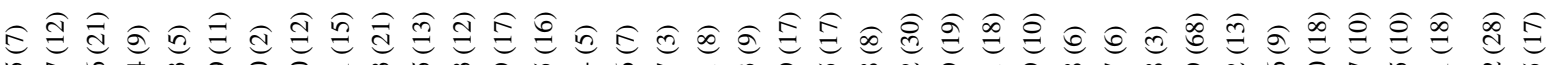

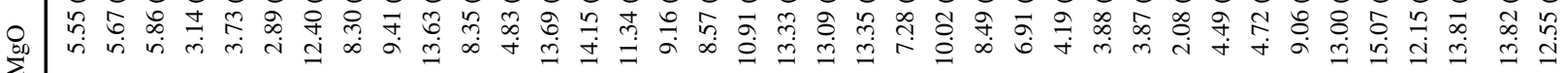

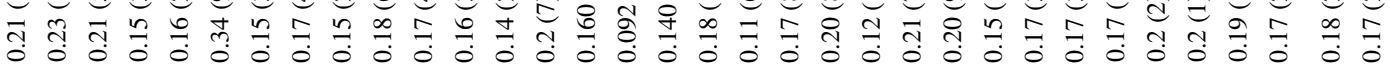

焉

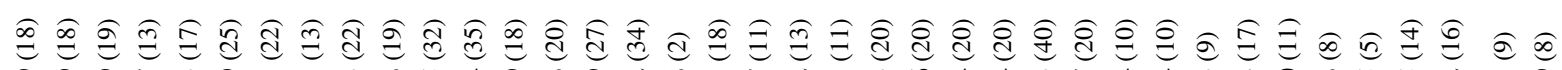

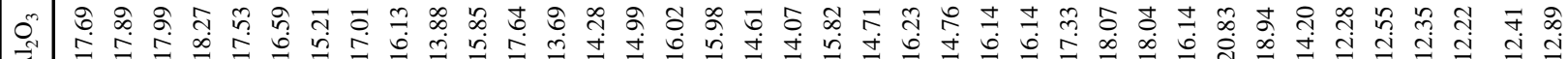

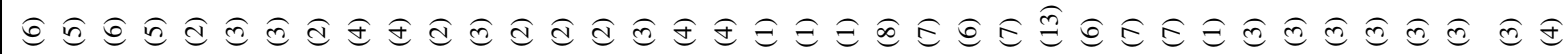
尚

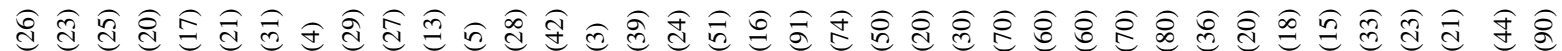

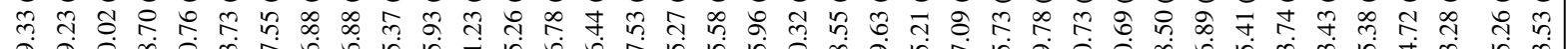
己 
- ㄷำ चँ

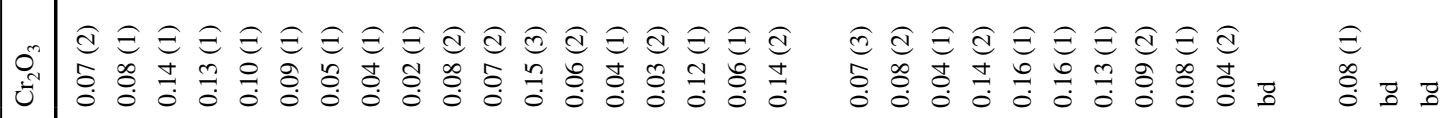

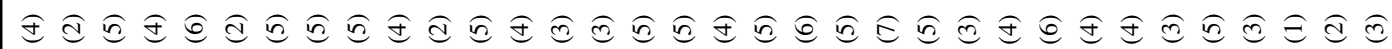
年

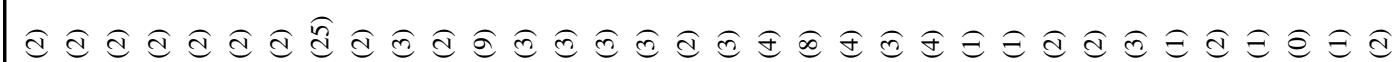

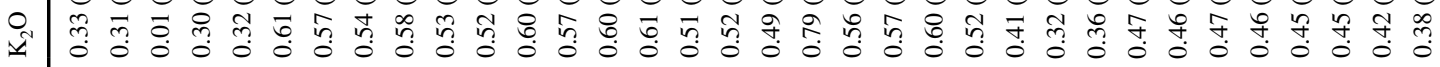

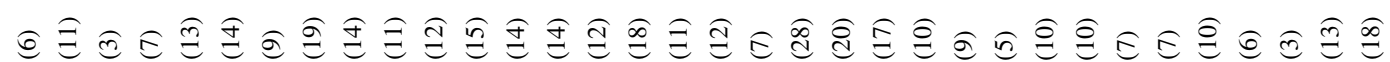

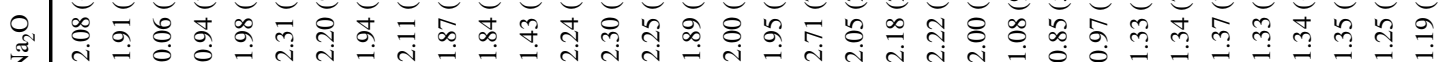

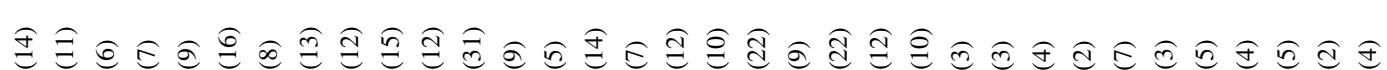

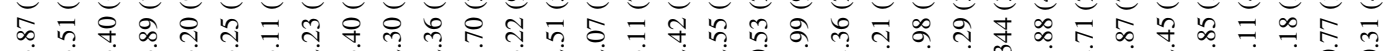

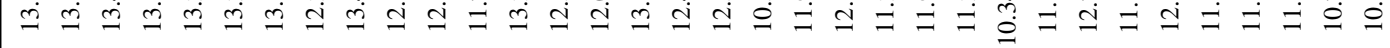

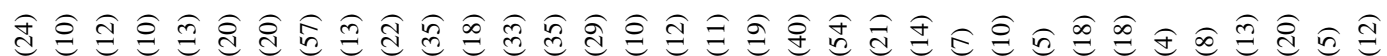
○ సे

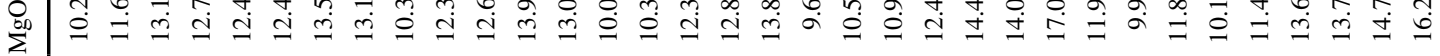

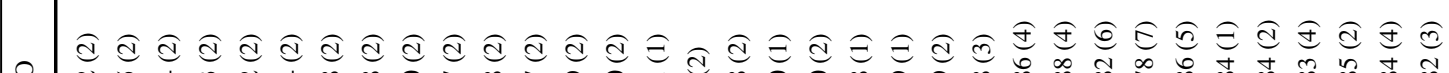
㤢

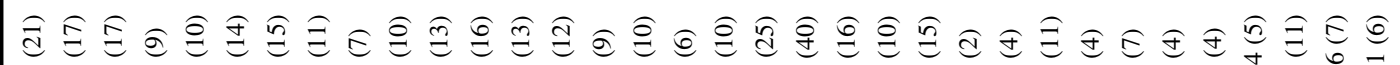

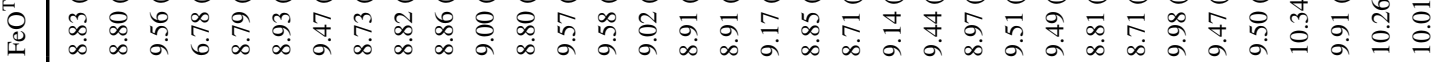

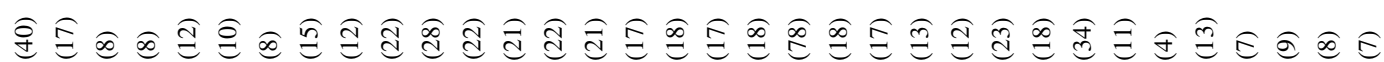

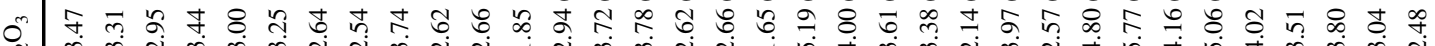

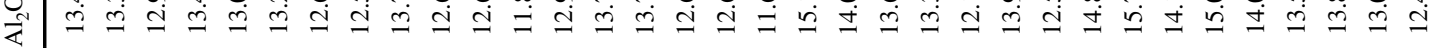

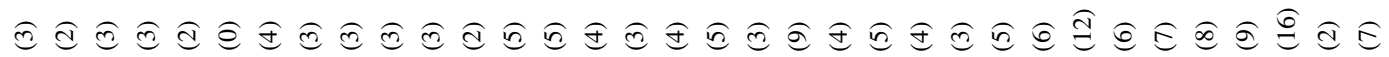
O

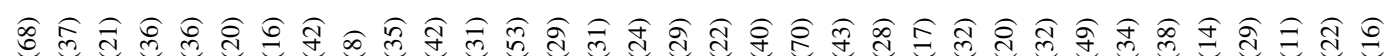

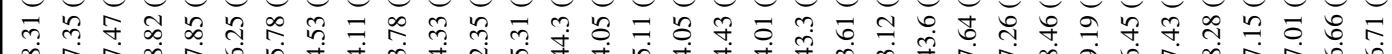
党

$=0$

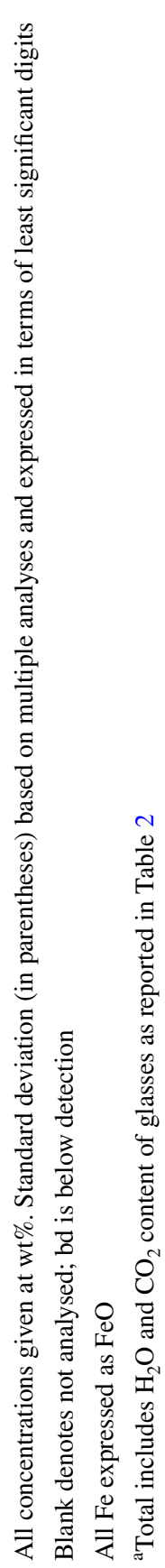


$(n=61)$ and basaltic andesites $(n=10)$ and a single dacite (HAB-26). $\mathrm{H}_{2} \mathrm{O}$ and $\mathrm{CO}_{2}$ range from zero (nominally) up to 8.3 and $1.2 \mathrm{wt} \%$, respectively. Glass $\mathrm{MgO}$ contents range from 2 to $17 \mathrm{wt} \%$; olivines are $\mathrm{Fo}_{86}$ to $\mathrm{Fo}_{98}$ with $0.09-0.59 \mathrm{wt} \% \mathrm{MnO}$ (one at $\mathrm{Fo}_{65}$ and $0.56 \mathrm{wt} \% \mathrm{MnO}$ ) and 0.02-0.94 wt \% $\mathrm{CaO}$. Total alkalis $\left(\mathrm{Na}_{2} \mathrm{O}+\mathrm{K}_{2} \mathrm{O}\right)$ in the glasses range from 0.1 to $4.9 \mathrm{wt} \%$.

\section{Ferric-ferrous ratios}

$\mathrm{Fe}^{3+} / \Sigma \mathrm{Fe}$ ratios range from 0.06 to 0.84 ( $\mu$ XANES) and 0.04 to 0.80 (SMS). Typical uncertainties (2 s.d.) in $\mathrm{Fe}^{3+} / \Sigma \mathrm{Fe}$, propagated through the various sources of analytical error, are in the range $0.001-0.32$ (mean $=0.016$ ) for $\mu$ XANES; 0.02-0.07 (mean $=0.029$ ) for SMS; and $\sim 0.03$ for in-house Mössbauer and colorimetry. To test the homogeneity of individual glasses we used SMS to analyze three separate chips of water-poor glass RSV49_4 from the centre (RSV49_4a, b) and from the edge (RSV49_4c) of the experimental charge. All three measurements lie within 2 s.d. of each other (Table 3). Similarly, two SMS analyses of hydrous glass BM46 from the centre (BM46a) and periphery (BM46b) of the same glass chip give values of $\mathrm{Fe}^{3+} / \Sigma \mathrm{Fe}$ that agree within 2 s.d. (BM46c analysis is described below).

Two experimental glasses (XANES9, 6-4) analysed by SMS and in-house Mössbauer displayed consistency to within 2 s.d. (Table 3). SMS and colorimetry agree within 2 s.d. for three of the four glasses analysed by both techniques; the fourth (MAS1_B4) has a significantly higher $\mathrm{Fe}^{3+} / \Sigma \mathrm{Fe}$ by SMS $(0.289)$ than by colorimetry $(0.18)$. The cause of this discrepancy is unclear. However, it is noteworthy that the $\mathrm{Fe}^{3+} / \Sigma \mathrm{Fe}$ from colorimetry is significantly lower than other three values from glasses synthesised under similar conditions in the study of Lesne et al. (2011), i.e., 0.32-0.37, suggesting a potential problem with colorimetric analysis of MAS1_B4. For the 27 glasses analysed by both $\mu$ XANES and SMS, the former method gives significantly higher $\mathrm{Fe}^{3+} / \Sigma \mathrm{Fe}$ for all but ten (Table 3). This discrepancy is well outside the analytical uncertainty and is suggestive of oxidation by the X-ray beam during $\mu$ XANES analysis (Cottrell et al. 2018). The problem of oxidation is found to be most acute in hydrous glasses $\left(>0.5 \mathrm{wt} \% \mathrm{H}_{2} \mathrm{O}\right)$ containing a significant proportion of the oxidizable species, $\mathrm{Fe}^{2+}$. This is evident from a plot of the difference between $\mathrm{Fe}^{3+} / \Sigma \mathrm{Fe}$ by SMS and $\mathrm{Fe}^{3+} / \Sigma \mathrm{Fe}$ by $\mu$ XANES against the $\mathrm{Fe}^{3+} / \Sigma \mathrm{Fe}$ (by SMS) in glass (Fig. 4). For anhydrous glasses $\left(<0.5 \mathrm{wt} \% \mathrm{H}_{2} \mathrm{O}\right)$ the two methods agree across a broad range of $\mathrm{Fe}^{3+} / \Sigma \mathrm{Fe}$; for hydrous glasses the scale of the mismatch increases roughly linearly with decreasing $\mathrm{Fe}^{3+} / \Sigma \mathrm{Fe}$ (i.e., increasing $\left.\mathrm{Fe}^{3+} / \Sigma \mathrm{Fe}\right)$. This is consistent with the findings of Cottrell et al. (2018), albeit here based on a much wider range of glass compositions and $\mathrm{Fe}^{3+} / \Sigma \mathrm{Fe}$. Cottrell et al. (2018) conclude that oxidation is most acute when photon flux densities are as high as those used in our analyses; they recommend using flux densities some two orders of magnitude lower to minimise the oxidative effects of the beam.

To explore further the influence of photon dosage on in situ oxidation during $\mu$ XANES analysis, we ran a series of continuous time-scans at Diamond at energies corresponding to the peaks of the $\mathrm{Fe}^{2+}$ and $\mathrm{Fe}^{3+}$ regions of the preedge, without attenuating $\mathrm{Al}$ foils in front of the beam. This enables a semi-quantitative, real-time assessment of maximum beam damage. We analysed synthetic hydrous glasses MAS1_B4 and MAS1_B5 from Lesne et al. (2011) with 3.0 and $2.6 \mathrm{wt} \% \mathrm{H}_{2} \mathrm{O}$, respectively, alongside anhydrous glass standard LW_10 from Cottrell et al. (2009). Both hydrous glasses have $10.7 \mathrm{wt}^{2} \mathrm{FeO}^{\mathrm{T}}$; $\mathrm{LW}$ has $10.2 \mathrm{wt} \% \mathrm{FeO}^{\mathrm{T}}$ (Cottrell et al. 2009). All samples are moderately oxidised with $\mathrm{Fe}^{3+} / \Sigma \mathrm{Fe}$ of 0.18 (MAS1_B4) and 0.32 (MAS1_B5), as determined by colorimetry (Lesne et al. 2011), 0.289 (MAS1_B4) by SMS (Table 3), and 0.235 (LW_10) by inhouse Mössbauer (Cottrell et al. 2009). The sample shutter was kept closed until the beginning of counting, and counts were collected every $5 \mathrm{~s}$ for $500 \mathrm{~s}$, which is approximately the same length of time taken to reach the pre-edge region in our quantitative $\mu$ XANES analyses. For $L W \_10, \mathrm{Fe}^{3+}$ count rates (normalised to $\mathrm{I}_{0}$ ) showed only a minimal increase during the analysis, whereas MAS1_B4 and MAS1_B5 showed relatively small increases in apparent $\mathrm{Fe}^{3+} / \Sigma \mathrm{Fe}$ (calculated from peak height alone, not from a full area-weighted centroid fit) of $\sim 0.02$ and 0.05 , respectively (Supplementary Fig. 2).

This experiment confirms that beam damage during $\mu X A N E S$ is occurring in our samples, and that the extent of damage increases with higher $\mathrm{H}_{2} \mathrm{O}$ concentrations and lower initial redox state, as described in Cottrell et al. (2018). However, regardless of $\mathrm{H}_{2} \mathrm{O}$ concentration, the measured deviations are very weak in oxidised glasses with $\mathrm{Fe}^{3+} / \Sigma \mathrm{Fe} \geq 0.5$ and strongest in reduced glasses with $\mathrm{Fe}^{3+} / \Sigma \mathrm{Fe} \leq 0.5$ (Fig. 4). In unpublished $\mu$ XANES data from more evolved (rhyolitic) compositions we have also observed greater beam damage in reduced, $\mathrm{H}_{2} \mathrm{O}$-poor glasses than in oxidised, $\mathrm{H}_{2} \mathrm{O}$-rich equivalents. We suggest, therefore, that the dominant factor controlling beam-damage susceptibility is the initial redox state of the glass. However, as anhydrous glasses experience little or no damage, the presence of $\mathrm{H}_{2} \mathrm{O}$ is clearly important (Cottrell et al. 2018). During electron beam damage of hydrous glasses, $\mathrm{H}_{2} \mathrm{O}$ appears to facilitate damage by enhancing the diffusion of alkalis and $\mathrm{OH}$ towards or away from the centre of electron deposition (Humphreys et al. 2006). We speculate, following Cooper et al. (1996), that a similar effect may occur during X-ray irradiation, with $\mathrm{Fe}$ oxidation generated as a result of alkali migration towards the site of maximum X-ray flux. Such mechanisms could be tested in future by detailed mapping 


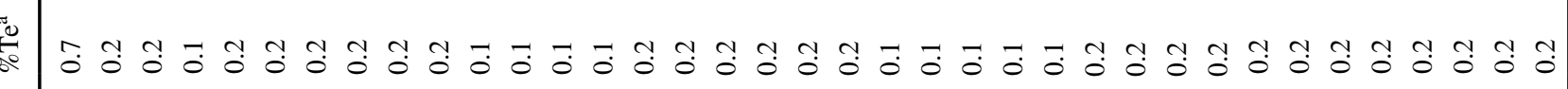

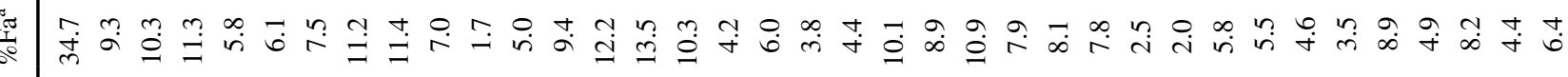

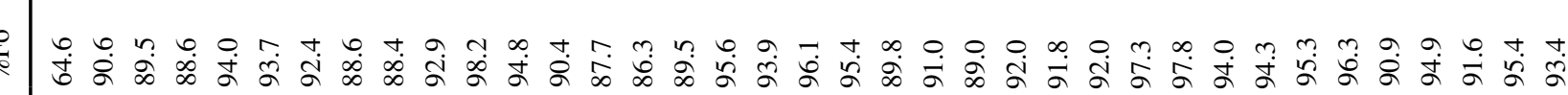
: $\infty$ 엉 \%

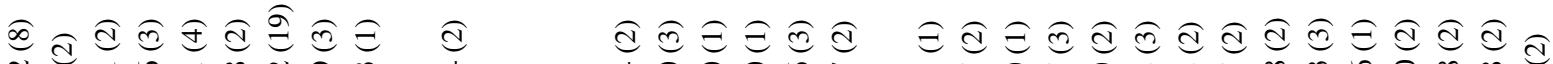

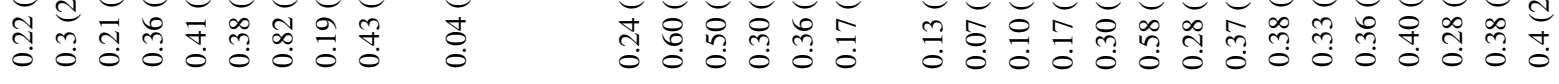

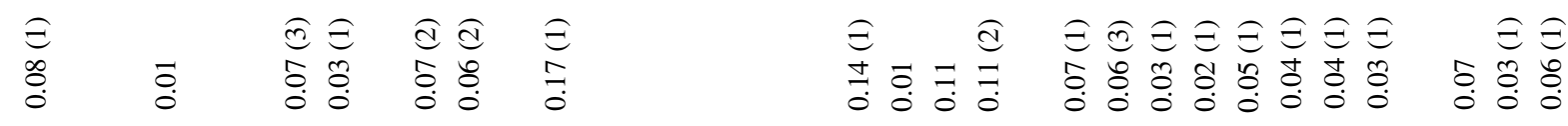

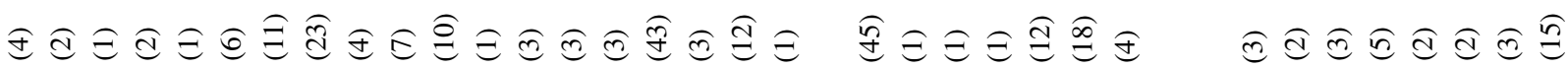

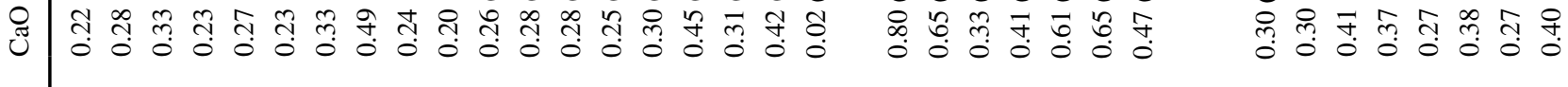

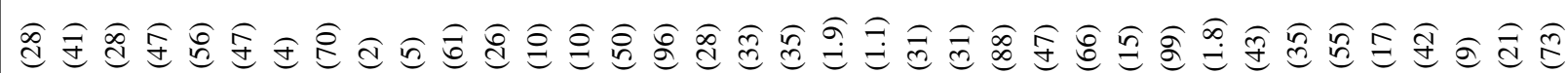

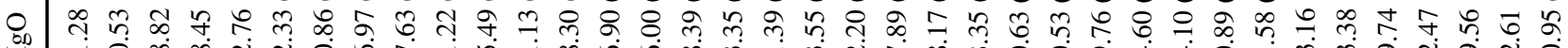

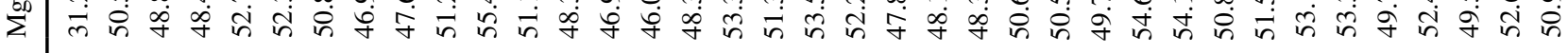

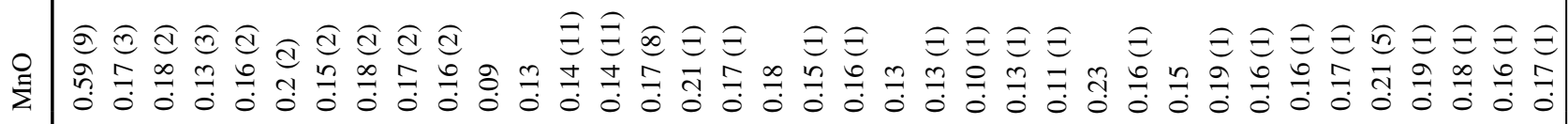

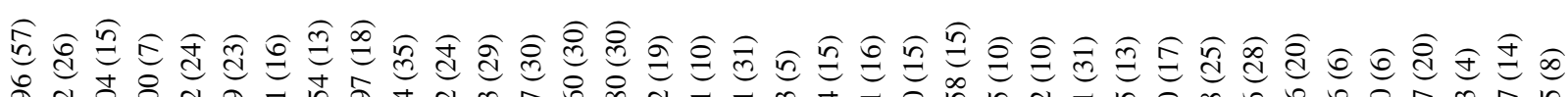
ते

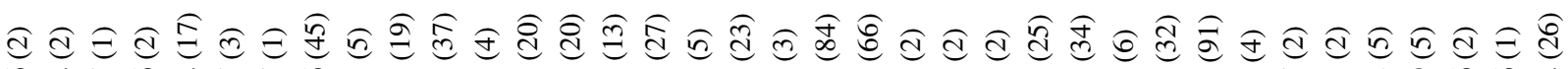
年

\begin{tabular}{|c|c|c|c|}
\hline 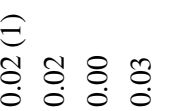 & 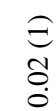 & 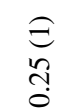 & $=\frac{9}{8}$ \\
\hline
\end{tabular}

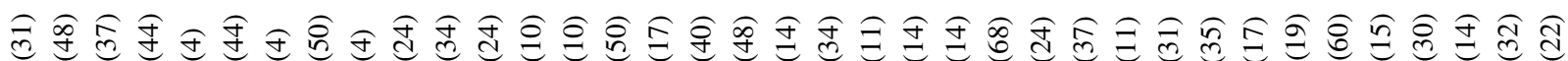

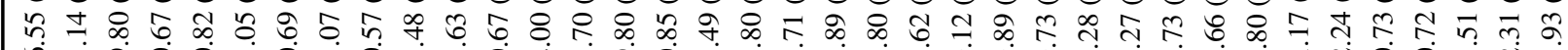

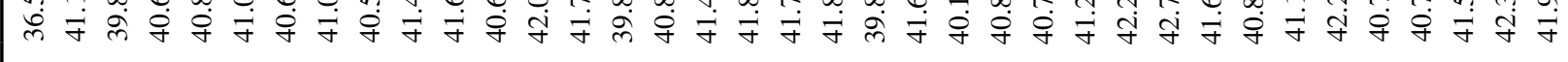

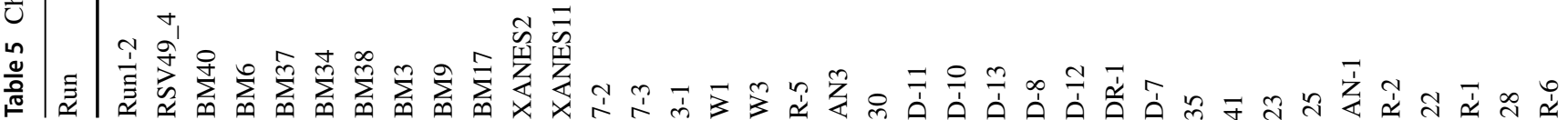




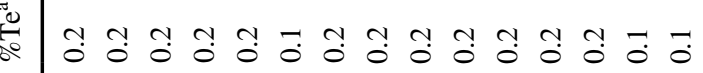
造

遂 สำ बूँ

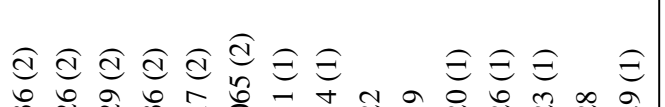
号

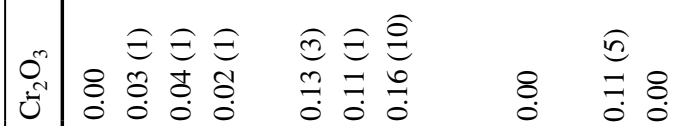

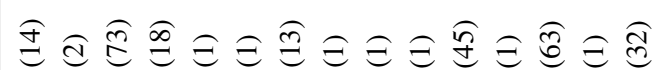

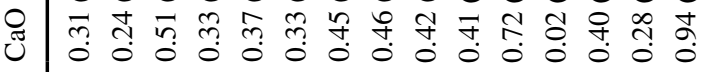
合

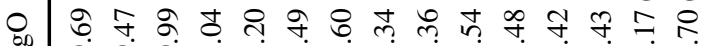

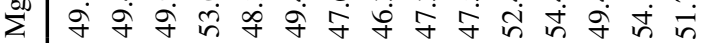

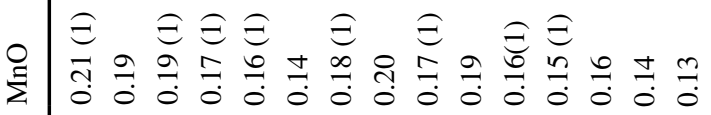

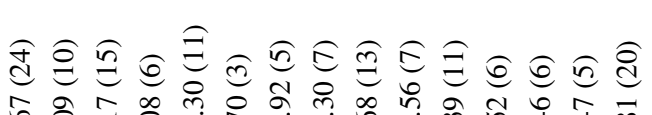

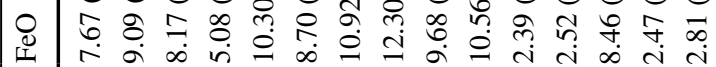

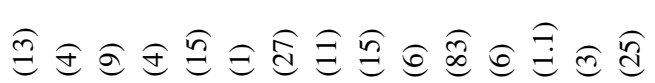

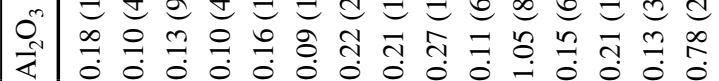

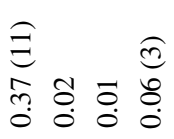

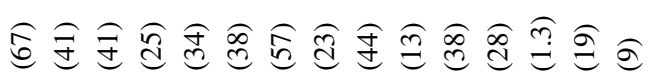
० ले

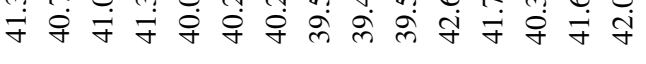




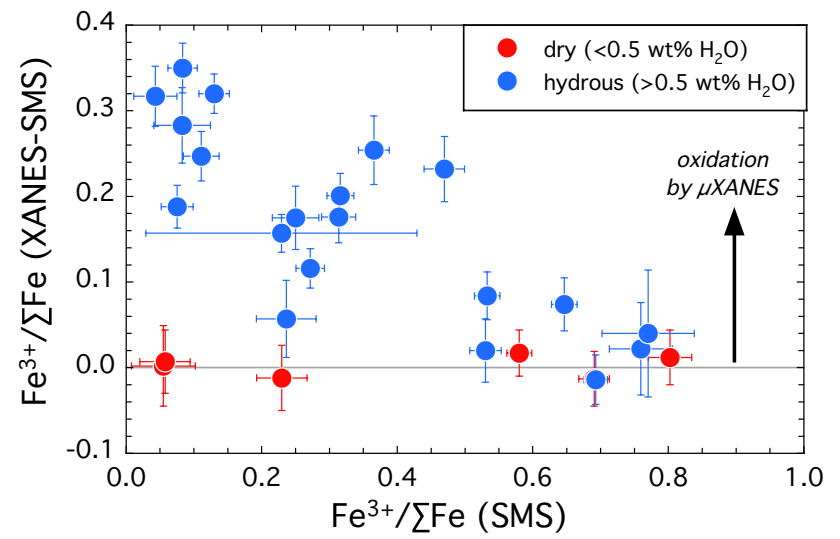

Fig. 4 Comparison of $\mu$ XANES and SMS methods used to measure $\mathrm{Fe}^{3+} / \Sigma \mathrm{Fe}$ in our experimental glasses. The difference between XANES and SMS measurements of $\mathrm{Fe}^{3+} / \Sigma \mathrm{Fe}$ is plotted versus that measured by SMS. $\mu$ XANES tends to overestimate $\mathrm{Fe}^{3+} / \Sigma \mathrm{Fe}$ due to beam damage at the high photon fluxes used. As the amount of oxidisable $\mathrm{Fe}^{2+}$ in the glass increases, so the tendency to oxidise during $\mu$ XANES increases for all but the most dry $\left(<0.5 \mathrm{wt} \% \mathrm{H}_{2} \mathrm{O}\right)$ glasses. Only for very oxidised $\left(\mathrm{Fe}^{3+} / \Sigma \mathrm{Fe}>0.5\right)$ or dry glasses do $\mu$ XANES and SMS agree within experimental uncertainty. Data are taken from Table 3; error bars are 2 sd

of cation distribution in the regions surrounding irradiated sites (Cottrell et al. 2018).

To directly simulate possible beam damage caused by $\mu X A N E S$ analysis at the high photon flux densities used at Diamond we analysed by SMS a glass chip from experiment BM46 previously exposed to comparable beam dosage to $\mu$ XANES. A spot on the sample (BM46c in Table 3) was first irradiated for 10 min with a beam flux of $10^{14}$ photon $\mathrm{s}^{-1}$, corresponding to a total photon dosage of $8 \times 10^{11}$. A dark spot appeared at the glass surface after irradiation. This spot was then analysed by SMS, using the same low photon flux as previously. The analysis revealed significantly higher $\mathrm{Fe}^{3+} / \Sigma \mathrm{Fe}(0.196 \pm 0.017)$ compared to un-irradiated spots (BM46a,b) on the same chip $(0.130 \pm 0.023$ and $0.104 \pm 0.020$ ), confirming that high photon-flux irradiation of hydrous glass, such as that during $\mu$ XANES at Diamond, causes appreciable oxidation. The extent of the oxidation is, however, somewhat less than we observed for the typical mismatch between SMS and $\mu$ XANES (Fig. 4), probably due to the smaller spot size of $\mu$ XANES (i.e., greater flux density) compared to the SMS simulation. The mechanism of oxidation is not clear, but may involve the formation of tiny magnetite nanolites (Di Genova et al. 2017; Hughes et al. 2018), as suggested by Raman spectra of some $\mu$ XANES spots and the darkening of the glass after irradiation. This mechanism may operate in tandem with the alkali migration proposed above.

In light of the likely oxidation of some hydrous glasses during $\mu$ XANES analysis, we favour SMS data over $\mu$ XANES data for all hydrous glasses. For glasses with $<0.5$ wt $\% \mathrm{H}_{2} \mathrm{O}$, but lacking SMS analyses, we have adopted the $\mu$ XANES $\mathrm{Fe}^{3+} / \Sigma \mathrm{Fe}$ values. Our 'preferred' $\mathrm{Fe}^{3+} / \Sigma \mathrm{Fe}$ values for each experiment are given in Table 3; these are the $\mathrm{Fe}^{3+} / \Sigma \mathrm{Fe}$ values used in all subsequent calculations and plots. Note that some hydrous glasses without SMS analysis have no preferred $\mathrm{Fe}^{3+} / \Sigma \mathrm{Fe}$ value and are not considered further. The total number of different glasses with preferred $\mathrm{Fe}^{3+} / \Sigma \mathrm{Fe}$ values is 47 , of which 28 were synthesised at known $f \mathrm{O}_{2}$ and 20 coexist with olivine.

We have supplemented our new experimental data with a further 108 experimental glasses of broadly basaltic (or haplobasaltic) and basaltic andesite $\left(\leq 60 \mathrm{wt} \% \mathrm{SiO}_{2}\right)$ composition with measured $\mathrm{Fe}^{3+} / \Sigma \mathrm{Fe}$ performed at controlled (or measured) $f \mathrm{O}_{2}$. This dataset was selected to include experiments that contain olivine and/or experiments where the glass contains known amounts of dissolved $\mathrm{H}_{2} \mathrm{O}$. This provides, respectively, an additional set of data with which to explore olivine-melt partitioning and an additional set of $\mathrm{Fe}^{3+} / \Sigma \mathrm{Fe}$ data for hydrous systems. The studies used are: Mysen (2006), Matzen et al. (2011), Partzsch et al. (2004), Botcharnikov et al. (2005), Vetere et al. (2014), Wilke et al. (2002), Moore et al. (1995), and Schuessler et al. (2008). The number and type of measurements from these studies are provided in Supplementary Table 2.

\section{Calculated $\mathrm{Fe}^{3+} / \mathbf{\Sigma F e}$ in hydrous basaltic melts}

In Fig. 5, we compare the measured $\mathrm{Fe}^{3+} / \Sigma \mathrm{Fe}$ in our 28 glasses from experiments with known $f \mathrm{O}_{2}$, together with the additional 108 glasses described above, to the calculated $\mathrm{Fe}^{3+} / \Sigma \mathrm{Fe}$ at the experimental $\mathrm{P}-\mathrm{T}-f \mathrm{O}_{2}$ using three different algorithms: the widely used algorithm of Kress and Carmichael (1991), which includes a pressure term; and the recent algorithms of Borisov et al. (2018) and O'Neill et al. (2018) that do not. ${ }^{1}$ None of these algorithms includes an explicit $\mathrm{H}_{2} \mathrm{O}$ term, even though O'Neill et al. (2018) did use the hydrous data of Moore et al. (1995) in their calibration. The agreement for all three algorithms is encouraging (average absolute deviation, aad $=0.06-0.08$ in $\mathrm{Fe}^{3+} / \Sigma \mathrm{Fe}$ ), with Borisov et al. (2018) performing marginally better than the other two. The observed aad is in excellent agreement with that claimed by Borisov et al. (2018) for their much larger, anhydrous calibrant dataset $\left( \pm 0.05\right.$ at $\left.\mathrm{Fe}^{3+} / \Sigma \mathrm{Fe}=0.25\right)$. The good performance of both algorithms is despite the fact that the combined dataset in Fig. $5(n=136)$ includes a large number $(n=79)$ of hydrous glasses, whereas only that of O'Neill et al. (2018) included any hydrous glass in their calibrations. For our dataset, plots (not shown) of the deviation of $\mathrm{Fe}^{3+} / \Sigma \mathrm{Fe}$ from the values calculated using any of the three algorithms against wt $\% \mathrm{H}_{2} \mathrm{O}$ (or $a \mathrm{H}_{2} \mathrm{O}$, calculated at

\footnotetext{
${ }^{1}$ For a useful comparison of a variety of pre-2016 algorithms for the relationship between $\mathrm{Fe}^{3-} / \Sigma \mathrm{Fe}$ and $f \mathrm{O}_{2}$ see Putirka (2016).
} 

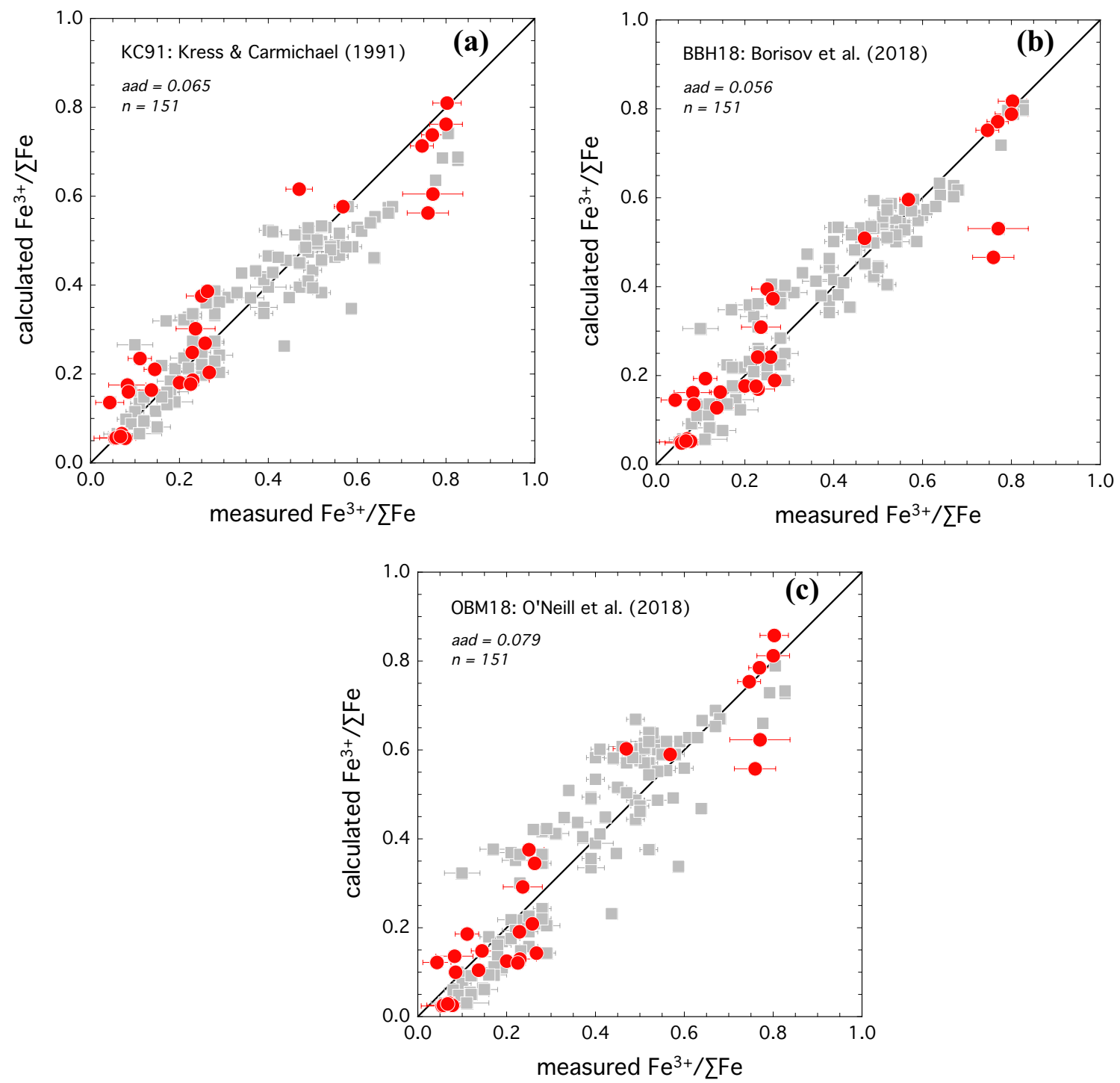

Fig. 5 Tests of the ability of three widely used algorithms to recover $\mathrm{Fe}^{3+} / \Sigma \mathrm{Fe}$ from experiments at know temperature and $f \mathrm{O}_{2}$. A Kress and Carmichael (1991); b Borisov et al. (2018); c O'Neill et al. (2018). Only Kress and Carmichael (1991) include a pressure term.

experimental conditions using the method of Burnham 1979) does not reveal any systematic behaviour. This finding is in agreement with previous studies that conclude that dissolved $\mathrm{H}_{2} \mathrm{O}$ has negligible influence on $\mathrm{Fe}^{3+} / \Sigma \mathrm{Fe}$ in silicate melts (e.g., Sisson and Grove 1993; Moore et al. 1995; Botcharnikov et al. 2005). If there is an influence on $\mathrm{Fe}^{3+} / \Sigma \mathrm{Fe}$ of $\mathrm{H}_{2} \mathrm{O}$ it is subtle and non-systematic, and requires further, targeted experimental exploration.

It is noteworthy that the two persistent outliers in all panels of Fig. 5 are both highly oxidised glasses from our dataset with $>8$ wt $\% \mathrm{H}_{2} \mathrm{O}$ (HAB-20, HAB-23). These are the wettest glasses yet analysed for $\mathrm{Fe}^{3+} / \Sigma \mathrm{Fe}$, so it is unclear whether their failure to lie on the 1:1 line reflects an effect
Plotted are new data from Table 3 (red symbols), alongside published data for hydrous basalts (grey symbols). A total of 151 glasses are plotted; the average absolute deviation ( $a a d$ ) from the analysed values is given in each panel

of very high $\mathrm{H}_{2} \mathrm{O}$ on $\mathrm{Fe}^{3+}-\mathrm{Fe}^{2+}$ equilibria or a consequence of analytical challenges in such unstable glasses even using SMS. We conclude that, except possibly for very $\mathrm{H}_{2} \mathrm{O}$-rich basaltic glasses, there is no appreciable interaction between $\mathrm{Fe}$ species and $\mathrm{H}_{2} \mathrm{O}$, such that the algorithms of Borisov et al. (2018), O'Neill et al. (2018) and Kress and Carmichael (1991) can be used with some confidence. For reference, in a typical basalt the average absolute deviation of \pm 0.05 in calculated $\mathrm{Fe}^{3+} / \Sigma \mathrm{Fe}$ equates to approximately $\pm 0.6 \log$ units of $f \mathrm{O}_{2}$ at $\mathrm{NNO}+1$ and $1250{ }^{\circ} \mathrm{C}$. This gives an indication of the accuracy available to recover $f \mathrm{O}_{2}$ from a hydrous mafic melt with known $\mathrm{Fe}^{3+} / \Sigma \mathrm{Fe}$ and equilibration temperature. In all subsequent calculations we will adopt, for convenience, 

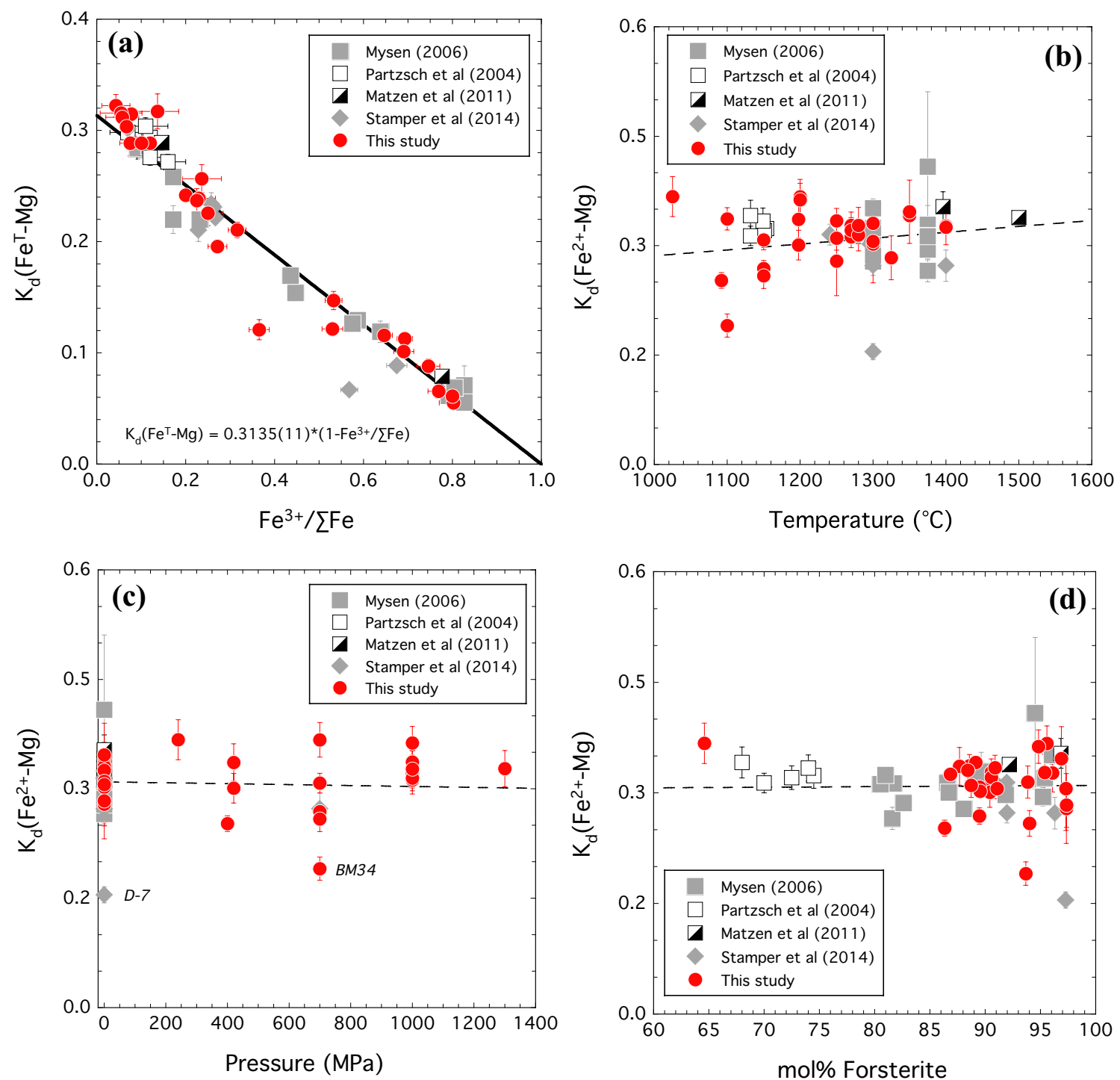

Fig. $6 \mathrm{Fe}-\mathrm{Mg}$ exchange between olivine and melt in new experiments and published studies given in Supplementary Table 2. a $\mathrm{Kd}_{\mathrm{Fe}^{T}-\mathrm{Mg}}$ versus measured $\mathrm{Fe}^{3+} / \Sigma \mathrm{Fe}$ showing the diluting effect of $\mathrm{Fe}^{3+}$. For clarity we distinguish the experiments of Stamper et al. (2014) that are included in Table 2. The line has a slope and inter-

cept of $0.3135 \pm 0.0011 . \mathrm{Kd}_{\mathrm{Fe}^{2+}-\mathrm{Mg}}$ versus b temperature; c pressure; and $\mathbf{d}$ olivine forsterite content (mol\%). The dashed lines are shown for guidance only. Note the two persistent outlier experiments (runs BM34 and D-7) in all panels; labelled in c

the Borisov et al. (2018) algorithm, although, according to Fig. 5, the results would be broadly similar for the other two algorithms, as well as that of Putirka (2016).

\section{Olivine-melt partitioning of $\mathrm{Fe}^{2+}, \mathrm{Mn}$ and $\mathrm{Mg}$}

Olivine-melt $\mathrm{Kd}_{\mathrm{Fe}^{T}-\mathrm{Mg}}$ shows a considerable range in our experimental dataset, as would be predicted from the presence of $\mathrm{Fe}^{3+}$ in the glass. As expected, $\mathrm{Kd}_{\mathrm{Fe}^{T}-\mathrm{Mg}}$ decreases with increasing $\mathrm{Fe}^{3+} / \Sigma \mathrm{Fe}$ as the availability of $\mathrm{Fe}^{2+}$ diminishes and, as a consequence, olivine becomes more Fo-rich (Fig. 6a). A weighted fit to Eq. (4) yields

$\mathrm{Kd}_{\mathrm{Fe}^{T}-\mathrm{Mg}}=0.3135 \pm 0.0011 \times\left(1-\frac{\mathrm{Fe}^{3+}}{\Sigma \mathrm{Fe}}\right)$.

This is consistent with a simple dilution of $\mathrm{Fe}^{2+}$ by $\mathrm{Fe}^{3+}$ in the melt, in the manner hinted at from the data of Roeder and Emslie (1970; Fig. 1). The linearity of the relationship across a very wide range of $\mathrm{Fe}^{3+} / \Sigma \mathrm{Fe}$ argues strongly against significant non-ideal interactions between $\mathrm{Fe}^{2+}$ and $\mathrm{Fe}^{3+}$ in the melt, of the type proposed by Jayasuriya et al. (2004). The intercept at $\mathrm{Fe}^{3+} / \Sigma \mathrm{Fe}$ equates to $\mathrm{Kd}_{\mathrm{Fe}^{2+}-\mathrm{Mg}}$ and is in excellent agreement with the canonical value of $0.30 \pm 0.03$ of Roeder and Emslie (1970). This observation 


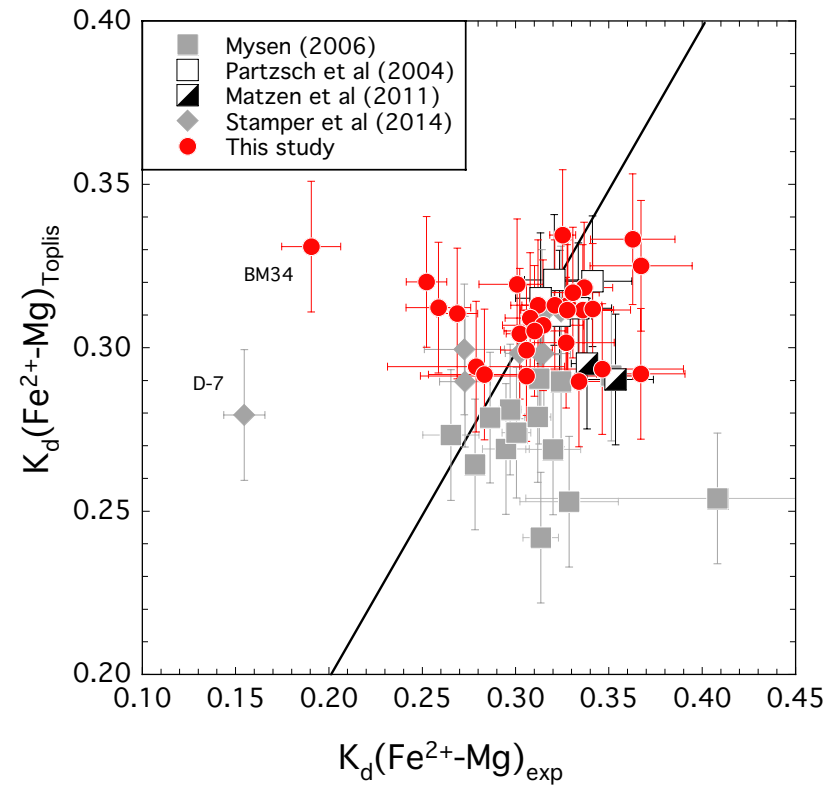

Fig. 7 Comparison of $\mathrm{Kd}_{\mathrm{Fe}^{2+}-\mathrm{Mg}}$ calculated using the algorithm of Toplis (2005) with the experimental data in Table 3. The 1:1 line is shown. The two persistent outliers in our dataset (runs BM34 and D-7) are highlighted. Error bars are 1 sd for the experimental measurements and \pm 0.02 for the Toplis (2005) method

confirms Roeder and Emslie's (1970) finding that $f \mathrm{O}_{2}$ has little effect on $\mathrm{Kd}_{\mathrm{Fe}^{2+}-\mathrm{Mg}}$. Consequently, the measured value of $\mathrm{Kd}_{\mathrm{Fe}^{T}-\mathrm{Mg}}$ can be used to recover $\mathrm{Fe}^{3+} / \Sigma \mathrm{Fe}$, provided that the potential role of olivine non-ideality can be disregarded or suitably accounted for. We return to this issue in a later section.

We explore the influence of other parameters on $\mathrm{Kd}_{\mathrm{Fe}^{2+}-\mathrm{Mg}}$ in Fig. 6b-d. There is no discernible influence of temperature (Fig. 6b) suggesting that over the studied temperature range the change in free energy of reaction (1), $\Delta G_{1}$, is relatively small. According to the standard state free energy of fusion data compiled by Toplis (2005) an increase in temperature from 1100 to $1500{ }^{\circ} \mathrm{C}$ would equate to an increase in $\Delta G_{1}$ of $2.9 \mathrm{~kJ} \mathrm{~mol}^{-1}$, corresponding to a $14 \%$ increase in $\mathrm{Kd}_{\mathrm{Fe}^{2+}-\mathrm{Mg}}$, broadly consistent with that observed. There is also no effect of dissolved $\mathrm{H}_{2} \mathrm{O}$ (as previously discussed) or pressure (Fig. 6c). Using the volume change for reaction (1), $\Delta \mathrm{V}_{1}$, as presented by Toplis (2005), we would expect very little change in $\mathrm{Kd}_{\mathrm{Fe}^{2+}-\mathrm{Mg}}$ over the pressure range studied. For example, at $1200{ }^{\circ} \mathrm{C}, \mathrm{Kd}_{\mathrm{Fe}^{2+}-\mathrm{Mg}}$ should increase by just $4 \%$ from one atmosphere to $1400 \mathrm{MPa}$, again broadly consistent with that observed.

Our observations raise the possibility that much of the pressure dependence claimed by Ulmer (1989) results simply from the effect of pressure on ferric-ferrous ratio in basaltic melts. For a given $f \mathrm{O}_{2}$, at higher pressures $\mathrm{Fe}^{2+}$ in the melt is stabilised relative to $\mathrm{Fe}^{3+}$ up to at least $3 \mathrm{GPa}$ (Kress and Carmichael, 1991). Thus, as pressure increases the availability of $\mathrm{Fe}^{2+}$ will increase, leading to an increase in $\mathrm{Kd}_{\mathrm{Fe}^{T}-\mathrm{Mg}}$. This is precisely the effect seen by Ulmer (1989); from 1 atmosphere to $3 \mathrm{GPa}$ his experiments show an increase in $\mathrm{Kd}_{\mathrm{Fe}^{T}-\mathrm{Mg}}$ from 0.30 to 0.37 . Assuming that $f \mathrm{O}_{2}$ in these experiments remains constant, relative to a solid state buffer such as $\mathrm{NNO}$, the $\mathrm{Fe}^{3+} / \Sigma \mathrm{Fe}$ ratio, calculated using Kress and Carmichael (1991) for Ulmer's (1989) starting material and a reference temperature of $1200{ }^{\circ} \mathrm{C}$, ranges from 0.191 at atmospheric pressure to 0.105 at $3 \mathrm{GPa}$. From the one atmosphere value of 0.30 , this equates to an increase in $\mathrm{Kd}_{\mathrm{Fe}^{T}-\mathrm{Mg}}$ to 0.33 , approximately $50 \%$ of the observed increase. However, Ulmer's (1989) higher pressure experiments used graphite-lined Pt capsules, and consequently are significantly more reduced than NNO, approximating the iron-wüstite buffer. Thus, the higher pressure melts will contain negligible $\mathrm{Fe}^{3+}$, leading to a further increase in $\mathrm{Kd}_{\mathrm{Fe}^{T}-\mathrm{Mg}}$ to 0.37 , relative to the 1 atmosphere value of 0.30 , as observed. We suggest that the apparent pressure increase in $\mathrm{Kd}_{\mathrm{Fe}^{T}-\mathrm{Mg}}$ observed by Ulmer (1989) is a combination of two effects: the decrease in $\mathrm{Fe}^{3+} / \Sigma \mathrm{Fe}$ that occurs with increasing pressure at fixed temperature along an $\mathrm{fO}_{2}$ buffer; and the more reduced nature of his higher pressure experiments compared to those at one atmosphere.

Finally, there is a small negative dependence of $\mathrm{Kd}_{\mathrm{Fe}^{2+}-\mathrm{Mg}}$ on olivine composition (Fig. 6d), consistent with modest non-ideality on the forsterite-fayalite join, as previously noted by Toplis (2005). For a symmetrical regular solution, characterised by a binary interaction parameter $W_{\mathrm{Fe}-\mathrm{Mg}}, \mathrm{Kd}_{\mathrm{Fe}^{2+}-\mathrm{Mg}}$ will decrease from $\mathrm{Fo}_{50}$ towards both the fayalite $\left(\mathrm{Fo}_{0}\right)$ and forsterite $\left(\mathrm{Fo}_{100}\right)$ end-members. With a value of $\mathrm{W}_{\mathrm{Fe}-\mathrm{Mg}}=2.6 \mathrm{~kJ} \mathrm{~mol}^{-1}$, as determined experimentally O'Neill et al. (2003), $\mathrm{Kd}_{\mathrm{Fe}^{2+}-\mathrm{Mg}}$ (at $1200{ }^{\circ} \mathrm{C}$ ) would be expected to decrease by $\sim 16 \%$ from $\mathrm{Fo}_{60}$ to $\mathrm{Fo}_{100}$. This is a small effect, but not inconsistent with the variation seen in Fig. 6d. In a subsequent section we incorporate olivine nonideality into our expression for $\mathrm{Kd}_{\mathrm{Fe}^{2+}-\mathrm{Mg}}$.

The fact that Eq. (5) holds across a wide range in pressure, temperature and melt composition (especially $\mathrm{H}_{2} \mathrm{O}$ ) contrasts with the strong melt compositional dependence of $\mathrm{Kd}_{\mathrm{Fe}^{2+}-\mathrm{Mg}}$ that was proposed by Toplis (2005) and Putirka (2016) based on large published experimental datasets. In Fig. 7, we compare our measured values of $\mathrm{Kd}_{\mathrm{Fe}^{2+}-\mathrm{Mg}}$ to those calculated using the method of Toplis (2005) at our experimental conditions. There is broad agreement (within about \pm 0.05 in $\mathrm{Kd}_{\mathrm{Fe}^{2+}-\mathrm{Mg}}$ ) despite the fact that Toplis (2005) does not include an explicit compositional term for $\mathrm{Fe}^{3+}$ in his parameterisation. Instead he used the parameterisation of Kilinc et al. (1983) to calculate $\mathrm{Fe}^{2+} / \mathrm{Fe}^{3+}$ at the run $\mathrm{T}-f \mathrm{O}_{2}$ conditions for his experimental dataset. Kilinc et al's (1983) parameterization was updated by Kress and Carmichael (1991) using additional experimental data, with significantly different temperature and composition parameters as a result. It is unclear to what extent 

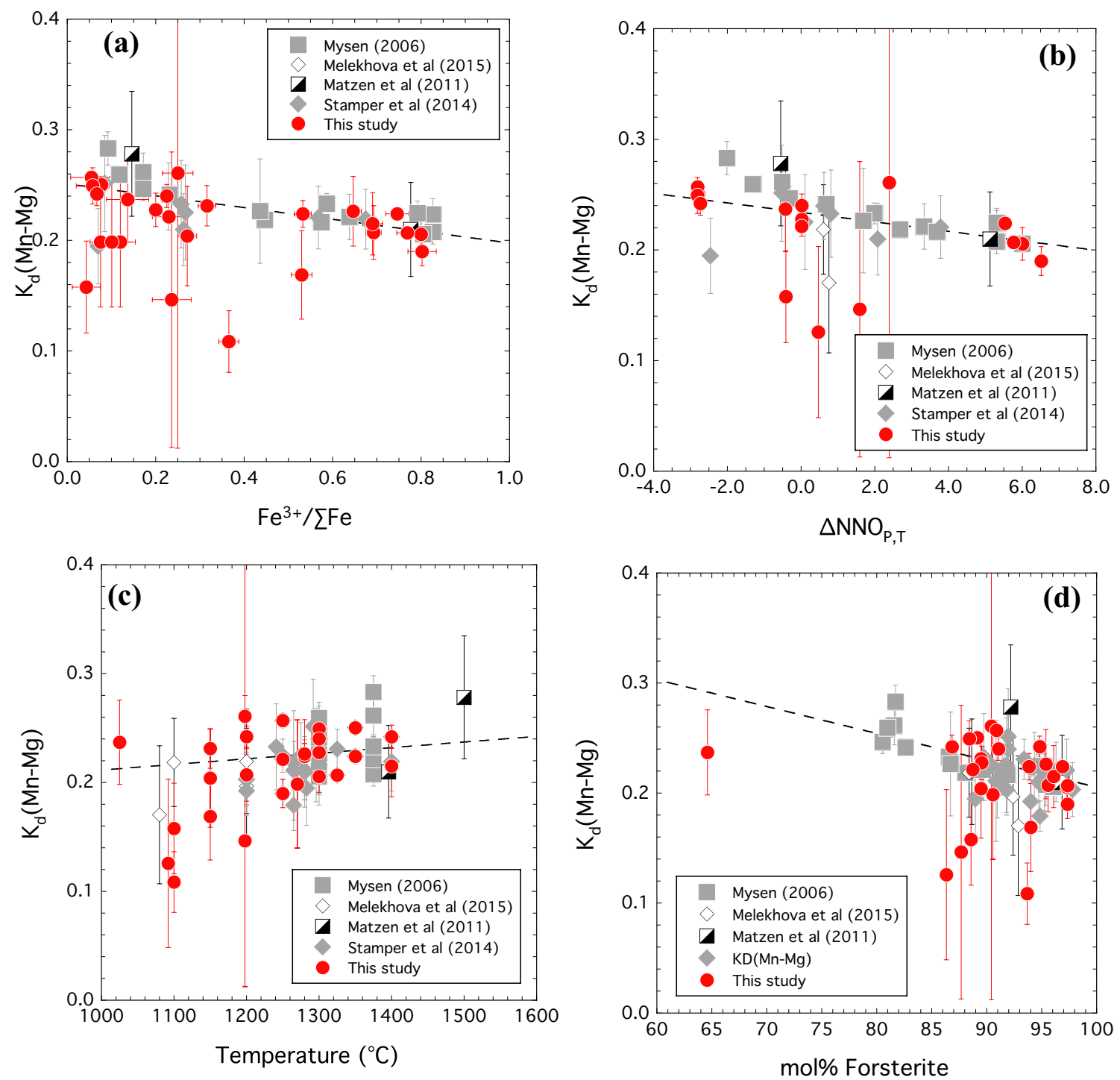

Fig. $8 \mathrm{Mn}-\mathrm{Mg}$ exchange between olivine and melt in new experiments and published studies given in the text-for clarity we distinguish the experiments of Stamper et al. (2014) and Melekhova et al.

some of the compositional dependence $\mathrm{Kd}_{\mathrm{Fe}^{2+}-\mathrm{Mg}}$ identified by Toplis (2005) is aliased to compositional dependence of $\mathrm{Fe}^{2+} /$ $\mathrm{Fe}^{3+}$ above and beyond that captured by the parameterisation of Kilinc et al. (1983). In this respect, it is notable that Toplis' (2005) compositional terms include a strong influence of molar $\mathrm{Na}_{2} \mathrm{O}$ and $\mathrm{K}_{2} \mathrm{O}$ in the melt, the two components known to exert the greatest influence on $\mathrm{Fe}^{2+} / \mathrm{Fe}^{3+}$ in melts at fixed $\mathrm{P}$, $\mathrm{T}$ and $\mathrm{fO}_{2}$ (Kress and Carmichael 1991; Borisov et al. 2018). It is very difficult to disentangle these two effects in the absence of measured $\mathrm{Fe}^{3+} / \Sigma \mathrm{Fe}$ in experimental glasses.

In contrast to $\mathrm{Fe}-\mathrm{Mg}$ exchange between olivine and melt, we would not expect $\mathrm{Mn}-\mathrm{Mg}$ exchange to be redox-sensitive under most terrestrial $f \mathrm{O}_{2}$ conditions. In Fig. 8, we plot $\mathrm{Kd}_{\mathrm{Mn}-\mathrm{Mg}}$ for our experimental dataset against a variety of
(2015). $\mathrm{Kd}_{\mathrm{Mn}-\mathrm{Mg}}$ versus: a measured $\mathrm{Fe}^{3+} / \Sigma \mathrm{Fe} ; \mathbf{b} f \mathrm{O}_{2}$ (expressed as $\log$ units relative to NNO buffer); $\mathbf{c}$ temperature; and $\mathbf{d}$ olivine forsterite content (mol\%). The dashed lines are shown for guidance only

intensive and compositional parameters. As expected, a strong variation with $\mathrm{Fe}^{3+} / \Sigma \mathrm{Fe}$ (Fig. 8a) is not observed, because $\mathrm{Mn}$ is divalent across almost all of the $\mathrm{fO}_{2}$ range considered (Stokes et al. 2019). Nonetheless, at the highest $\mathrm{Fe}^{3+} / \Sigma \mathrm{Fe}$, i.e., the most oxidised conditions, any Mn that is trivalent should lead to a small reduction in $\mathrm{Kd}_{\mathrm{Mn}-\mathrm{Mg}}$. In Fig. 8b, we show $\mathrm{Kd}_{\mathrm{Mn}-\mathrm{Mg}}$ plotted against $\triangle \mathrm{NNO}$ (the deviation in log units relative to the $\mathrm{NNO}$ buffer at $\mathrm{P}$ and $\mathrm{T})$. Any reduction in $\mathrm{Kd}_{\mathrm{Mn}-\mathrm{Mg}}$ at the highest $\triangle \mathrm{NNO}$ is evidently very small, consistent with the observation that $\mathrm{Mn}^{3+} / \Sigma \mathrm{Mn}$ in lime-alumina-silica melts is low, even in air (Tamura et al. 1987). Moreover, $\mathrm{Mn}^{3+} / \Sigma \mathrm{Mn}$ decreases significantly with decreasing molar $\mathrm{Na} / \mathrm{Si}$ ratios (Schreiber et al. 1994), such that for basalts $(\mathrm{Na} / \mathrm{Si} \approx 0.1)$ equilibrated in air at $\sim 1150{ }^{\circ} \mathrm{C} \mathrm{Mn}^{3+} / \Sigma \mathrm{Mn}$ will be less than 


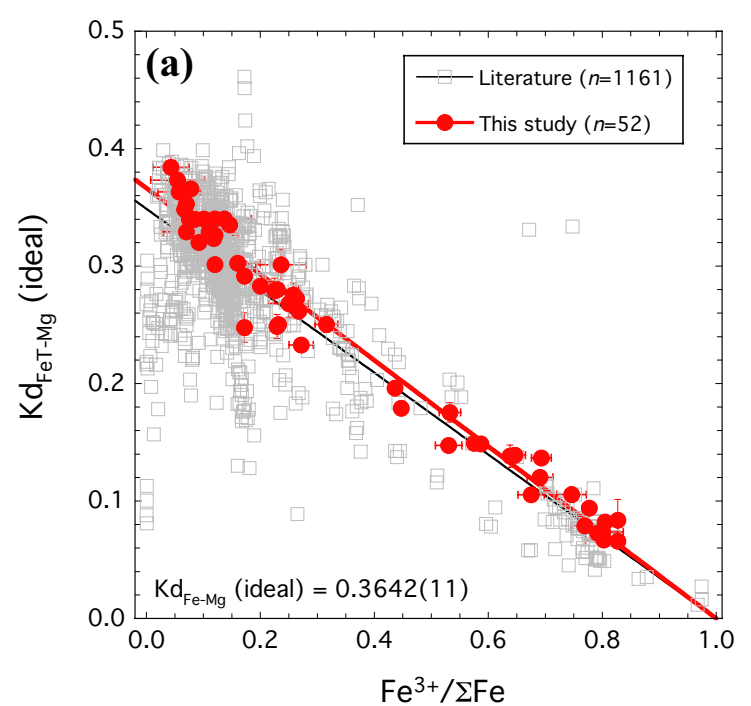

Fig. 9 Models for $\mathrm{Fe}-\mathrm{Mg}$ and $\mathrm{Mn}-\mathrm{Mg}$ exchange coefficients. a $\mathrm{Kd}_{\mathrm{Fe}^{T}-\mathrm{Mg}}$ (after correction for olivine non-ideality, as described in text) versus $\mathrm{Fe}^{3+} / \Sigma \mathrm{Fe}$. Data labelled 'this study' include experiments presented in Table 2 plus those additionally plotted in Fig. 6a for which $\mathrm{Fe}^{3+} / \Sigma \mathrm{Fe}$ is independently measured (see Supplementary Table 2). 'Literature data' are taken from the compilation of Matzen et al. (2011), whence original sources can be found, plus additional data from Laubier et al. (2014), Gaetani and Grove (1997), Mallman and O'Neill (2009, 2013), Canil (1997), and Canil and Fedortchouk

0.02. Thus the effect of redox on $\mathrm{Kd}_{\mathrm{Mn}-\mathrm{Mg}}$ is expected to be minimal under all conditions investigated experimentally and likely to be found in nature (e.g., Stokes et al. 2019).

$\mathrm{Kd}_{\mathrm{Mn}-\mathrm{Mg}}$ shows minor dependence on temperature (Fig. 8c) and olivine composition (Fig. 8d), as expected for trace element substitution. To a large extent these effects are interlinked in the experimental dataset and should be considered in combination. $\mathrm{Mn}^{2+}$ exchange for $\mathrm{Fe}^{2+}$ or $\mathrm{Mg}^{2+}$ in olivine is likely to be highly non-ideal, due to the large sixfold ionic radius differences (Shannon, 1976) between $\mathrm{Mn}^{2+}(0.83 \AA), \mathrm{Fe}^{2+}(0.78 \AA)$ and $\mathrm{Mg}^{2+}(0.72 \AA)$. The ease of inserting an $\mathrm{Mn}^{2+}$ ion into the olivine lattice increases with temperature at fixed olivine composition, and with decreasing forsterite content at fixed temperature. This behaviour is consistent with the lattice strain model of trace element partitioning (Blundy and Wood, 1994), as developed further below.

\section{Discussion}

The experimental data presented above show the strong dependence of $\mathrm{Fe}-\mathrm{Mg}$ exchange on $f \mathrm{O}_{2}$, but the relative insensitivity of $\mathrm{Mn}-\mathrm{Mg}$ exchange to the same parameter. This raises the possibility of using $\mathrm{Fe}-\mathrm{Mg}$ partitioning systematics to determine $f \mathrm{O}_{2}$ from equilibrium pairs of olivine and silicate melt, for example in high-pressure experiments

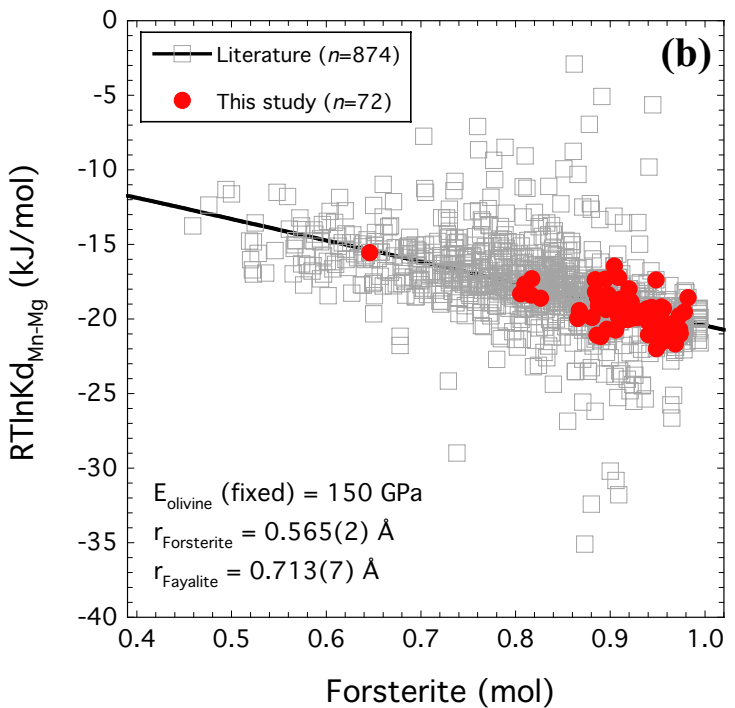

(2001). Glass $\mathrm{Fe}^{3+} / \Sigma \mathrm{Fe}$ was not measured in these experiments; the plotted value is calculated using Borisov et al. (2018) at the experimental $T-f \mathrm{O}_{2}$ and, therefore, subject to greater uncertainty than the measured values. The line (red) fitted to the data from this study data has a slope and intercept of $\mathrm{Kd}_{\mathrm{Fe}^{2+}-\mathrm{Mg}}^{0}=0.3642 \pm 0.0011$. The line (black) through the entire literature dataset has a very similar slope of $0.349 \pm 0.002$. b $R T \operatorname{lnKd} \mathrm{dn}_{\mathrm{Mg}}$ (in $\mathrm{kJ} \mathrm{mol}^{-1}$ ) plotted against molar fraction Fo in olivine. Data sources as in a. The black line is a fit to the lattice strain Eq. (10) with the fit parameters given

where $f \mathrm{O}_{2}$ is hard to control/monitor, and using the redoxinsensitive $\mathrm{Mn}-\mathrm{Mg}$ exchange as a means to test for olivinemelt equilibrium. Ultimately our goal is to introduce a simple method to correct olivine-hosted melt inclusion compositions for post-entrapment crystallization (using $\mathrm{Mn}-\mathrm{Mg}$ ) and then recover the magmatic $f \mathrm{O}_{2}$ (using $\mathrm{Fe}-\mathrm{Mg}$ ). We are helped in this enterprise by the fact that existing models for ferric-ferrous equilibria in silicate melts as a function of redox (e.g., Kress and Carmichael 1991; Borisov et al. 2018; O'Neill et al. 2018), have proven surprisingly accurate, even for hydrous basaltic compositions (Fig. 5). The first step is to develop models for $\mathrm{Fe}-\mathrm{Mg}$ and $\mathrm{Mn}-\mathrm{Mg}$ exchange between olivine and melt, and then to test these expressions against large datasets of experimental olivine-melt pairs.

\section{A model for Fe-Mg partitioning in basaltic melts}

Ignoring, for the moment, non-ideality in the melt, $\mathrm{Fe}^{2+}-\mathrm{Mg}$ exchange can be described by the following relationship (cf. Toplis 2005):

$\mathrm{Kd}_{\mathrm{Fe}^{2+}-\mathrm{Mg}}=\exp \left\{\frac{-\Delta H_{1}+T \Delta S_{1}-P \Delta V_{1}+W_{\mathrm{FeMg}}^{\text {olivine }}\left(1-2 X_{\mathrm{Fo}}\right)}{R T}\right\}$, 
where the terms $\Delta \mathrm{H}_{1}, \Delta S_{1}$ and $\Delta V_{1}$ denote, respectively, the enthalpy, entropy and volume changes of reaction (1), and $W_{\mathrm{FeMg}}^{\text {olivine }}$ is a symmetrical regular solution interaction parameter for the forsterite-fayalite binary solid solution. $W_{\mathrm{FeMg}}^{\text {olivine }}$ has been constrained experimentally to be in the region of a few $\mathrm{kJ} \mathrm{mol}^{-1}$; we will adopt the value of $2.6 \mathrm{~kJ} \mathrm{~mol}^{-1}$ of O'Neill et al. (2003). As noted above, our experimental data provide some constraints on $\Delta H_{1}, \Delta S_{1}$ and $\Delta V_{1}$ over the $\mathrm{P}-\mathrm{T}-\mathrm{X}$ studied. Given the limited temperature dependence (Fig. 6b) $\Delta H_{1}$ is expected to lie close to zero. We did explore the use of $\Delta H_{1}=+6.766 \mathrm{~kJ} \mathrm{~mol}^{-1}$ derived from the free energy of fusion of forsterite and fayalite (Toplis 2005), ${ }^{2}$ but it led to no improvement in our modelled fits, suggesting that the effective $\Delta \mathrm{H}_{1}$ is smaller than this value, probably due to fortuitous cancelation by non-ideal interactions of $\mathrm{Fe}^{2+}$ and $\mathrm{Mg}$ in the melt. Beattie (1993), for example, obtains a value for $\Delta \mathrm{H}_{1}$ of $+3.2 \pm 0.8 \mathrm{~kJ} \mathrm{~mol}^{-1}$ using experimental olivinemelt pairs. The limited pressure dependence (Fig. 6c) suggests that $\Delta V_{1}$ is also small; Toplis (2005) proposes a value of $-0.35 \mathrm{~kJ} \mathrm{GPa}^{-1} \mathrm{~mol}^{-1}$, while Beattie (1993) obtains a value of $-0.09 \pm 0.11 \mathrm{~kJ} \mathrm{GPa}^{-1} \mathrm{~mol}^{-1}$ from experimental olivine-melt data. The remaining term, $\Delta S_{1}$, embraces the entropy of mixing of $\mathrm{Fe}^{2+}$ and $\mathrm{Mg}$ in both olivine and melt. The quantity $\exp \left(\Delta S_{1} / R\right)$ in Eq. (6) equates to the 'ideal' value of $\mathrm{Kd}_{\mathrm{Fe}^{2+}-\mathrm{Mg}}$ (termed $\mathrm{Kd}_{\mathrm{Fe}^{2+} \mathrm{Mg}}^{0}$ ) prior to any correction for olivine non-ideality. The value of $\exp \left(\Delta \mathrm{S}_{1} / R\right)$ using the derived thermodynamic data of Beattie (1993) is 0.121; the equivalent value from Toplis (2005) is 0.414 . We can use our experimental data to derive a value for $\mathrm{Kd}_{\mathrm{Fe}^{2+}-\mathrm{Mg}}^{0}$ by modifying Eq. (6) to

$\mathrm{Kd}_{\mathrm{Fe}^{2+}-\mathrm{Mg}}=\mathrm{Kd}_{\mathrm{Fe}^{2+}-\mathrm{Mg}}^{0} \times \exp \left(\frac{\Delta W_{\mathrm{Fe}^{2+} \mathrm{Mg}}^{\text {olivine }}\left(1-2 X_{\mathrm{Fo}}\right)}{R T}\right)$,

where $\mathrm{Kd}_{\mathrm{Fe}^{2+}-\mathrm{Mg}}^{0}$ can then be obtained from a weighted regression of $\mathrm{Kd}_{\mathrm{Fe}^{T}-\mathrm{Mg}} / \exp \left(\frac{\Delta W_{\mathrm{Fe}^{2}+\mathrm{Mg}}^{\text {olive }}\left(1-2 X_{\mathrm{Fo}}\right)}{R T}\right)$ against $\mathrm{Fe}^{3+} / \Sigma \mathrm{Fe}$. For the 52 experiments with known $\mathrm{Fe}^{3+} / \Sigma \mathrm{Fe}$ the regressed value of $\mathrm{Kd}_{\mathrm{Fe}}^{0}-\mathrm{Mg}$ is $0.3642 \pm 0.0011$ at $\mathrm{Fe}^{3+} / \Sigma \mathrm{Fe}=0$ (Fig. 9a). To obtain this value we eliminated two persistent outliers in the dataset: experiments D-7 of Stamper et al (2014) and BM34 of Melekhova et al (2015). Note that for a symmetrical, regular solution $\mathrm{Kd}_{\mathrm{Fe}^{2+}-\mathrm{Mg}}^{0}=0.3642$ gives the $\mathrm{Fe}^{2+}-\mathrm{Mg}$ exchange coefficient at $\mathrm{Fo}_{50}$; it will be lower for olivines with higher or lower $\mathrm{Fo}$ than 0.5. This accounts for the difference from the value of $\mathrm{Kd}_{\mathrm{Fe}^{2+}-\mathrm{Mg}}=0.3135$ (Fig. 6a) presented above, which takes no account of olivine non-ideality. For example, for a $\mathrm{Fo}_{70}$

\footnotetext{
${ }^{2}$ Note the change in sign because Toplis (2005) provides data for the reverse of reaction (1).
}

olivine at $1200{ }^{\circ} \mathrm{C}$, the bracketed term in Eq. (7) equals 0.92; for $\mathrm{Fo}_{90}$ at $1450{ }^{\circ} \mathrm{C}$ it equals 0.86 . It is worth noting that the strong dependence of the olivine-melt $\mathrm{Mg}$ partition coefficient $\left(D_{\mathrm{Mg}}\right)$ on olivine Fo content will lead to an apparent negative correlation between $\mathrm{Kd}_{\mathrm{Fe}-\mathrm{Mg}}$ and $D_{\mathrm{Mg}}$, such as that observed by Herzberg and O'Hara (2002). Evidently, any such correlation should be carefully evaluated in the light of olivine non-ideality, as discussed above in the context of Fig. 6c.

An assumption in using Eq. (7) to describe $\mathrm{Fe}^{2+}-\mathrm{Mg}$ exchange between olivine and melt is that melt composition does not play a role, i.e., a single value of $\mathrm{Kd}_{\mathrm{Fe}^{2+}-\mathrm{Mg}}^{0}$ captures the full variation in the data provided that $\mathrm{Fe}^{3+} / \Sigma \mathrm{Fe}$ is known (measured) and can be treated as an independent variable. Toplis (2005) and Putirka (2016) have argued, on the basis of an experimental dataset for which $\mathrm{Fe}^{3+} / \Sigma \mathrm{Fe}$ was not measured, that additional compositional terms are important. Unfortunately, the experimental, olivine-bearing dataset with measured glass $\mathrm{Fe}^{3+} / \Sigma \mathrm{Fe}$ is too small $(n=55)$ to explore fully such additional melt compositional effects. Thus, as noted by Matzen et al. (2011) in their Appendix, some of the compositional dependence in the $\mathrm{Kd}_{\mathrm{Fe}} e^{2+}-\mathrm{Mg}$ expressions of Toplis (2005) may arise through any compositional dependence of melt $\mathrm{Fe}^{3+} / \Sigma \mathrm{Fe}$ not fully captured by the algorithm of Kilinc et al. (1983). To illustrate this point, we show also in Fig. 9a a database of over 1000 experimental olivine-melt $\mathrm{Kd}_{\mathrm{Fe}^{T}-\mathrm{Mg}}$, for which $f \mathrm{O}_{2}$ is known but $\mathrm{Fe}^{3+} / \Sigma \mathrm{Fe}$ is not. The data are fitted to an adapted version of Eq. (5) that allows for olivine non-ideality, using the expression in Eq. (7), to give

$\mathrm{Kd}_{\mathrm{Fe}^{T}-\mathrm{Mg}}=0.3642 \times\left(1-\frac{\mathrm{Fe}^{3+}}{\Sigma \mathrm{Fe}}\right) \times \exp \left(\frac{312.7\left(1-2 X_{\mathrm{Fo}}\right)}{T}\right)$,

where $T$ is in Kelvin and $X_{\mathrm{Fo}}$ is the molar fraction forsterite in olivine. In fitting this equation, we calculated $\mathrm{Fe}^{3+} / \Sigma \mathrm{Fe}$ at the experimental $\mathrm{T}-f \mathrm{O}_{2}$ conditions using the expression of Borisov et al (2018). The bulk of the data lie close to the regression line; $57 \%$ of all of the calculated $\mathrm{Kd}_{\mathrm{Fe}^{T}-\mathrm{Mg}}$ values lie within 0.02 of the experimental values, and the average absolute deviation (aad) of all 1135 experiments is 0.030 . If we consider only the natural compositions, i.e., those with non-zero alkalis, aad reduces to 0.022 . The $a a d$ is also dependent on the total alkali contents $\left(\mathrm{Na}_{2} \mathrm{O}+\mathrm{K}_{2} \mathrm{O}\right)$. For example, melts with $\mathrm{Na}_{2} \mathrm{O}+\mathrm{K}_{2} \mathrm{O} \geq 6 \mathrm{wt} \%$ have $a a d=0.040$, while those with $\mathrm{Na}_{2} \mathrm{O}+\mathrm{K}_{2} \mathrm{O} \geq 9$ wt $\%$ have $a a d=0.063$. This behaviour cannot be attributed to olivine non-ideality; it must instead be the result of either non-ideality in the melt [the interpretation preferred by Toplis (2005), and Putirka (2016)] or a failure of the Borisov et al (2018) algorithm to capture fully the effect of alkalis on $\mathrm{Fe}^{3+} / \Sigma \mathrm{Fe}$. In all likelihood the deviation is a combination of these two factors, but without determinations of $\mathrm{Fe}^{3+} / \Sigma \mathrm{Fe}$ in these 
alkali-rich experiments it is not possible to disentangle the two effects. We conclude that Eq. (8) is best suited to basalts with between 0 and 8 wt $\% \mathrm{Na}_{2} \mathrm{O}+\mathrm{K}_{2} \mathrm{O}(a a d=0.019)$; at higher alkali contents its precision is reduced slightly. As noted by Toplis (2005), the analytical precision of $\mathrm{Kd}_{\mathrm{Fe}^{T}-\mathrm{Mg}}$. determinations in most experiments is of the order 0.02 .

The observed scatter in the data at low $\mathrm{Fe}^{3+} / \Sigma \mathrm{Fe}$ (Fig. 9a) is curious. It cannot arise through olivine nonideality or temperature. It may arise instead from the failure of the Borisov et al (2018) algorithm to capture precisely $\mathrm{Fe}^{3+} / \Sigma \mathrm{Fe}$ at low $f \mathrm{O}_{2}$, as suggested by Fig. 5 b. Such a situation likely has its origins in the difficul of determining $\mathrm{Fe}^{3+} / \Sigma \mathrm{Fe}$ precisely by spectroscopic or wet chemical means when the $\mathrm{Fe}^{3+}$ content is very low (O'Neill et al. 2018). This problem warrants further investigation, with additional data on $\mathrm{Fe}^{3+} / \Sigma \mathrm{Fe}$ at very reducing conditions. For the time being we consider that Eq. (8) provides an adequate description of $\mathrm{Kd}_{\mathrm{Fe}^{T}-\mathrm{Mg}}$ for basaltic magmas under most terrestrial redox conditions.

The advantage that Eq. (8) offers over that of Toplis (2005) is that it contains no empirical fit parameters to describe the effect of melt non-ideality on $\mathrm{Kd}_{\mathrm{Fe}^{T}-\mathrm{Mg}}$. Any advocate caution in applying Eq. (8) at pressures higher than this. Likewise, as noted above, we do not see an apparent increase of $\mathrm{Kd}_{\mathrm{Fe}^{T}-\mathrm{Mg}}$ with melt $\mathrm{SiO}_{2}$ content, in contrast to Toplis (2005) and Putirka (2016). This again likely reflects the limited compositional range of experimental glasses from our olivine-bearing experiments (45.9-56.9 wt\% $\mathrm{SiO}_{2}$ on an anhydrous basis; Table 4) and those in the other data listed in Supplementary Table 2. For this reason we would not recommend using Eq. (8) for olivine-bearing andesitic liquids with more than $\sim 60 \mathrm{wt} \% \mathrm{SiO}_{2}$.

\section{A model for Mn-Mg partitioning in basaltic melts}

Unlike $\mathrm{Fe}^{2+}, \mathrm{Mn}$ is a minor (or trace) element in most natural olivines, allowing for a different thermodynamic treatment. Based on the observations in Fig. 8, we will deploy the lattice strain model for trace element partitioning (Blundy and Wood 1994), as recast for the case of a 'proxy' element (Eq. 8 of Blundy and Wood 2003). In this formulation, which is well suited to describing exchange coefficients $(K d \mathrm{~s})$ between trace and major elements, the proxy is $\mathrm{Mg}$ and the trace is $\mathrm{Mn}$. This yields

$\mathrm{Kd}_{\mathrm{Mn}-\mathrm{Mg}}=\exp \left[\frac{-4 \pi N_{\mathrm{A}} E_{\mathrm{M}}^{2+}}{R T}\left\{\frac{r_{0(\mathrm{M})}^{2+}}{2}\left(r_{\mathrm{Mg}}^{2}-r_{\mathrm{Mn}}^{2}\right)-\frac{1}{3}\left(r_{\mathrm{Mg}}^{3}-r_{\mathrm{Mn}}^{3}\right)\right\}\right]$,

melt compositional dependencies arise exclusively from those in the algorithm used for $\mathrm{Fe}^{3+} / \Sigma \mathrm{Fe}$, in this case Borisov et al (2018); the term for olivine compositional dependence is independently derived. Equation (8) offers a straightforward means to determine the composition of olivine crystallising from a melt at known temperature and $f \mathrm{O}_{2}$. Conversely, from a measured value of $\mathrm{Kd}_{\mathrm{Fe}^{T}-\mathrm{Mg}}$ at known temperature and olivine composition $\left(X_{\mathrm{Fo}}\right), \mathrm{Fe}^{3+} / \Sigma \mathrm{Fe}$ (and $f \mathrm{O}_{2}$ ) can be recovered by rearrangement of Eq. (8) and use of an algorithm such as that of Borisov et al (2018) or Putirka (2016).

Our data do not suggest a pressure dependence of $\mathrm{Kd}_{\mathrm{Fe}^{T}-\mathrm{Mg}}$ in contrast to several previous studies (e.g., Ulmer 1989; Herzberg and O'Hara 1998; Putirka 2005, 2016; Toplis 2005). We speculate above that changing $\mathrm{Fe}^{3+} / \Sigma \mathrm{Fe}$ in the melt with increasing pressure may account for some apparent pressure dependence. Unfortunately there are no high pressure experimental data with measured $\mathrm{Fe}^{3+} / \Sigma \mathrm{Fe}$ at known $f \mathrm{O}_{2}$ with which to test this idea, and our experimental dataset does not extend above $1.7 \mathrm{GPa}$. For this reason we would where $N_{\mathrm{A}}$ is Avogadro's number, $R$ is the gas constant, $T$ is temperature in Kelvin, $E_{\mathrm{M}}^{2+}$ is the effective Young's Modulus of the VI-fold M-site in olivine, and $r_{0(\mathrm{M})}^{2+}$ is the optimum radius of that site. $r_{\mathrm{Mg}}$ and $r_{\mathrm{Mn}}$ are the ionic radii of $\mathrm{Mg}^{2+}$ and $\mathrm{Mn}^{2+}$ in VI-fold coordination, 0.72 and $0.83 \AA$, respectively (Shannon 1976). The ideal M-site cation radius changes along the forsterite-fayalite solid solution, because $\mathrm{Fe}^{2+}(0.78 \AA)$ is larger than $\mathrm{Mg}^{2+}(0.72 \AA)$. Thus $r_{0(\mathrm{M})}^{2+}$ is not constant. In principle we can use the experimental data, from this study and from the literature, to derive values for $E_{\mathrm{M}}^{2+}$ and for $r_{0(\mathrm{M})}^{2+}$ as a function of olivine composition. However, as noted by Wood and Blundy (1997), there is considerable trade-off between these two parameters from least squares fitting. For that reason, we fix $E_{\mathrm{M}}^{2+}=150 \mathrm{GPa}$, following Beattie (1994) and Purton et al. (2000), and fit only for $r_{0(\mathrm{M})}^{2+}$. We do this by assuming that $r_{0(\mathrm{M})}^{2+}$ increases linearly from forsterite $\left(r_{0(\mathrm{Fo})}^{2+}\right)$ to fayalite $\left(r_{0(\mathrm{Fa})}^{2+}\right)$. Thus, Eq. (9) can be rewritten and linearised in such a way that a plot of

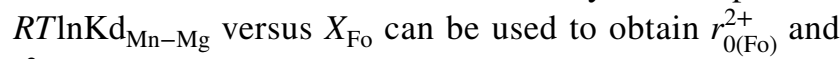
$r_{0(\mathrm{Fa})}^{2+}$ :

$R T \ln \mathrm{Kd}_{\mathrm{Mn}-\mathrm{Mg}}=-150 \times 4 \pi N_{\mathrm{A}}\left\{\left(\frac{X_{\mathrm{Fo}} r_{0(\mathrm{Fo})}^{2+}+\left(1-X_{\mathrm{Fo}}\right) r_{0(\mathrm{Fa})}^{2+}}{2}\right)\left(r_{\mathrm{Mg}}^{2}-r_{\mathrm{Mn}}^{2}\right)-\frac{1}{3}\left(r_{\mathrm{Mg}}^{3}-r_{\mathrm{Mn}}^{3}\right)\right\}$. 


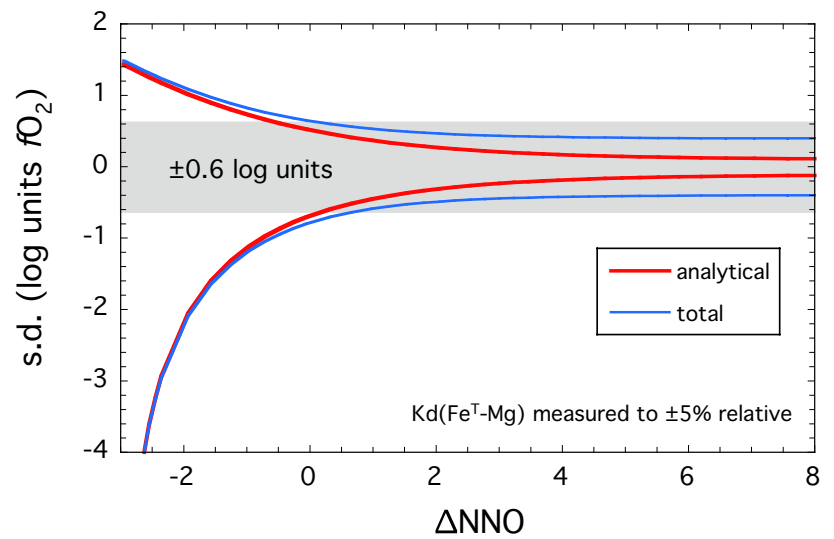

Fig. 10 Fully propagated uncertainty estimates for $\triangle \mathrm{NNO}$ calculations using $\mathrm{Kd}_{\mathrm{Fe}^{T}-\mathrm{Mg}}$. Calculated values are strongly dependent on $\Delta \mathrm{NNO}$, and greatly magnified at low $f \mathrm{O}_{2}$. Shown are curves for the typical, propagated analytical uncertainty (red), assuming $5 \%$ relative error in $\mathrm{Kd}_{\mathrm{Fe}}{ }^{T}-\mathrm{Mg}$, and the total uncertainty (blue) that includes 0.38 $\log$ units in $f \mathrm{O}_{2}$ as given by Borisov et al. (2018) for their $\mathrm{Fe}^{3+} / \Sigma \mathrm{Fe}$ algorithm. The shaded region illustrates an uncertainty of $\pm 0.6 \log$ units in $f \mathrm{O}_{2}$

Using the literature experimental dataset described above, as well as the new data presented here, we find that this equation describes well the $\mathrm{Mn}-\mathrm{Mg}$ exchange coefficient for the entire experimental dataset (Fig. 9b), returning values of $r_{0(\mathrm{Fo})}^{2+}=0.565 \pm 0.002 \AA$ and $r_{0(\mathrm{Fa})}^{2+}=0.713 \pm 0.007 \AA$. A more complex expression, that takes into account the possible temperature dependence of $r_{0(\mathrm{Fo})}^{2+}$ and $r_{0(\mathrm{Fa})}^{2+}$ is not warranted. There is no evidence for strong melt compositional depend-

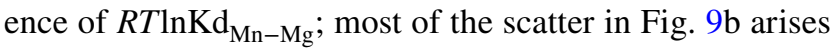
through analytical uncertainty on the $\mathrm{MnO}$ contents of experimental olivines, which are more difficult to measure precisely than major elements (for instance $\mathrm{MnO}$ is usually reported to two significant figures compared to four for $\mathrm{MgO}$ ). For example, a typical uncertainty on $\mathrm{Kd}_{\mathrm{Mn}-\mathrm{Mg}}$ of $15 \%$ relative, translates to an uncertainty of $\pm 2 \mathrm{~kJ} \mathrm{~mol}^{-1}$ in $R T \operatorname{lnKd} \mathrm{dn}_{\mathrm{Mn}-\mathrm{Mg}}$, which encompasses over $80 \%$ of the observed scatter in Fig. 9b. Note that this approach takes into account both the temperature and olivine composition dependence of $\mathrm{Kd}_{\mathrm{Mn}-\mathrm{Mg}}$, in contrast to the expression of Matzen et al (2017) that considers only the effect of melt $\mathrm{MgO}$ content. For olivine-saturated systems, the latter is, of course, a function of both temperature and olivine composition.

Regarding the influence of melt composition on $\mathrm{Mn}-\mathrm{Mg}$ partitioning, there is no evidence for such an effect in our basaltic experimental dataset. In contrast, Kohn and Schofield (1994) in their study of Mn partitioning between olivine $\left(\mathrm{Fo}_{100}\right)$ and melt in the system forsterite-albite-anorthite show that $R T \operatorname{lnKd} d_{\mathrm{Mn}-\mathrm{Mg}}$ varies with the degree of melt polymerisation, increasing from $\sim 0.12$ to 0.23 over a wide range in NBO/T (0.09-0.37). However, the overall variation in $R T \ln \mathrm{Kd}_{\mathrm{Mn}-\mathrm{Mg}}$ for their experiments is -20.6 to

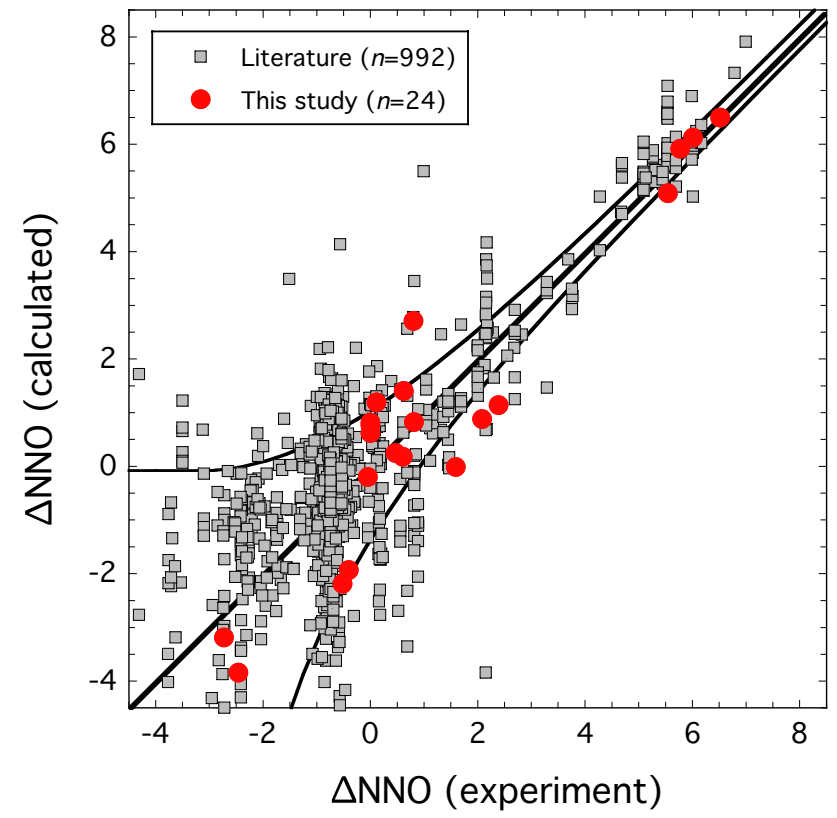

Fig. 11 Calculated $\triangle \mathrm{NNO}$ for olivine-melt pairs from Table 2 and in the dataset of published experiments introduced in Fig. 8a. Only experiments run at $f \mathrm{O}_{2}$ above $\mathrm{NNO}-4.5$ are plotted. The 1:1 line and error envelopes from Fig. 10 are shown as black lines

$-22.9 \mathrm{~kJ} \mathrm{~mol}^{-1}$, compared to the value of $-20.4 \mathrm{~kJ} \mathrm{~mol}^{-1}$ calculated for $\mathrm{Fo}_{100}$ olivine using Eq. (10). The mean deviation of Kohn and Schofield's (1994) data from this value is only $\pm 1.3 \mathrm{~kJ} \mathrm{~mol}^{-1}$, despite the wide range in NBO/T. This gives a sense of the relatively small influence of melt composition on $R T \operatorname{lnKd} \mathrm{d}_{\mathrm{Mn}-\mathrm{Mg}}$ compared to olivine composition, which changes by $4.3 \mathrm{~kJ} \mathrm{~mol}^{-1}$ from $\mathrm{Fo}_{100}$ to $\mathrm{Fo}_{70}$ (Fig. 9b).

\section{Applications}

Equation (8) obviously has wide utility in modelling the crystallisation and melting of olivine-bearing systems. By way of example, we focus on two novel oxybarometry applications using the derived expressions for $\mathrm{Kd}_{\mathrm{Fe}^{T}-\mathrm{Mg}}$ and $\mathrm{Kd}_{\mathrm{Mn}-\mathrm{Mg}}$. The first involves determination of $f \mathrm{O}_{2}$ for experimental, olivine-bearing melts using $\mathrm{Kd}_{\mathrm{Fe}^{T}-\mathrm{Mg}}$; the second involves determination of $\mathrm{Fe}^{3+} / \Sigma \mathrm{Fe}$ in olivinehosted melt inclusions that have first been corrected for post-entrapment modification (crystallisation or dissolution) by the host olivine using $\mathrm{Kd}_{\mathrm{Mn}-\mathrm{Mg}}$.

\section{Oxygen fugacity estimates from olivine-bearing experiments}

Equation (8) can be rearranged to obtain $\mathrm{Fe}^{3+} / \Sigma \mathrm{Fe}$ of an experimental glass in equilibrium with olivine of a known 
Table 6 Calculated $f \mathrm{O}_{2}$ for Lesser Antilles experiments using olivine Fe-Mg exchange oxybarometry

\begin{tabular}{|c|c|c|c|c|c|c|c|c|c|}
\hline \multirow[t]{2}{*}{ Source } & \multirow[t]{2}{*}{ Run } & \multirow[t]{2}{*}{$T^{\circ} \mathrm{C}$} & \multirow[t]{2}{*}{ P, GPa } & \multirow[t]{2}{*}{$\mathrm{H}_{2} \mathrm{O}^{\mathrm{c}}$} & \multicolumn{5}{|l|}{$\triangle \mathrm{NNO}$} \\
\hline & & & & & $\mu \mathrm{XANES}^{\mathrm{a}}$ & $\mathrm{Ol}-\mathrm{Sp}^{\mathrm{a}}$ & $\mathrm{AuPd}^{\mathrm{a}}$ & $\mathrm{KC} 91^{\mathrm{b}}$ & $\mathrm{BBH} 18^{\mathrm{b}}$ \\
\hline Stamper et al. (2014) & W-1 & 1150 & 0.7 & $4.99(21)$ & 3.6 & 2.0 & -0.3 & 1.7 & 1.5 \\
\hline Stamper et al. (2014) & $\mathrm{W}-3$ & 1200 & 0.7 & $3.62(18)$ & 5.2 & & & 4.7 & 4.1 \\
\hline Stamper et al. (2014) & W-7-J & 1175 & 0.7 & $5.48(25)$ & 5.5 & & & 5.3 & 4.9 \\
\hline Stamper et al. (2014) & AN-1 & 1400 & 0.7 & $0.28(4)$ & 5.3 & 4.3 & 3.7 & 5.7 & 4.8 \\
\hline Stamper et al. (2014) & $\mathrm{AN}-3$ & 1400 & 1.0 & $0.38(6)$ & 5.5 & & & 5.5 & 4.4 \\
\hline Stamper et al. (2014) & $\mathrm{R}-5$ & 1280 & 1.0 & $2.56(22)$ & 4.9 & & & 4.0 & 3.1 \\
\hline Stamper et al. (2014) & 30 & 1280 & 1.3 & $3.73(14)$ & 6.1 & 3.8 & 1.2 & 5.2 & 4.0 \\
\hline Stamper et al. (2014) & 35 & 1200 & 0.2 & $2.93(12)$ & 6.6 & 5.3 & 3.2 & 6.4 & 6.2 \\
\hline Stamper et al. (2014) & 41 & 1200 & 0.7 & $3.70(14)$ & 5.4 & & & 4.2 & 3.8 \\
\hline Stamper et al. (2014) & 23 & 1275 & 0.7 & $3.15(15)$ & 4.2 & & & 3.9 & 3.3 \\
\hline Stamper et al. (2014) & 25 & 1280 & 0.7 & $3.42(18)$ & 4.7 & 3.8 & 3.0 & 4.6 & 4.0 \\
\hline Stamper et al. (2014) & R-2 & 1265 & 1.0 & $3.26(31)$ & 3.7 & & & 3.0 & 2.3 \\
\hline Stamper et al. (2014) & 22 & 1265 & 1.0 & $2.90(17)$ & 5.3 & 4.2 & 2.8 & 5.2 & 4.4 \\
\hline Stamper et al. (2014) & $\mathrm{R}-1$ & 1300 & 1.0 & $2.78(21)$ & 3.2 & & & 1.8 & 1.1 \\
\hline Stamper et al. (2014) & 28 & 1300 & 1.0 & $3.10(14)$ & 5.7 & & & 4.9 & 3.9 \\
\hline Stamper et al. (2014) & R-6 & 1325 & 1.0 & $2.90(23)$ & 3.9 & & & 3.0 & 2.1 \\
\hline Stamper et al. (2014) & 12 & 1200 & 1.3 & $3.77(37)$ & 4.4 & 3.1 & 2.6 & 3.7 & 2.8 \\
\hline Stamper et al. (2014) & 10 & 1250 & 1.3 & $3.59(56)$ & 3.7 & 1.7 & 2.2 & 2.0 & 1.2 \\
\hline Stamper et al. (2014) & 15 & 1265 & 1.3 & $3.63(15)$ & 4.0 & 2.3 & 2.9 & 2.9 & 1.9 \\
\hline Stamper et al. (2014) & 32 & 1280 & 1.7 & $2.89(19)$ & 6.0 & 3.7 & 3.1 & 5.2 & 3.8 \\
\hline Stamper et al. (2014) & 40 & 1200 & 0.1 & $1.90(10)$ & 4.6 & & & 4.5 & 4.6 \\
\hline Stamper et al. (2014) & 24 & 1280 & 1.0 & $2.74(15)$ & 4.8 & & & 5.0 & 4.2 \\
\hline Stamper et al. (2014) & 19 & 1265 & 1.7 & & 4.0 & & & 4.3 & 2.9 \\
\hline Stamper et al. (2014) & 34 & 1325 & 1.7 & & 3.7 & & & 0.5 & 0.0 \\
\hline Stamper et al. (2014) & 37 & 1350 & 1.7 & $3.78(20)$ & 3.8 & & & 4.2 & 2.8 \\
\hline Melekhova et al. (2015) & RSV49_4 & 1270 & 1.0 & 0.6 & -0.2 & 1.9 & & -1.8 & -2.2 \\
\hline Melekhova et al. (2015) & RSV49_11 & 1250 & 1.0 & 0.7 & & 2.3 & & 3.2 & 2.5 \\
\hline Melekhova et al. (2015) & bmn1 & 1080 & 0.4 & 2.8 & & -0.9 & & 1.6 & 2.0 \\
\hline Melekhova et al. (2015) & BM38 & 1200 & 0.7 & $2.50(8)$ & 2 & 2.2 & & 2.6 & 2.2 \\
\hline Melekhova et al. (2015) & BM40 & 1150 & 0.7 & $3.05(9)$ & 2.9 & 1.7 & & 2.5 & 2.3 \\
\hline Melekhova et al. (2015) & BM43 & 1100 & 0.7 & $3.02(9)$ & & 2.5 & & 3.0 & 2.9 \\
\hline Melekhova et al. (2015) & BM3 & 1200 & 1.0 & $2.94(3)$ & 2.3 & & & -0.1 & -0.4 \\
\hline Melekhova et al. (2015) & BM6 & 1100 & 1.0 & $4.42(35)$ & 2.8 & -0.4 & & & \\
\hline Melekhova et al. (2015) & bmn2 & 1080 & 0.4 & 8.3 & & 0.1 & & 3.6 & 3.9 \\
\hline Melekhova et al. (2015) & BM37 & 1150 & 0.7 & $5.2(14)$ & 4.2 & 4.0 & & 4.4 & 4.2 \\
\hline Melekhova et al. (2015) & BM34 & 1100 & 0.7 & $7.2(21)$ & 4.9 & 3.9 & & 4.6 & 4.8 \\
\hline Melekhova et al. (2015) & BM24 & 1030 & 1.0 & $9.3(98)$ & & 1.8 & & 2.0 & 1.9 \\
\hline Melekhova et al. (2015) & BM17 & 1080 & 1.0 & $6.7(5)$ & 4.4 & 3.4 & & 3.2 & 2.9 \\
\hline Melekhova et al. (2015) & BM9 & 1100 & 1.0 & $5.34(48)$ & 3.2 & 0.6 & & 0.5 & 0.4 \\
\hline Melekhova et al. (2015) & BM49 & 1150 & 1.3 & $6.00(17)$ & & 3.0 & & 4.1 & 3.5 \\
\hline
\end{tabular}

${ }^{a} \triangle N N O$ reported in the original source using the method indicated: $\mu$ XANES; olivine-spinal oxybarometry; Fe in AuPd alloy

${ }^{\mathrm{b}} \Delta \mathrm{NNO}$ calculated using method described in text in combination with algorithm of Kress and Carmichael (1991) or Borisov et al. (2018)

${ }^{\mathrm{c}} \mathrm{wt} \% \mathrm{H}_{2} \mathrm{O}$ by SIMS, except where calculated by mass balance (italics). Figure in parentheses is $1 \mathrm{sd}$ in terms of least significant figures

composition at a known (experimental) temperature. This value of $\mathrm{Fe}^{3+} / \Sigma \mathrm{Fe}$ can then be used to derive $f \mathrm{O}_{2}$ using the algorithm of Borisov et al (2018), which we adopt here in light of its slightly greater ability to recover experimental $f \mathrm{O}_{2}$ for our sample set (Fig. 5b). Determination of $f \mathrm{O}_{2}$ for experiments is particularly useful at high pressure, when buffering redox and/or preventing the egress or ingress of hydrogen are perennial problems. 


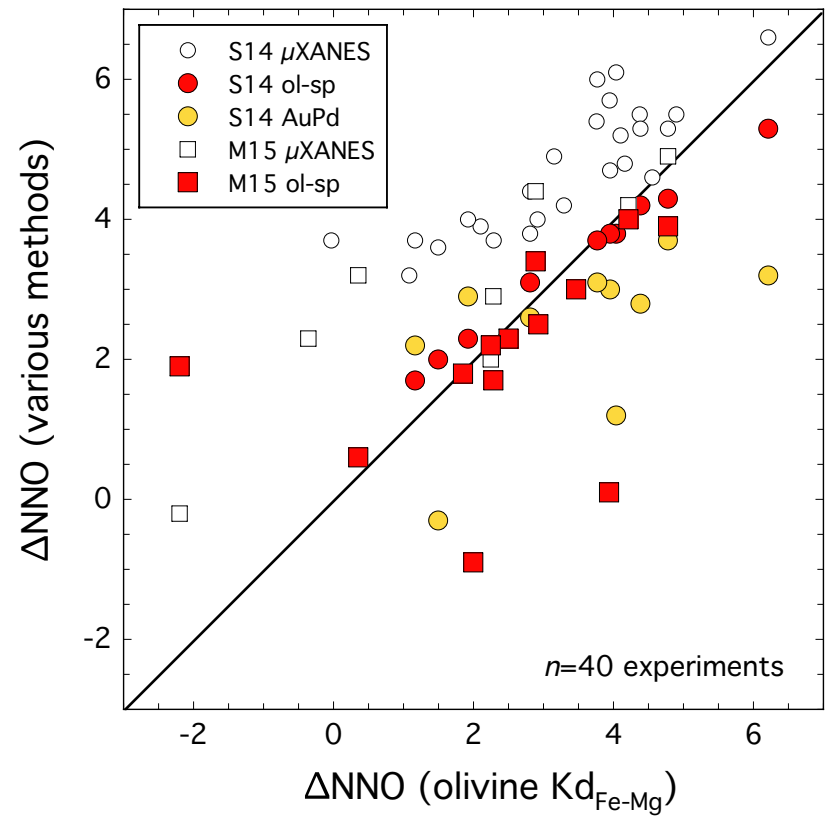

Fig. 12 Calculated $\triangle \mathrm{NNO}$ for 40 high-pressure experiments on hydrous Lesser Antilles basalts from Melekhova et al. (2015) noted as M15 and Stamper et al. (2014) noted as S14. The horizontal axis shows the values determined from olivine-melt $\mathrm{Fe}-\mathrm{Mg}$ exchange, while the vertical axis shows values obtained by three independent methods, described in the text and reported by the original authors. $\mu$ XANES analyses suffer from oxidation due to the high photon flux used (see also Fig. 4)

Before testing our approach against the experimental olivine-melt pairs produced at known redox conditions, it is instructive to gauge the likely precision of the method. The uncertainty on the calculation is not linear with $f \mathrm{O}_{2}$. The method relies, in effect, on the difference between $\mathrm{Kd}_{\mathrm{Fe}^{T}-\mathrm{Mg}}$ and $\mathrm{Kd}_{\mathrm{Fe}^{2+}-\mathrm{Mg}}$, after first accounting for olivine non-ideality. As $\mathrm{Fe}^{3+} / \Sigma \mathrm{Fe}$ approaches zero, so $\mathrm{Kd}_{\mathrm{Fe}^{T}-\mathrm{Mg}}$ approaches $\mathrm{Kd}_{\mathrm{Fe}^{2+}-\mathrm{Mg}}$. This leads to significant uncertainty on $\mathrm{Fe}^{3+} / \Sigma \mathrm{Fe}$, which propagates to considerable uncertainty on calculated $f \mathrm{O}_{2}$. The same problem is not encountered under more oxidising conditions, when $\mathrm{Fe}^{3+} / \Sigma \mathrm{Fe}$ approaches 1 and $\mathrm{Kd}_{\mathrm{Fe}^{T}-\mathrm{Mg}}$ tends to zero. To capture this non-linearity in the uncertainty we have propagated the errors from the various fits performed on the data through the analytical uncertainty, assuming a $5 \%$ relative uncertainty on the measured $\mathrm{Kd}_{\mathrm{Fe}^{T}-\mathrm{Mg}}$, as well as that arising from the Borisov et al (2018) calibration $\left(0.38 \log\right.$ units in $\left.f \mathrm{O}_{2}\right)$. The resulting behaviour is shown in Fig. 10. As expected, uncertainty is greatly magnified under reducing conditions, exceeding 0.6 $\log$ units around $\mathrm{NNO}-1$, and clearly becoming meaningless below $\mathrm{NNO}-4$. The uncertainty contracts considerably at more oxidising conditions, attaining the limit provided by the Borisov et al (2018) calibration above $\mathrm{NNO}+2$. Over almost all of the $\mathrm{fO}_{2}$ range, this calibration uncertainty dominates over that due to analytical precision, emphasising the need for continuous refinement of the $\mathrm{Fe}^{3+} / \Sigma \mathrm{Fe}$ algorithm, especially at very low $\mathrm{fO}_{2}$.

In Fig. 11, we plot the calculated $f \mathrm{O}_{2}$ (relative to $\mathrm{NNO}$ ) for all experiments in the dataset conducted above $\mathrm{NNO}-4$; we eliminate only the subset of data where $\mathrm{Kd}_{\mathrm{Fe}^{T}-\mathrm{Mg}}>\mathrm{Kd}_{\mathrm{Fe}^{2+}-\mathrm{Mg}}$ equating to a spurious negative value of $\mathrm{Fe}^{3+} / \Sigma \mathrm{Fe}$. The observed behaviour is in line with the expectations from Fig. 10, namely that precision deteriorates dramatically below NNO -1 . Nonetheless, in $72 \%$ of all experiments at $\mathrm{NNO}-2$ and above we recover $f \mathrm{O}_{2}$ to within $\pm 1.2 \mathrm{log}$ units; $44 \%$ are recovered within $\pm 0.6 \log$ units. In addition to the factors discussed above, uncertainty also accrues from the effects of alkalis on $\mathrm{Kd}_{\mathrm{Fe}^{T}-\mathrm{Mg}}$, either directly through melt non-ideality, or indirectly through the algorithm used to recover $f \mathrm{O}_{2}$ from $\mathrm{Fe}^{3+} / \Sigma \mathrm{Fe}$. Once again we emphasise that our method is best applied only to relatively oxidised melts (above $\sim \mathrm{NNO}-1$ ) with less than about $8 \mathrm{wt} \% \mathrm{Na}_{2} \mathrm{O}+\mathrm{K}_{2} \mathrm{O}$.

We test our approach on a set of real high-pressure experiments where the $f \mathrm{O}_{2}$ was either not constrained directly, e.g., by solid-state buffers, or may have been compromised by hydrogen diffusion through the capsule walls. We have selected 40 experiments from Stamper et al. (2014) and Melekhova et al. (2015) on magnesium-rich basalts from the Lesser Antilles with varying amounts of added $\mathrm{H}_{2} \mathrm{O}$ (Table 6). In these experiments various alternative strategies were employed to recover $f \mathrm{O}_{2}$, including $\mu$ XANES, olivine-spinel oxybarometry (O'Neill and Wall 1987), and the solubility of iron in AuPd alloy capsules (Barr and Grove 2010). In Fig. 12, we compare these different methods. As expected, we find that the $\mu$ XANES analyses of the glasses from these hydrous experiments yield higher $f \mathrm{O}_{2}$ estimates than all other methods, due to the oxidative effects of the high photon flux used in the analyses. We can also see the wide variation in $f \mathrm{O}_{2}$ that results from varying amounts of Fe redox due to hydrogen diffusion, a phenomenon hard to avoid in most piston-cylinder experiments where, unlike with internally-heated gas-pressure vessels, $f \mathrm{H}_{2}$ cannot be easily maintained without external (solid-state) buffers. The methodology developed here reproduces very well the estimates from olivine-spinel barometry in those runs where spinel was large enough to analyse. The Fe-in-AuPd approach also yields results that lie close to our new method, albeit with much greater scatter, primarily due to the difficulty of analysing $\mathrm{Fe}$ at very low concentrations in $\mathrm{Au}-\mathrm{Pd}$ close to the melt-capsule interface where secondary fluorescence can be a problem. We conclude that our olivine-melt oxybarometer has the potential to recover $f \mathrm{O}_{2}$ from olivine-bearing experiments that are either lacking spinel or where the runproduct spinel is too small to analyse. However, care must be taken to screen for Fe-loss to the capsule material during the experiment. This problem is especially acute under reducing conditions and in Au alloy or Pt capsules (Barr and Grove 


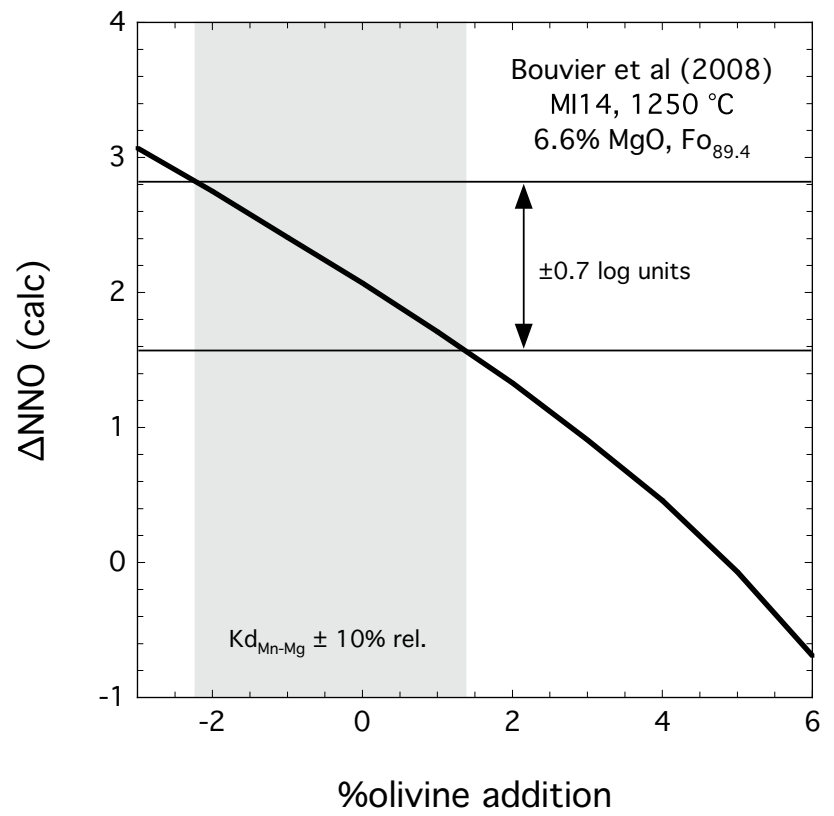

Fig. 13 Illustration of the effect of olivine addition on calculated $f \mathrm{O}_{2}$ (expressed as $\triangle \mathrm{NNO}$ ) for a melt inclusion from St. Vincent (MI14 of Bouvier et al. 2008). The optimal correction to match the calculated $\mathrm{Kd}_{\mathrm{Mn}-\mathrm{Mg}}$ is $-0.5 \mathrm{wt} \%$ olivine (i.e., olivine dissolution). An analytical uncertainty of $\pm 10 \%$ relative on this value is shown as the grey bar, which translates to an uncertainty in $f \mathrm{O}_{2}$ of $\pm 0.7 \log$ units. With increasing olivine addition the calculated $\mathrm{fO}_{2}$ drops significantly, emphasising the need for precise $\mathrm{Mn}$ measurements of olivine and glass for this method

2010). Uptake of metallic iron $\left(\mathrm{Fe}^{0}\right)$ by the capsule occurs via disproportionation of melt $\mathrm{Fe}^{2+}$ to $\mathrm{Fe}^{0}+\mathrm{Fe}^{3+}$ leading to an apparent increase in glass $\mathrm{Fe}^{3+} / \Sigma \mathrm{Fe}$ and hence calculated $f \mathrm{O}_{2}$. To ensure reliable application of our oxybarometer the effects of Fe-loss must be fully accounted for.

\section{$\mathrm{Fe}^{3+} / \Sigma \mathrm{Fe}$ estimates from olivine-hosted melt inclusions}

Olivine-hosted melt inclusions are widely used to determine volatile contents of pre-eruptive magmas, with implications for volatile recycling at subduction zones or magma storage conditions, for example. Most olivine-hosted melt inclusions have experienced some degree of post-entrapment modification, for example by crystallisation of olivine on the inclusion wall, dissolution of the olivine host, or diffusive exchange between melt and host (Danyushevsky et al. 2002). Standard practice in these situations is to correct the melt inclusion composition for these effects by adding (or subtracting) some amount of host olivine (or $\mathrm{FeO}$ and $\mathrm{MgO}$ ) to the melt inclusion to bring the pair back into equilibrium. This inevitably leads to some modification to $\mathrm{Kd}_{\mathrm{Fe}^{T}-\mathrm{Mg}}$, the parameter required for oxybarometry. To obviate this circularity, we

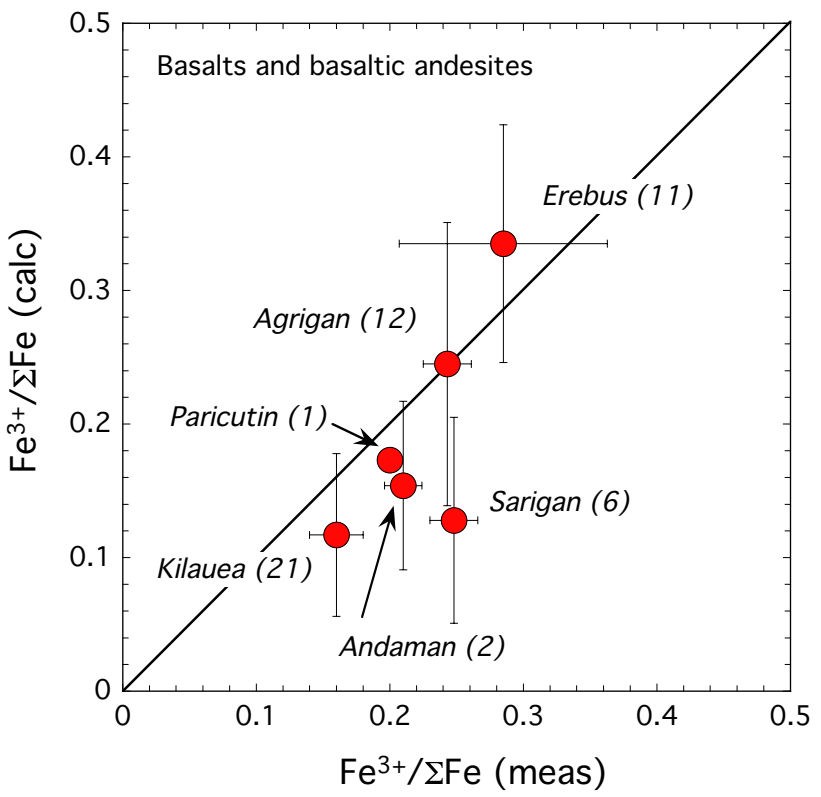

Fig. 14 Calculated $\mathrm{Fe}^{3+} / \Sigma \mathrm{Fe}$ for basaltic melt inclusions using the technique described in the text for six volcanoes for which $\mathrm{Fe}^{3+} / \Sigma \mathrm{Fe}$ was determined by $\mu$ XANES. The average and sd for each volcano are plotted; the number of individual analyses is given in parentheses. Data sources are: Erebus (Moussallam et al. 2014); Agrigan, Mariana (Kelley and Cottrell 2012; Brounce et al. 2014); Sarigan, Mariana (Brounce et al. 2014); Kilauea (Moussallam et al. 2016); Andaman Islands, and Paricutin, Mexico (Kelley and Cottrell 2009)

propose to use the systematics of redox-insensitive $\mathrm{Mn}-\mathrm{Mg}$ exchange to perform the post-entrapment corrections, and then use the $\mathrm{Kd}_{\mathrm{Fe}^{T}-\mathrm{Mg}}$ of the corrected melt and its host olivine to recover $\mathrm{Fe}^{3+} / \Sigma \mathrm{Fe}$. To make the post-entrapment correction requires some knowledge of the equilibrium temperature, which can be obtained, for example, through olivine-melt thermometry (e.g., Beattie 1993; Putirka et al. 2007).

Before testing our approach on natural melt inclusions, it is instructive once again to get a sense of the expected uncertainty of the method. In addition to the other factors considered above, the correction for post-entrapment modification adds further uncertainty; the more olivine that is added back into the inclusion, the higher the resulting $\mathrm{Kd}_{\mathrm{Fe}^{T}-\mathrm{Mg}}$ and the lower the calculated $\mathrm{Fe}^{3+} / \Sigma \mathrm{Fe}$ (and hence $f \mathrm{O}_{2}$ ). To illustrate this we have calculated the effect on calculated $f \mathrm{O}_{2}$ due to varying amounts of olivine addition (and subtraction) from an Mg-rich basaltic melt inclusion (\#14) from St. Vincent (Bouvier et al. 2008). We use a temperature of $1200{ }^{\circ} \mathrm{C}$ and an initial (measured) $\mathrm{Kd}_{\mathrm{Fe}^{T}-\mathrm{Mg}}=0.205$ for the calculations (Fig. 13). The calculated, equilibrium $\mathrm{Kd}_{\mathrm{Fe}^{2+}-\mathrm{Mg}}$, after taking account of olivine $\left(\mathrm{Fo}_{89}\right)$ non-ideality is 0.31 ; deviation of $\mathrm{Kd}_{\mathrm{Fe}^{T}-\mathrm{Mg}}$ from this value enables us to calculate $\mathrm{Fe}^{3+} / \Sigma \mathrm{Fe}$ and thence $f \mathrm{O}_{2}$. It is clear that addition (or subtraction) of just a few percent olivine can lead to dramatic reduction (or 
increase) in $\mathrm{Kd}_{\mathrm{Fe}^{T}-\mathrm{Mg}}$ and hence in calculated $f \mathrm{O}_{2}$. Using Eq. (10), alongside the reported $\mathrm{MnO}$ contents of olivine and melt inclusion, the required correction is a subtraction of just $0.5 \mathrm{wt} \%$ olivine, i.e., due to dissolution of the host olivine. The calculated $f \mathrm{O}_{2}(\Delta \mathrm{NNO}=2.2)$ accords well with that estimated for St. Vincent high-Mg basalt $(\triangle \mathrm{NNO}+1.5$ to +1.8 ) using spinel oxybarometry (Heath et al. 1998). Within the uncertainty of the measurement of $\mathrm{MnO}$ in olivine and glass, a range of olivine corrections is permissible. In Fig. 13, we show that a relative uncertainty of $\pm 10 \%$ in $\mathrm{Kd}_{\mathrm{Mn}-\mathrm{Mg}}$ translates to uncertainty of $\pm 1.3 \%$ in the olivine correction, or $\pm 0.7 \log$ units in $f \mathrm{O}_{2}$. Evidently, having precise measurements of olivine and melt $\mathrm{MnO}$ contents is critical for this method, yet is often not a priority in melt inclusion studies. For comparison, using the method of Danyushevsky et al. (2000, 2002), Bouvier et al. (2008) estimate post-entrapment crystallisation of $6.5 \mathrm{wt} \%$ olivine, well outside the permissible bounds based on Mn-Mg exchange (Fig. 13).

Having established what is possible with our melt inclusion oxybarometer we have tested it against five olivine-hosted melt inclusions studies from the literature: Brounce et al (2014), Kelley and Cottrell $(2009,2012)$ and Moussallam et al $(2014,2016)$. In all of these cases melt $\mathrm{Fe}^{3+} / \Sigma \mathrm{Fe}$ was determined by $\mu$ XANES, but using a lower flux than that used in our analyses. For these reasons the measured $\mathrm{Fe}^{3+} / \Sigma \mathrm{Fe}$ is considered more reliable; however, the presence of various amounts sulphur in all of the analysed glasses raises the prospect of Fe redox during melt inclusion quenching through $\mathrm{Fe}-\mathrm{S}$ redox couples. This is a perennial problem with microbeam analysis of $\mathrm{Fe}^{3+} / \Sigma \mathrm{Fe}$ in sulphur-bearing glasses, but not for our methodology, as olivine-melt $\mathrm{Fe}-\mathrm{Mg}$ exchange by diffusion is unlikely to have taken place on quenching timescales; if it did, there would be evidence in the form of thin overgrowth rims on the walls of the melt inclusion.

To calculate $\mathrm{Fe}^{3+} / \Sigma \mathrm{Fe}$ in each of the melt inclusion sets we first correct for post-entrapment modification using Eq. (10) with the measured $\mathrm{Kd}_{\mathrm{Mn}-\mathrm{Mg}}$ and an equilibrium temperature from olivine-melt thermometry (or other petrological method) provided in the original sources. An iterative procedure was used. The corrected melt composition for each inclusion, following olivine addition or subtraction, was then used to calculate $\mathrm{Fe}^{3+} / \Sigma \mathrm{Fe}$, using Eq. (8). For each volcano studied we present the average value of $\mathrm{Fe}^{3+} / \Sigma \mathrm{Fe}$ and its standard deviation in Fig. 14. For five of the studied volcanoes our method reproduces the mean $\mu$ XANES $\mathrm{Fe}^{3+} / \Sigma \mathrm{Fe}$ values within 1 s.d. The only exception is Sarigan, where our method consistently underestimates $\mathrm{Fe}^{3+} / \Sigma \mathrm{Fe}$. Notably these were the melt inclusions that required the greatest post-entrapment calculation (2-7 wt\% olivine addition). Nonetheless, our method appears to have an accuracy of about \pm 0.04 in $\mathrm{Fe}^{3+} / \Sigma \mathrm{Fe}$ and captures the broad variation from one sample suite to the next. It is a much simpler analytical method than $\mu X A N E S$ (or SMS), requiring much less sample preparation, and can be performed easily on large numbers of melt inclusions, as a means to explore broad-scale variations in $\mathrm{Fe}^{3+} / \Sigma \mathrm{Fe}$ (and $f \mathrm{O}_{2}$ ) in space and in time. Moreover, as noted above, it is not susceptible to $\mathrm{Fe}-\mathrm{S}$ redox exchange during quenching. However, our method does not take account of any diffusive $\mathrm{Fe}-\mathrm{Mg}$ exchange between melt inclusion and host olivine during cooling (e.g., Danyushevsky et al. 2002), a problem that also afflicts in situ measurements of $\mathrm{Fe}^{3+} / \Sigma \mathrm{Fe}$. As diffusive re-equilibration with the host olivine lowers the $\mathrm{Fe}^{2+}$ content of the melt inclusion, but not its $\mathrm{Fe}^{3+}$ content, such a process will lead to erroneously high estimated $\mathrm{Fe}^{3+} / \Sigma \mathrm{Fe}$ (and hence $f \mathrm{O}_{2}$ ) unless it is explicitly accounted for.

Acknowledgements This project has been carried out over 7 years, during which time many people have provided support and feedback. We thank S. Fawcett for meticulously preparing SMS wafers, C. Stamper for assistance at Diamond in the beginning of the project, A. Matzen for providing his olivine-melt experimental database, E. Cottrell and $\mathrm{O}$. Shorttle for highlighting the issues of $\mu$ XANES beam damage, and H. O'Neill for helpful discussions. K. Putirka and R. Lange provided exceptionally helpful reviews. We acknowledge the ESRF for provision of beam time at ID18. This work relied on the assistance of beamline scientists A. Chumakov, K. Ignatyev and T. Geraki. JB is grateful for visiting scientist support at University of Western Australia (Robert and Maude Gledden Fellowship), Caltech (Gordon and Betty Moore Scholarship) and Australian National University (ARC Discovery Project DP170103140). JB and EM acknowledge support from NERC project FAMOS (NE/P017371/1) and RB from NERC project DisEqm (NE/N018575/1).

Open Access This article is licensed under a Creative Commons Attribution 4.0 International License, which permits use, sharing, adaptation, distribution and reproduction in any medium or format, as long as you give appropriate credit to the original author(s) and the source, provide a link to the Creative Commons licence, and indicate if changes were made. The images or other third party material in this article are included in the article's Creative Commons licence, unless indicated otherwise in a credit line to the material. If material is not included in the article's Creative Commons licence and your intended use is not permitted by statutory regulation or exceeds the permitted use, you will need to obtain permission directly from the copyright holder. To view a copy of this licence, visit http://creativecommons.org/licenses/by/4.0/.

\section{References}

Alberto HV, da Cunha JP, Mysen BO, Gil JM, de Campos NA (1996) Analysis of Mössbauer spectra of silicate glasses using a twodimensional Gaussian distribution of hyperfine parameters. J Non-Cryst Solids 194:48-57

Barr JA, Grove TL (2010) AuPdFe ternary solution model and applications to understanding the $f \mathrm{O}_{2}$ of hydrous, high-pressure experiments. Contrib Mineral Petrol 160:631-643

Beattie P (1993) Olivine-melt and orthopyroxene-melt equilibria. Contrib Mineral Petrol 115:103-111 
Beattie P (1994) Systematics and energetics of trace-element partitioning between olivine and silicate melts: implications for the nature of mineral/melt partitioning. Chem Geol 117:57-71

Beattie P, Ford C, Russell D (1991) Partition coefficients for olivinemelt and orthopyroxene-melt systems. Contrib Miner Petrol 109:212-224

Blundy J, Wood B (1994) Prediction of crystal-melt partition coefficients from elastic moduli. Nature 372:452-454

Blundy J, Wood B (2003) Mineral-melt partitioning of uranium, thorium and their daughters. Rev Mineral Geochem 52:59-123

Borisov A, Behrens H, Holtz F (2018) Ferric/ferrous ratio in silicate melts: a new model for 1 atm data with special emphasis on the effects of melt composition. Contrib Mineral Petrol 173:98

Botcharnikov RE, Koepke J, Holtz F, McCammon C, Wilke M (2005) The effect of water activity on the oxidation and structural state of $\mathrm{Fe}$ in a ferro-basaltic melt. Geochim Cosmochim Acta 69:5071-5085

Bouvier AS, Metrich N, Deloule E (2008) Slab-derived fluids in the magma sources of St. Vincent (Lesser Antilles Arc): volatile and light element imprints. J Petrol 49:1427-1448

Brounce MN, Kelley KA, Cottrell E (2014) Variations in $\mathrm{Fe}^{3+} / \sum$ $\mathrm{Fe}$ of Mariana Arc basalts and mantle wedge $\mathrm{fO}_{2}$. J Petrol 55:2513-2536

Burnham CW (1979) The importance of volatile constituents. In: Yoder HS (ed) The evolution of the igneous rocks. Princeton University Press, Princeton, pp 439-482

Canil D (1997) Vanadium partitioning and the oxidation state of Archaean komatiite magmas. Nature 389:842-845

Canil D, Fedortchouk Y (2001) Olivine-liquid partitioning of vanadium and other trace elements, with applications to modern and ancient picrites. Can Mineral 39:319-330

Cooper RF, Fanselow JB, Poker DB (1996) The mechanism of oxidation of a basaltic glass: chemical diffusion of network-modifying cations. Geochim Cosmochim Acta 60:3253-3265

Cottrell E, Kelley KA, Lanzirotti A, Fischer RA (2009) High-precision determination of iron oxidation state in silicate glasses using XANES. Chem Geol 268:167-179

Cottrell E, Lanzirotti A, Mysen B, Birner S, Kelley KA, Botcharnikov R, Davis FA, Newville M (2018) A Mössbauer-based XANES calibration for hydrous basalt glasses reveals radiation-induced oxidation of Fe. Am Mineral 103:489-501

Danyushevsky LV, Della-Pasqua FN, Sokolov S (2000) Re-equilibration of melt inclusions trapped by magnesian olivine phenocrysts from subduction-related magmas: petrological implications. Contrib Mineral Petrol 138:68-83

Danyushevsky LV, Sokolov S, Falloon TJ (2002) Melt inclusions in olivine phenocrysts: using diffusive re-equilibration to determine the cooling history of a crystal, with implications for the origin of olivine-phyric volcanic rocks. J Petrol 43:1651-1671

Di Genova D, Sicola S, Romano C, Vona A, Fanara S, Spina L (2017) Effect of iron and nanolites on Raman spectra of volcanic glasses: a reassessment of existing strategies to estimate the water content. Chem Geol 475:76-86

Ejima T, Osanai Y, Akasaka M, Adachi T, Nakano N, Kon Y, Ohfuji H, Sereenen J (2018) Oxidation states of Fe in constituent minerals of a spinel lherzolite xenolith from the Tariat Depression, Mongolia: the significance of $\mathrm{Fe}^{3+}$ in olivine. Minerals 8:204

Gaetani GA, Grove TL (1997) Partitioning of moderately siderophile elements among olivine, silicate melt, and sulfide melt: constraints on core formation in the Earth and Mars. Geochim Cosmochim Acta 61:1829-1846

Heath E, Macdonald R, Belkin H, Hawkesworth C, Sigurdsson H (1998) Magma genesis at Soufriere Volcano, St Vincent, Lesser Antilles Arc. J Petrol 39:1721-1764

Herzberg C, O'Hara MJ (2002) Plume-associated ultramafic magmas of Phanerozoic age. J Petrol 43:1857-1883
Herzberg C, O'Hara MJ (1998) Phase equilibrium constraints on the origin of basalts, picrites, and komatiites. Earth Sci Rev 44:39-79

Hughes EC, Buse B, Kearns SL, Blundy JD, Kilgour G, Mader HM, Brooker RA, Balzer R, Botcharnikov RE, Di Genova D, Almeev RR (2018) High spatial resolution analysis of the iron oxidation state in silicate glasses using the electron probe. Am Mineral 103:1473-1486

Humphreys MC, Kearns SL, Blundy JD (2006) SIMS investigation of electron-beam damage to hydrous, rhyolitic glasses: implications for melt inclusion analysis. Am Mineral 91:667-679

Jayasuriya KD, O’Neill HSC, Berry AJ, Campbell SJ (2004) A Mössbauer study of the oxidation state of Fe in silicate melts. Am Mineral 89:1597-1609

Kägi R, Müntener O, Ulmer P, Ottolini L (2005) Piston-cylinder experiments on $\mathrm{H}_{2} \mathrm{O}$ undersaturated $\mathrm{Fe}$-bearing systems: an experimental setup approaching $f \mathrm{O}_{2}$ conditions of natural calc-alkaline magmas. Am Mineral 90:708-717

Kelley KA, Cottrell E (2009) Water and the oxidation state of subduction zone magmas. Science 325:605-607

Kelley KA, Cottrell E (2012) The influence of magmatic differentiation on the oxidation state of $\mathrm{Fe}$ in a basaltic arc magma. Earth Planet Sci 329:109-121

Kilinc A, Carmichael ISE, Rivers ML, Sack RO (1983) The ferricferrous ratio of natural silicate liquids equilibrated in air. Contrib Mineral Petrol 83:136-140

Kohn SC, Schofield PF (1994) The importance of melt composition in controlling trace-element behaviour: an experimental study of $\mathrm{Mn}$ and $\mathrm{Zn}$ partitioning between forsterite and silicate melts. Chem Geol 117:73-87

Kress VC, Carmichael ISE (1991) The compressibility of silicate liquids containing $\mathrm{Fe}_{2} \mathrm{O}_{3}$ and the effect of composition, temperature, oxygen fugacity and pressure on their redox states. Contrib Mineral Petrol 108:82-92

Lagarec K, Rancourt DG (1997) Extended Voigt-based analytic lineshape method for determining $N$-dimensional correlated hyperfine parameter distributions in Mössbauer spectroscopy. Nucl Instrum Methods Phys Res Sect B 129:266-280

Lange RL, Carmichael ISE (1990) Thermodynamic properties of silicate liquids with emphasis on density, thermal expansion and compressibility. Rev Mineral Geochem 24:25-64

Laubier M, Grove TL, Langmuir CH (2014) Trace element mineral/ melt partitioning for basaltic and basaltic andesitic melts: an experimental and laser ICP-MS study with application to the oxidation state of mantle source regions. Earth Planet Sci Lett 392:265-278

Lesne P, Kohn SC, Blundy J, Witham F, Botcharnikov RE, Behrens H (2011) Experimental simulation of closed-system degassing in the system basalt- $\mathrm{H}_{2} \mathrm{O}-\mathrm{CO}_{2}-\mathrm{S}-\mathrm{Cl}$. J Petrol 52:1737-1762

Mallmann G, O'Neill HSC (2009) The crystal/melt partitioning of V during mantle melting as a function of oxygen fugacity compared with some other elements (Al, P, Ca, Sc, Ti, Cr, Fe, Ga, Y, Zr and $\mathrm{Nb})$. J Petrol 50:1765-1794

Mallmann G, O'Neill HSC (2013) Calibration of an empirical thermometer and oxybarometer based on the partitioning of Sc, Y and $\mathrm{V}$ between olivine and silicate melt. J Petrol 54:933-949

Matzen AK (2012) Fe-Mg and Ni partitioning between olivine and silicate melt. $\mathrm{PhD}$ thesis, California Institute of Technology

Matzen AK, Baker MB, Beckett JR, Stolper EM (2011) Fe-Mg partitioning between olivine and high-magnesian melts and the nature of Hawaiian parental liquids. J Petrol 52:1243-1263

Matzen AK, Wood BJ, Baker MB, Stolper EM (2017) The roles of pyroxenite and peridotite in the mantle sources of oceanic basalts. Nat Geosci 10:530-535

McCammon CA (2004) Mössbauer spectroscopy: applications. In: Beran A, Libowitsky E (eds) Spectroscopic methods in mineralogy, vol 6. Eötvös University Press, Budapest, pp 369-398 
Melekhova E, Blundy J, Robertson R, Humphreys MC (2015) Experimental evidence for polybaric differentiation of primitive arc basalt beneath St. Vincent, Lesser Antilles. J Petrol 56:161-192

Melekhova E, Blundy J, Martin R, Arculus R, Pichavant M (2017) Petrological and experimental evidence for differentiation of waterrich magmas beneath St. Kitts, Lesser Antilles. Contrib Mineral Petrol 172:98

Moore G, Righter K, Carmichael ISE (1995) The effect of dissolved water on the oxidation state of iron in natural silicate liquids. Contrib Mineral Petrol 120:170-179

Moussallam Y, Oppenheimer C, Scaillet B, Gaillard F, Kyle P, Peters N, Hartley M, Berlo K, Donovan A (2014) Tracking the changing oxidation state of Erebus magmas, from mantle to surface, driven by magma ascent and degassing. Earth Planet Sci Lett 393:200-209

Moussallam Y, Edmonds M, Scaillet B, Peters N, Gennaro E, Sides I, Oppenheimer C (2016) The impact of degassing on the oxidation state of basaltic magmas: a case study of Kīlauea volcano. Earth Planet Sci Lett 450:317-325

Mysen BO (2006) Redox equilibria of iron and silicate melt structure: implications for olivine/melt element partitioning. Geochim Cosmochim Acta 70:3121-3138

Mysen BO, Virgo D (1989) Redox equilibria, structure, and properties of Fe-bearing aluminosilicate melts: relationships among temperature, composition, and oxygen fugacity in the system $\mathrm{Na}_{2} \mathrm{O}-$ $\mathrm{Al}_{2} \mathrm{O}_{3}-\mathrm{SiO}_{2}-\mathrm{Fe}-\mathrm{O}$. Am Mineral 74:58-76

Nash WM, Smythe DJ, Wood BJ (2019) Compositional and temperature effects on sulfur speciation and solubility in silicate melts. Earth Planet Sci Lett 507:187-198

O'Neill HSC, Pownceby MI (1993) Thermodynamic data from redox reactions at high temperatures. I. An experimental and theoretical assessment of the electrochemical method using stabilized zirconia electrolytes, with revised values for the $\mathrm{Fe}-" \mathrm{FeO}$ ", $\mathrm{Co}-\mathrm{CoO}$, $\mathrm{Ni}-\mathrm{NiO}$ and $\mathrm{Cu}-\mathrm{Cu}_{2} \mathrm{O}$ oxygen buffers, and new data for the $\mathrm{W}-$ $\mathrm{WO}_{2}$ buffer. Contrib Mineral Petrol 114:296-314

O'Neill HSC, Wall VJ (1987) The Olivine-Orthopyroxene-Spinel oxygen geobarometer, the nickel precipitation curve, and the oxygen fugacity of the Earth's Upper Mantle. J Petrol 28:1169-1191

O'Neill HSC, Pownceby MI, McCammon CA (2003) The magnesiowüstite: iron equilibrium and its implications for the activitycomposition relations of $(\mathrm{Mg}, \mathrm{Fe})_{2} \mathrm{SiO}_{4}$ olivine solid solutions. Contrib Mineral Petrol 146:308-325

O'Neill HSC, Berry AJ, Mallmann G (2018) The oxidation state of iron in Mid-Ocean Ridge Basaltic (MORB) glasses: implications for their petrogenesis and oxygen fugacities. Earth Planet Sci Lett 504:152-162

Partzsch G, Lattard D, McCammon C (2004) Mössbauer spectroscopic determination of $\mathrm{Fe}^{3+} / \mathrm{Fe}^{2+}$ in synthetic basaltic glass: a test of empirical $f \mathrm{O}_{2}$ equations under superliquidus and subliquidus conditions. Contrib Mineral Petrol 147:565-580

Pichavant M, Martel C, Bourdier JL, Scaillet B (2002) Physical conditions, structure, and dynamics of a zoned magma chamber: Mount Pelée (Martinique, Lesser Antilles Arc). J Geophys Res Solid Earth 107(5):ECV-1

Potapkin V, Chumakov AI, Smirnov G, Celse JP, Rüffer R, McCammon C, Dubrovinsky L (2012) The ${ }^{57} \mathrm{Fe}$ synchrotron Mössbauer source at the ESRF. J Synch Rad 19:559-569

Prescher C, McCammon C, Dubrovinsky L (2012) MossA: a program for analyzing energy-domain Mössbauer spectra from conventional and synchrotron sources. J App Crystal 45:329-331

Purton JA, Blundy JD, Allan NL (2000) Computer simulation of high-temperature, forsterite-melt partitioning. Am Mineral 85:1087-1091

Putirka KD (2005) Mantle potential temperatures at Hawaii, Iceland, and the mid-ocean ridge system, as inferred from olivine phenocrysts: evidence for thermally driven mantle plumes. Geochem Geophys Geosys 6:Q05L08
Putirka K (2016) Rates and styles of planetary cooling on Earth, Moon, Mars, and Vesta, using new models for oxygen fugacity, ferricferrous ratios, olivine-liquid $\mathrm{Fe}-\mathrm{Mg}$ exchange, and mantle potential temperature. Am Mineral 101:819-840

Putirka KD, Perfit M, Ryerson F, Jackson MG (2007) Ambient and excess mantle temperatures, olivine thermometry, and active vs. passive upwelling. Chem Geol 241:177-206

Rancourt DG (1989) Accurate site populations from Mössbauer spectroscopy. Nucl Instrum Methods Phys Res Sect B 44:199-210

Roeder PL, Emslie R (1970) Olivine-liquid equilibrium. Contrib Mineral Petrol 29:275-289

Rüffer R, Chumakov AI (1996) Nuclear resonance beamline at ESRF. Hyperfine Interact 97:589-604

Schreiber HD, Kochanowski BK, Schreibe CW, Morgan AB, Coolbaugh MT, Dunlap TG (1994) Compositional dependence of redox equilibria in sodium silicate glasses. J Non-Cryst Solids 177:340-346

Schuessler JA, Botcharnikov RE, Behrens H, Misiti V, Freda C (2008) Amorphous materials: properties, structure, and durability: oxidation state of iron in hydrous phono-tephritic melts. Am Mineral 93:1493-1504

Shannon RD (1976) Revised effective ionic radii and systematic studies of interatomic distances in halides and chalcogenides. Acta Crystallogr Sect A Crystal Phys Diffract Theor Gen Crystallogr 32:751-767

Sisson TW, Grove TL (1993) Experimental investigations of the role of $\mathrm{H}_{2} \mathrm{O}$ in calc-alkaline differentiation and subduction zone magmatism. Contrib Mineral Petrol 113:143-166

Stamper CC, Melekhova E, Blundy JD, Arculus RJ, Humphreys MCS, Brooker RA (2014) Oxidised phase relations of a primitive basalt from Grenada, Lesser Antilles. Contrib Mineral Petrol 167:954

Stokes TN, Bromiley GD, Potts NJ, Saunders KE, Miles AJ (2019) The effect of melt composition and oxygen fugacity on manganese partitioning between apatite and silicate melt. Chem Geol 506:162-174

Stolper DA, Bucholz CE (2019) Neoproterozoic to early Phanerozoic rise in island arc redox state due to deep ocean oxygenation and increased marine sulfate levels. PNAS 116:8746-8755

Tamura Y, Nakamura S, Sano N (1987) Oxidation-reduction equilibria of manganese in $\mathrm{MntO}-\mathrm{CaO}-\mathrm{SiO}_{2}-\mathrm{Al}_{2} \mathrm{O}_{3}$ melts. Tetsu-to-Hagané 73:2214-2218

Toplis MJ (2005) The thermodynamics of iron and magnesium partitioning between olivine and liquid: criteria for assessing and predicting equilibrium in natural and experimental systems. Contrib Mineral Petrol 149:22-39

Ulmer P (1989) The dependence of the $\mathrm{Fe}^{2+}-\mathrm{Mg}$ cation-partitioning between olivine and basaltic liquid on pressure, temperature and composition. Contrib Mineral Petrol 101:261-273

Vetere F, Holtz F, Behrens H, Botcharnikov RE, Fanara S (2014) The effect of alkalis and polymerization on the solubility of $\mathrm{H}_{2} \mathrm{O}$ and $\mathrm{CO}_{2}$ in alkali-rich silicate melts. Contrib Mineral Petrol 167:1014

Wilke M, Behrens H, Burkhard DJ, Rossano S (2002) The oxidation state of iron in silicic melt at $500 \mathrm{MPa}$ water pressure. Chem Geol 189:55-67

Wood BJ, Blundy JD (1997) A predictive model for rare earth element partitioning between clinopyroxene and anhydrous silicate melt. Contrib Mineral Petrol 129:166-181

Zhang HL, Cottrell E, Solheid PA, Kelley KA, Hirschmann MM (2018) Determination of $\mathrm{Fe}^{3+} / \Sigma \mathrm{Fe}$ of XANES basaltic glass standards by Mössbauer spectroscopy and its application to the oxidation state of iron in MORB. Chem Geol 479:166-175

Publisher's Note Springer Nature remains neutral with regard to jurisdictional claims in published maps and institutional affiliations. 